\title{
Main Achievements of the Multidisciplinary SINAPS@ Research Project: Towards an Integrated Approach to Perform Seismic Safety Analysis of Nuclear Facilities
}

\author{
C. Berge-Thierry, ${ }^{1}$ (D) F. Voldoire, ${ }^{2}$ F. Ragueneau, ${ }^{3}$ F. Lopez-Caballero, ${ }^{4}$ and A. Le Maoult ${ }^{1}$
}

\begin{abstract}
This contribution provides an overview of the SINAPS@ French research project and its main achievements. SINAPS@ stands for "Earthquake and Nuclear Facility: Improving and Sustaining Safety", and it has gathered the broad research community together to propose an innovative seismic safety analysis for nuclear facilities. This five-year project was funded by the French government after the 2011 Japanese Tohoku large earthquake and associated tsunami that caused a major accident at the Fukushima Daïchi nuclear power plant. Soon after this disaster, the international community involved in nuclear safety questioned the current methodologies used to define and to account for seismic loadings for nuclear facilities during the design and periodic assessment review phases. Within this framework, worldwide nuclear authorities asked nuclear licensees to perform 'stress tests' to estimate the capacity of their existing facilities for sustaining extreme seismic motions. As an introduction, the French nuclear regulatory framework is presented here, to emphasize the key issues and the scientific challenges. An analysis of the current French practices and the need to better assess the seismic margin of nuclear facilities contributed to the shaping of the scientific roadmap of SINAPS@. SINAPS@ was aimed at conducting a continuous analysis of completeness and gaps in databases (for all data types, including geology, seismology, site characterization, materials), of reliability or deficiency of models available to describe physical phenomena (i.e., prediction of seismic motion, site effects, soil and structure interactions, linear and nonlinear wave propagation, material constitutive laws in the nonlinear domain for structural analysis), and of the relevance or weakness of methodologies used for seismic safety assessment. This critical analysis that confronts the methods (either deterministic or probabilistic) and the available data in terms of the international state of the art systematically addresses the uncertainty issues. We present the key results achieved in SINAPS@ at each step of the full seismic analysis, with a focus on uncertainty identification,
\end{abstract}

1 Alternative Energies and Atomic Energy Commission (CEA), SEISM Institute, Centre de Saclay, DEN/DANS/DM2S, Université Paris-Saclay, 91191 Gif sur Yvette, France. E-mail: catherine.berge-thierry@cea.fr

2 Électricité de France, R\&D Division, SEISM Institute, IMSIA UMR EDF-CNRS-CEA-ENSTA 9219, Palaiseau, France.

3 École Normale Supérieure Cachan, SEISM Institute, Université Paris-Saclay, Cachan, France.

4 CentraleSupelec, SEISM Institute, Université Paris-Saclay, Laboratoire MSS-Mat. CNRS UMR 8579, Gif sur Yvette, France. quantification, and propagation. The main lessons learned from SINAPS@ are highlighted. SINAPS@ promotes an innovative integrated approach that is consistent with Guidelines \#22, as recently published by the French Nuclear Safety Authority (Guidelines ASN \#22 2017), and opens the perspectives to improve current French practice.

Key words: Seismic safety analysis, uncertainties, seismic margin, nuclear facilities.

\section{Introduction}

\subsection{Post-Fukushima Context, Complementary Safety Studies, and PSHA Studies in France}

Following the magnitude (Mw) 9 Tohoku earthquake off the Pacific coast of Japan in March 2011, a tsunami caused many deaths and great damage, and also led to a major nuclear accident at the FukushimaDaïchi nuclear power plant, that was ranked level 7 (i.e., highest on the International Nuclear and Radiological Event Scale of nuclear and radiological accidents). The international community involved in nuclear safety was immediately questioned about the reliability of its estimates, especially regarding external events (e.g., earthquakes, floods), the appropriateness of the approaches deployed, and the adequacy of the margins retained at the design stage of new nuclear facilities or during periodic assessment review of existing nuclear facilities.

The nuclear accident triggered an immediate reaction from the nuclear authorities worldwide to urge all operators of nuclear plants to carry out seismic risk and safety analysis on their existing structures. The objective of these stress tests was to verify the adequacy of the safety standards used when nuclear power plants (NPPs) received their 
authorization, in view of potential extreme external hazards (e.g., seismic, tsunamic, flood hazard). In France, these on-site analyses and verifications were carried out in 2011 as the initial phase of the complementary safety studies (2011-2012). These allowed an appreciation of the seismic margins of the various structures and components that were mainly based on expert opinions and computational methodologies, traditionally implemented for design purposes.

In a second step, the French Nuclear Safety Authority (ASN) that is an independent body handling the nuclear safety (http://www.asn.gouv.fr/) and the licensees defined a new concept, the 'hard core', "as a set of engineering buildings, equipment, and organization processes that will significantly increase the seismic safety of a plant, to allow it to sustain extreme natural events". This hard core aims to make installations even more robust and able to withstand rare and extreme natural hazards. The hard core structures and equipment need to be scaled for seismic levels, known as the 'hard core seismic levels' (HCSLs). The proposal by the licensees of these HCSLs was the subject of discussions with the ASN and its technical support, the Institute of Radiation Protection and Nuclear Safety (IRSN), between 2012 and 2016. At the end of 2012, the review of French complementary safety studies by a committee of international experts led the ASN to request licensees to update their HCSL proposals based on purely deterministic French historical practice, through probabilistic seismic hazard assessment (PSHA) to characterize the seismic hazard in terms of probability of occurrence. In 2014 and 2015, the ASN finally defined the characteristics that the HCSLs had to meet for licensees, as a set of deterministic and probabilistic levels known as the 'safe shutdown earthquake', increased by a $50 \%$ factor and a $2 \times 10^{4}$ years return period, respectively.

The implementation of state-of-the-art probabilistic approaches for seismic hazard assessment (SHA) is a first in France for nuclear plants. Previously, the characterization of seismic hazard for French nuclear plants was only based on the seismic scenario philosophy (i.e., a seismic level corresponds to a scenario of specific magnitude and one distance to the site), with the uncertainties considered implicitly or explicitly through safety coefficients. The implementation of PSHA gave rise to numerous expert discussions and highlighted the need for additional scientific enhancement (see for instance Martin et al. 2018). Indeed, if nobody can agree on what a seismic hazard can be estimated, it is very questionable that an agreement on seismic risk evaluation can be reached. Beyond the seismic hazard, estimation of the whole facility capacity remains a huge challenge. Even during the Tohoku earthquake, the components related to plant safety worked appropriately during the vibratory phase, whereas the global safety failed during the tsunami phase (IAEA 2015 report). There was a specific need to improve seismic margin assessments and to propose the rationale to design and verify structures, systems and components as consistent with the performance objectives, and consequently to define the explicit criteria. In France in particular, there was no consensual rationale (and at the time, no regulatory documents), this lack of approved practice for assessing of the ultimate seismic capacity of structures, systems and components has resulted in notably increased difficulties since the introduction of the 'beyond design' seismic levels, such as associated with the hard core in France. These difficulties happened in France during the post-Fukushima complementary safety studies, and even though every seismic expert agreed on the existence of these margins, there was no confidence in their values. This difficulty was reported by the board of experts of the European countries involved in the cross-assessment of all of these studies. This situation also motivated and justified the research performed in SINAPS@, as further detailed below.

\subsection{Implementation of the SINAPS@Project}

In this post-Fukushima context in 2012, 12 partners built the SINAPS@ project (Earthquake and Nuclear Installation: Improving and Sustaining Safety): Commissariat à l'Energie Atomique et aux Energies Alternatives (CEA), Electricité de France (EDF), École Normale Supérieure Paris-Saclay, CentraleSupelec, Institute of Radiation Protection and Nuclear Safety, Soil-Solids-Structures and Risks Laboratory (Polytechnic Institute of Grenoble), École Centrale de Nantes (ECN), and EGIS-industry, 
FRAMATOME, ISTERRE, IFSTTAR and CEREMA. The SINAPS@ research program identified three critical weaknesses in French practice at the time for seismic analysis (especially following the design regulatory practices): (1) the large gap between hazard and vulnerability assessment methodologies; (2) the lack of a consistent and explicit treatment of uncertainties; and (3) the incompleteness of seismic analyses, which were rarely, if ever, taken to the ultimate stage of the risk estimate (i.e., combination of the failure probability and the consequences). Although identified, these three critical points greatly reduced, or if not, made impossible, assessment of the available seismic margins of nuclear facilities.

SINAPS@was then intended to evaluate seismic safety continuously from the fault to the civil engineering works and equipment, to emphasize the quantification and propagation of the uncertainties. The exploration of epistemic and aleatory uncertainties concerned all of the databases and metadata that were used, the knowledge and modeling of the physical processes of the coupling and interactions between the geological medium and the building that are strongly related to the level of the seismic occurrences considered, and the methods used at each stage of the assessment of seismic hazard and the vulnerability of the nuclear structures and components. SINAPS@ was structured around six topics, called Work Packages (WPs) (see Fig. 1), that covered the entire seismic analysis chain: WP1, Seismic hazard; WP 2, Nonlinear interactions between near and far wave fields, the geological medium, and the structures; WP 3, Seismic behavior of structures and components; WP4, Seismic risk assessment; WP5, Experimental contributions/building-building interaction studies; and WP6, Knowledge dissemination and training sessions. The project was financed by the French Government in 2013, and benefited from this national funding. In particular, SINAPS@ supported nine PhD students and 21 one-year post-doctoral positions. The main objectives of SINAPS@were to:

- Rank various parameters and evaluate the impact of uncertainties (through data and methods) at each step: seismic hazards, site effects, dynamic soil- structure interaction (SSI), seismic behavior of structures and equipment, and failure assessment;

- Propose an innovative method (as verified and validated calculation software) for the modeling of seismic wave propagation in the most integrated and continuous way, from the fault to the seismic response of the structures and equipment;

- Improve seismic margin assessment methodologies;

- Formulate recommendations on research and development actions and data acquisition, and on engineering practices, and in particular for assessment of the vulnerability of structures and components, and enhancement of analytical methodologies, including preparation of their dissemination and the evolution of the regulations.

\subsection{Seismic Risk Regulatory Framework in France for Nuclear Facilities}

In France, nuclear safety is handled by ASN within the framework of a set of documents that have different legal standing, as illustrated in Fig. 2.

At the top of the regulatory corpus there is the Nuclear Safety and Transparency (TSN) Law, which was promulgated in 2006, as declared by the Government through Decrees and by the ASN through Decisions (the approval of which is shared between the Government and the ASN, or is the responsibility of the ASN only). These documents constitute a legally binding system for licensees. At the base of the corpus, the ASN published a set of technical documents, of approaches that were considered acceptable for the licensees to use in the safety demonstration: Guidelines and Fundamental Safety Rules (RFS). These documents are not legally binding, meaning that licensees can propose alternative methods if supported by the necessary justification: although apparently pragmatic and flexible, this regulatory scheme is often driven, and sometimes dominated, by expert debate.

The documents published by the ASN related to the safety management of seismic risk are shown Fig. 3. RFS 1.3.c deals with "geological and geotechnical studies of the site; determination of soil characteristics, and studies of soil behavior". RFS 


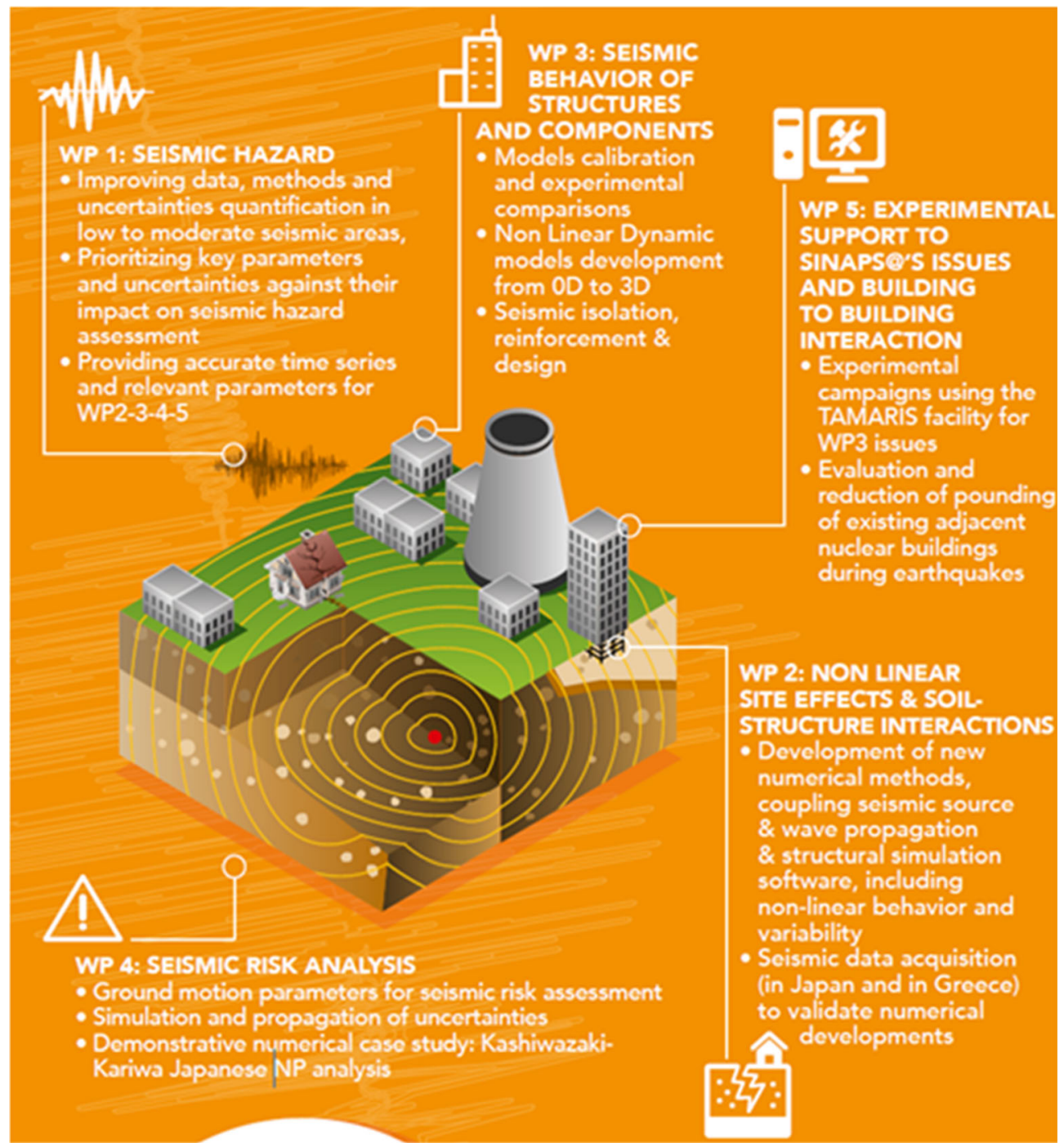

Figure 1

SINAPS@ project organization according to the steps of the seismic risk assessment chain (from Berge-Thierry et al. 2017a)

2001-01 proposes an acceptable method for determination of seismic movement that must be taken into account for the design of a facility with respect to seismic risk (RFS 2001-01, 2001). Guideline ASN/2/ 01 (2006) proposes acceptable methods for the ASN to determine the seismic response of the civil engineering structures, by considering their interactions with the equipment and evaluation of the stresses to be considered in their design (Civil Engineering- $\mathrm{CW}$ - and materials). Finally, RFS 1.3.b. defines the nature, location and operating conditions of the seismic instrumentation required for rapid acquisition of seismic movement to which buildings and structures with systems and components that are important for safety can be subjected, to compare these to the seismic movement that serves as the basis for the design of the facilities.

The French nuclear safety approach is based on a purely deterministic concept, with postulation of failure modes and putting in place of defense lines. This means, in particular, within the framework of seismic risk, such that the estimation of the seismic hazard is of a seismic scenario type that is related to reference earthquakes that arise from analysis of the 


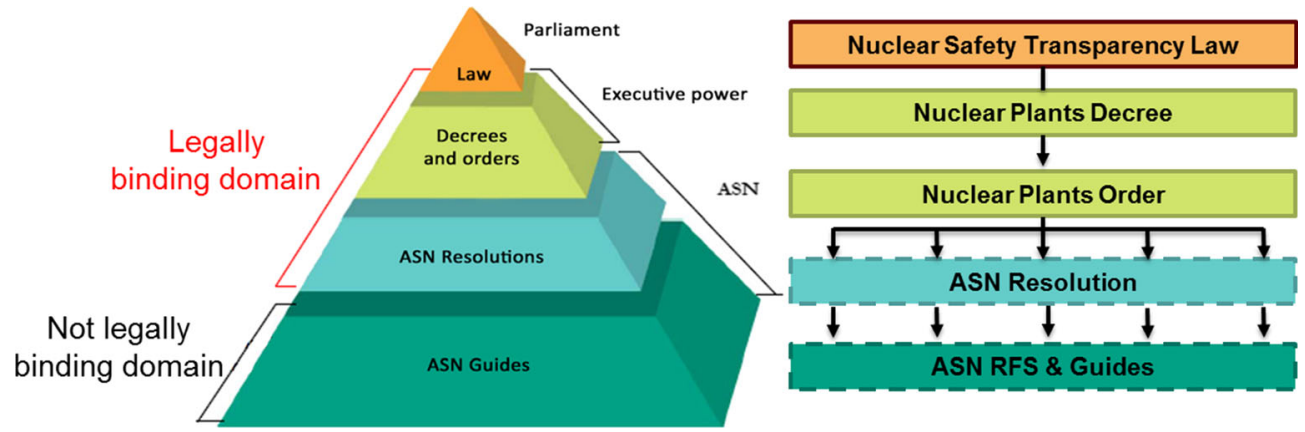

Figure 2

Description of the documentation related to nuclear safety in France

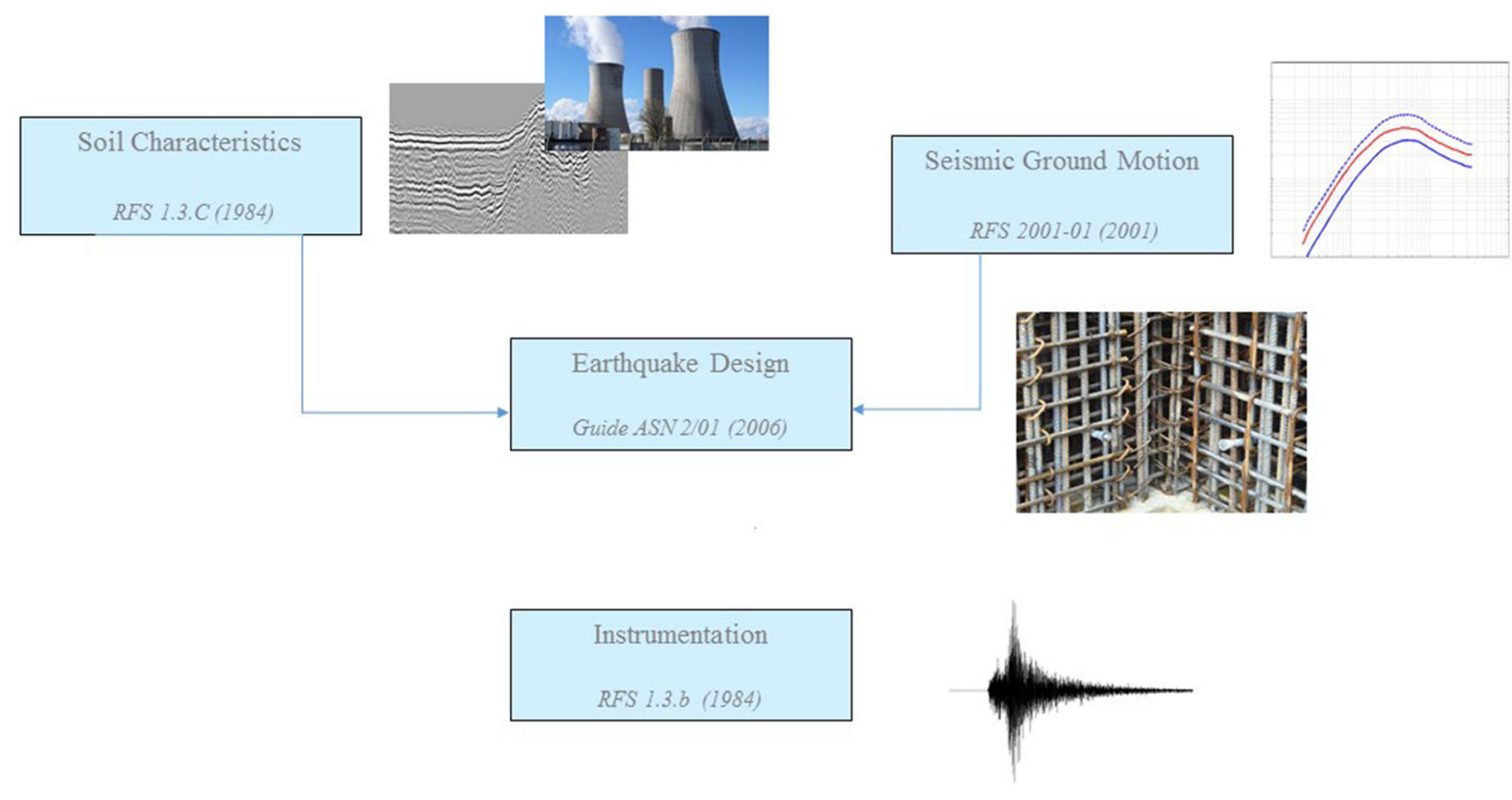

Figure 3

Presentation of the reference documents in force in France relevant to the seismic risk for nuclear plants safety, with the date of publication of their updates

seismicity catalogs (i.e., historical, instrumental, paleo-historical). Some uncertainties are taken into account through conservatism (implicit or explicit), such as for the safety coefficients (see Berge-Thierry et al. 2017b).

Two natural consequences of this approach are that the seismic hazard results (i.e., seismic movement) are not characterized by confidence levels, as uncertainties are not explicitly explored, and are not associated to any probabilistic information, such as the annual frequency of occurrence or exceedance. Due to this latter reason, these deterministic SHAs cannot be used as inputs of probabilistic safety assessments that are currently carried out; e.g., during quantification of seismic margins (except to check possible cliff-edge effects). The deterministic concept is illustrated in the structural and equipment part by use of simplified methods and constraining assumptions, such as the need to ensure linear behavior. In addition, the uncertainties and/or 
specific effects are, or can be, accounted for through fixed margins that are not always very explicit. All of these practices basically lead to the impossibility to correctly and fully assess seismic margins, and in particularly, they clearly do not allow to quantify them.

This deterministic approach prevails in RFS 2001-01 and Guidelines ASN/2/01, which singled the French practice for several decades from other nuclear countries and international recommendations that were more oriented toward probabilistic approaches. In the most recent references, however, the International Atomic Energy Agency (IAEA; e.g., IAEA SSG 9 Guidelines hereafter IAEA 2010), the Western European Nuclear Regulators Association (e.g., Safety Reference Levels for Existing Reactors) and Guidelines ASN \#22 published in 2017 recommended the use of both deterministic and probabilistic methods to assess seismic hazard (i.e., for the design and assessment phases), and to perform probabilistic safety analysis. In these latter Guidelines ASN \#22, the target value of the seismic level is an annual frequency of $10^{-4}$ for the design, and the need to reach at least the minimal spectral acceleration of $0.1 \times g$. Again, in Guidelines ASN \#22, the objective is not formulated in view of an overall global safety performance, nor in terms of associated criteria.

Note that most of these documents were prepared and published more than 30 years ago (RFS 1.3.C in 1985, RFS 1.3.b. in 1984), with the most recent ones dated more than 10 years ago, with Guidelines ASN/ 2/01 revised in 2006, and RFS 2001-01 revised in 2001. From this regulatory framework, we can also highlight that:

1. there is no grading of seismic hazard estimate that depends on the nature of the nuclear facility and its potential to cause damage to humans and/or the environment (i.e., the actual associated risk). The earthquake-related stresses are estimated using the same approach used for a laboratory or facility, as used here for a pressurized water reactor: while the behavioral requirements of the structures should differ allowing to reach specific safety requirements. It should be noted that at the international level of the nuclear countries, the IAEA Safety
Standards (cf. Chapter 10, Guidelines SSG-9, IAEA 2010) recommend that the importance of seismic levels be classified by facility category according to their associated risks and potential (i.e., radiological contamination potential, in particular). This difference stems directly from the application of a deterministic approach to define seismic hazard in France; conversely, the definition of seismic hazard via a probabilistic approach implies a target in terms of the level of protection (i.e., the probability of exceeding a parameter over a given period of time).

2. RFS 2001-01 and Guidelines ASN/2/01 provide acceptable methods for the definition of seismic movement for the design of the facilities. There are no specific reference documents for the safety review phases of installations, which take place every 10 years in France. Guidelines ASN \#22 (2017) as applicable to the design of nuclear power reactors are also considered as the main reference for nuclear plant assessment. During these review periods, safety is entirely evaluated by the licensee. From the seismic risk point of view, this includes conducting seismic margin studies on the existing facility in the light of an updated state-of-the-art SHA. These studies require implementation of the most up-to-date databases, and also the most representative methods to define the actual behavior of the structure during an earthquake. Taking uncertainties into account in seismic analysis is necessary to fully assess the behavior of any facility with respect to an updated hazard, or on the contrary, to identify its weaknesses and to define potential solutions to improve its seismic safety, or to confirm the safety coefficients. The SINAPS@ project is fully in line with this framework for estimation and quantification of seismic margins of new and existing nuclear facilities.

\subsection{Synthesis of French Seismic Risk Management for Nuclear Safety: from 1960s Until Today, and Perspectives}

Figure 4 summarizes the chronology of the reference documents applicable to France for management of seismic risk for all basic nuclear facilities 

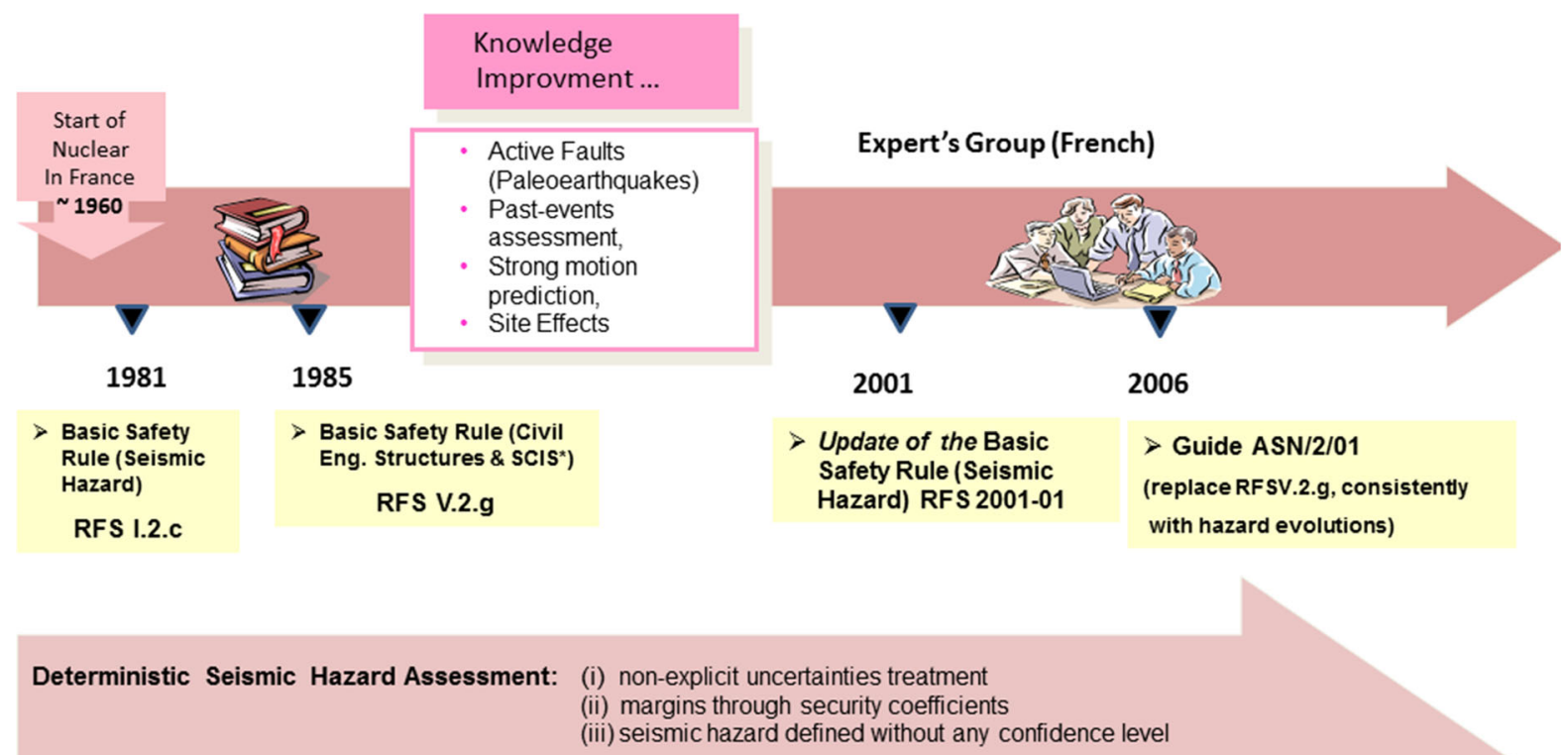

* SCIS: systems and components important for safety

(excluding deep storage) that were applicable between 1960 and 2006, the date of the last revision of the design principles. To this corpus of regulations are added references shared between licensees for the design, such as the Rules for Design, Manufacture, Installation and Commissioning (RCCs; e.g., mechanical components, civil engineering), and in line with other international standards (e.g., American Society of Mechanical Engineers, American Society of Civil Engineering).

Figure 5 complements Fig. 4 from 2001 and 2005, respectively, as the last update of the RFS and Guidelines to Design, including the new important documentation and key dates and projects related to seismic risk management in France and elsewhere. After the TSN law in 2006, the Basic Nuclear Plant Decree was published, which stated the general rules for nuclear plants. This Decree stipulates that "their application will be based on an approach commensurate with the importance of the risks or inconveniences presented by the installation". Finally, in 2015, the ASN published a Decision (Décision ASN 2015) that established a classification of the basic nuclear installations with regard to the risks and disadvantages they pose for the interests mentioned in Article L. 593-1 of the Environment Code, where three categories were defined on the basis of criteria set out in the Decision. The ASN confirmed this classification by Decision in 2017 (Décision ASN 2017), with the publication of a list of all of the basic nuclear facilities in France, and their association according to category.

Guidelines ASN \#22 were published in 2017, although they are not yet used operationally, and they are presented as being the reference for the design of pressurized water reactors. They are also indicated as the reference document in the case of assessments, without giving any performance objectives or any associated criteria. This is quite surprising, as on the other hand, these Guidelines require the licensee to 
Continuous evolution of knowledge (Hazard, Site effects, Soil-Structure Interaction, Structural \& components vulnerability, du Risk estimate)

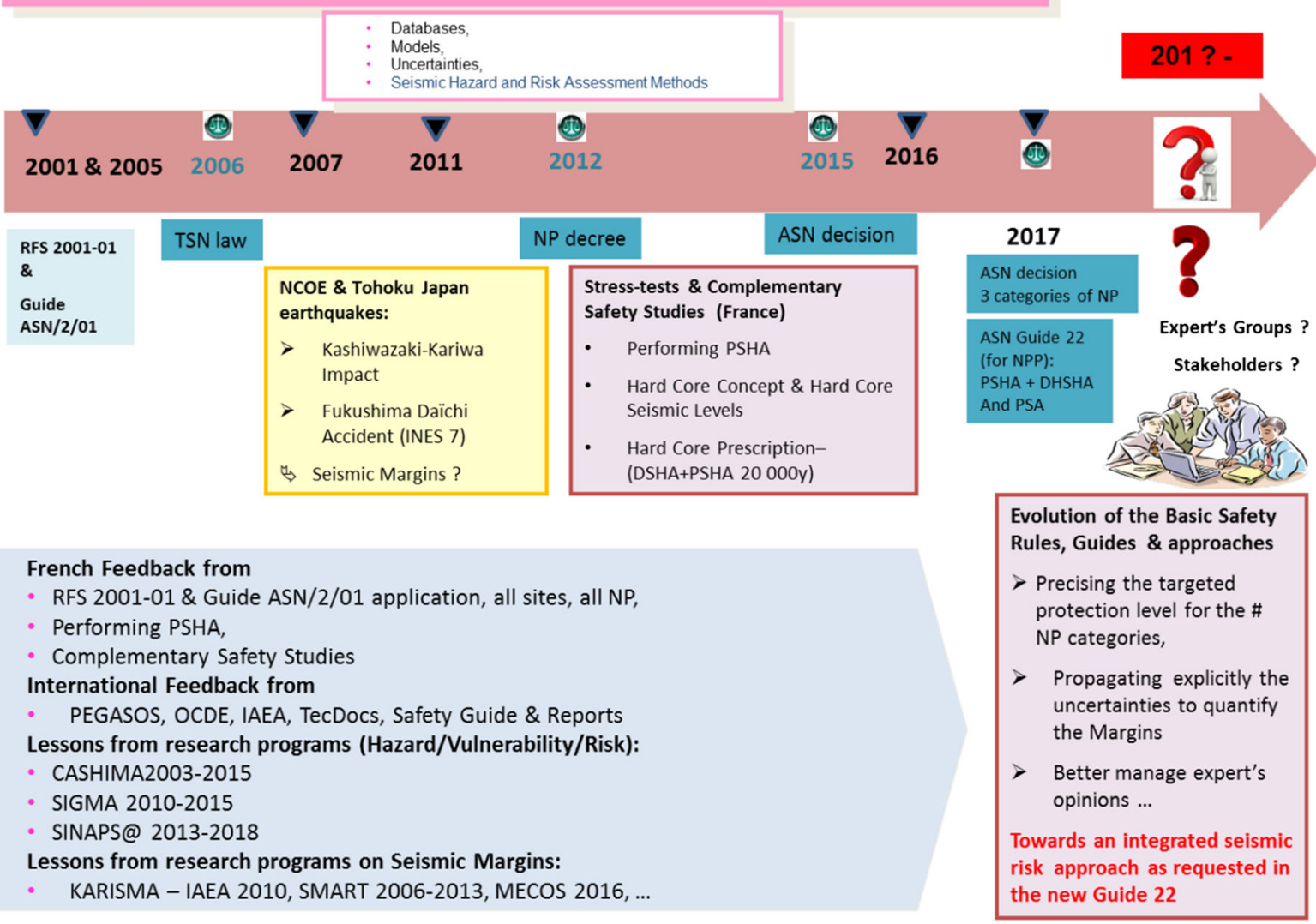

Figure 5

Highlights since the last revision of the reference documents in France. Emergence in France and prescription of the PSHA for the hard core levels defined after the Fukushima accident in the framework of the French complementary safety studies. PSHA and DSHA promoted in the new Guidelines ASN \#22 (2017 applicable to NPP) and requested for performing probabilistic safety analysis

systematically perform probabilistic seismic analysis. Furthermore, as the Guidelines cover all types of seismic levels, from the classical design levels (i.e., safe shutdown earthquake) to beyond the design, to include the HCSLs. As the guidelines are not written in a performance-based approach, their application should be accompanied by, or even preceded by, the definition of the safety objectives for each context (i.e., design, assessment, beyond design), and the associated performance expectations from structures and components. Definition of the criteria is needed, as the acceptable assumptions and methods to demonstrate that objectives are reached and criteria fulfilled. The texts published from 2015 to 2017 are thus an evolution in relation to the initial doctrine, as described above.

At the international scale, the Niigata-Chuetsu Oki earthquakes in 2007 and especially the Tohoku earthquake in 2011 in Japan have indeed reinforced the need to characterize and quantify the seismic margin analysis of nuclear facilities. In France, complementary safety studies led the ASN to prescribe seismic levels beyond the design of the structures and components of the hard core. In particular, the ASN enjoined licensees to propose hard core spectra of deterministic (RFS 2001-01) and probabilistic spectra to 20,000 years of return period (without confidence level precision), and including site effects. This decision is the first regarding the use of PSHA. At the same time, international and French experience from the feedback post-Fukushima, research programs on seismic margins, and all of the seismic risk themes (including SINAPS@) provided an opportunity for stakeholders to update the French corpus of regulations. The possible evolution towards integrated 


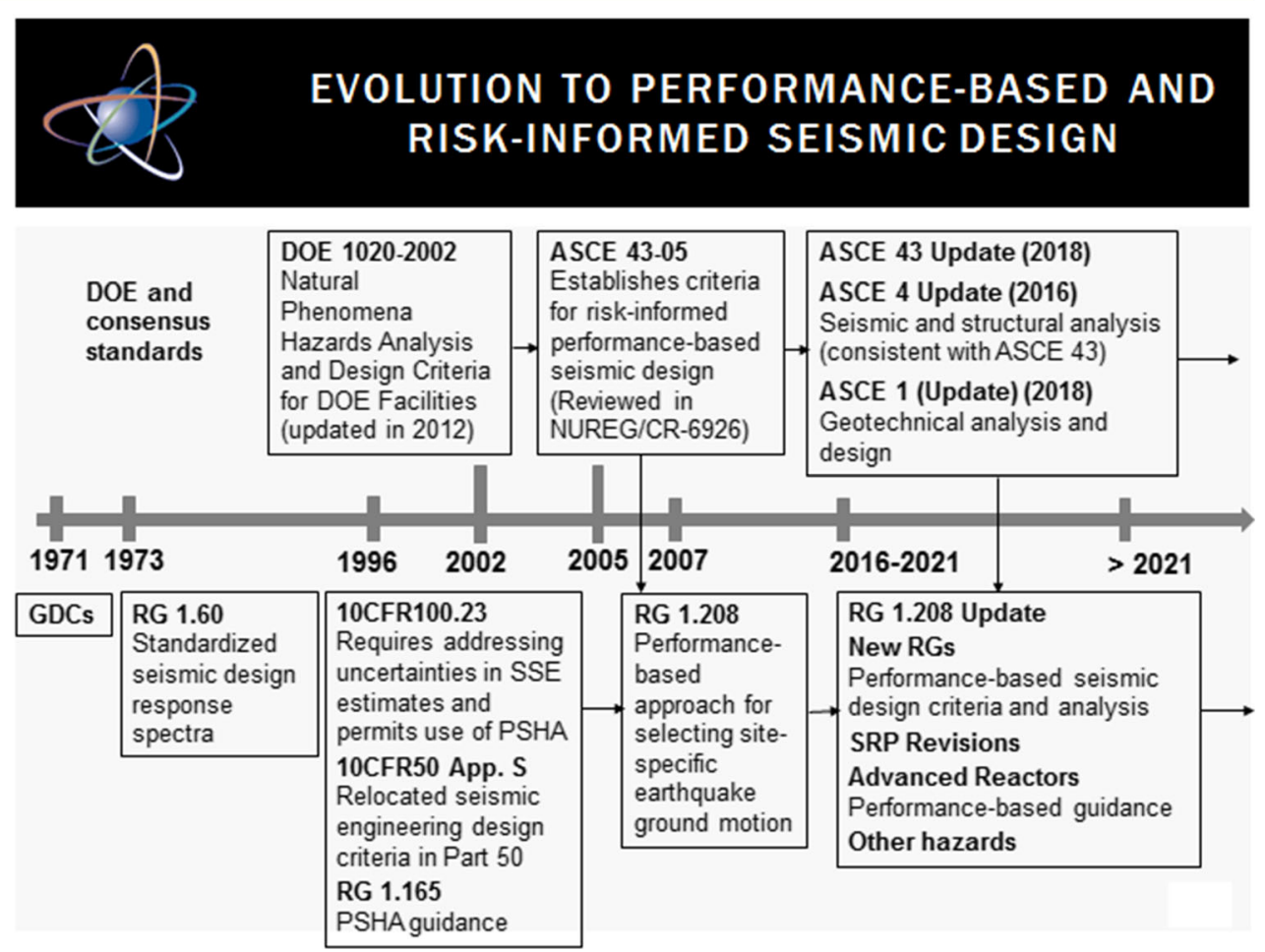

Figure 6

Illustration of the evolution and revisions of references to the consideration of seismic risk for nuclear power, as carried out by the US-NRC in 2017 (source: N. Chockshi, SMIRT-24, Busan, 2017). RG, regulatory guidelines; DOE, Department of Energy Technical Standards; ASCE,

American Society of Civil Engineering; ASME, American Society of Mechanical Engineers

seismic safety approaches is illustrated through the approach of the Nuclear Regulatory Commission in the USA (US-NRC), as illustrated in Fig. 6. The explicit propagation of uncertainties to define seismic hazard (i.e., via PSHA) has been a requirement of the US-NRC since 1996, and the evolution toward integrated risk approaches has been effective since 2005 (through the Regulatory Guidelines and supporting documents), under the term 'Risk-Informed' Performance Based Seismic Design (see NRC RG.1.208 2007).

\subsection{Links Between the French Nuclear Seismic Context and the SINAPS@Research}

To summarize the issues in France, important facts that motivated the SINAPS@ research directions are listed here:

- The regulatory framework is fully and only dedicated to the design stage of structures and components, although it is clearly not a 'performance-based approach' nor a 'risk-informed approach', as it is in the US, for example.

- There is no grading regarding the severity of a facility failure with respect to its environmental and human impacts.

- Without a clear performance-based approach, discussions during the assessment of existing facilities are particularly difficult, as they are constrained by the whole deterministic safety approach. The historical French choice to retain a deterministic seismic level to design nuclear facilities implicitly prevents the association of seismic motion with occurrence frequency. Such deterministic SHA can then not be used to perform any classical probabilistic seismic analysis, as requested in Guidelines ASN \#22.

- The Guidelines ASN \#22 requirement to initially perform deterministic SHA (DSHA), and then if possible PSHA, is surprising, as the licensee needs to conduct full probabilistic seismic analysis. The 
coexistence of DSHA and PSHA in these Guidelines should be further explained. Indeed, it is not recommended to mix nor confuse these two approaches, the outputs for which are very different in terms of physical meaning, of engineering practice, and with respect to the treatment of uncertainties (and consequently to the confidence levels).

- As a consequence of previous observations, SINAPS@ promotes alternative approaches to those currently used in France for the design stage (which are mainly based on simplified assumptions and methods, with nonexplicit treatment of uncertainties through fixed safety coefficients, which lead to not homogeneous margins between sites).

As a first priority, the association of reliable confidence levels and return periods to seismic hazard outputs is clearly defended, as it is not possible to avoid any probabilistic assessment. There is also a necessity to be able to appreciate the overall risk of a specific nuclear facility with respect to another nuclear facility for the same seismic level, and/or to rank the various hazards between two nuclear facilities. Secondly, an integrated methodology is promoted to compute the seismic wavefield from its nucleation on a fault, through the complex geological medium, up to the structure foundations and its transmission to the sensitive equipment. For this approach, there is an explicit and mastered propagation of the uncertainties. SINAPS@ focuses on the consistency between all of these interfaces, to ensure that the seismic hazard outputs are adapted and well used by geotechnicians and engineers. Last but not least, the relevance of the assumptions and methods used to model the seismic response is checked; in particular, the physical phenomena involved strongly depend on the seismic level considered (i.e., nonlinear behavior of soil and materials, and interactions).

\subsection{Identification of the SINAPS@Specificities and Research Directions}

Due to the French context, as detailed above, and driven mainly by a deterministic safety approach that is devoted to the design of nuclear facilities, the probabilistic tools remain sparse and are not, or are weakly, consolidated. There was then a real necessity to improve the probabilistic practice to satisfy the new safety requirements, as for those mentioned in the recent Guidelines ASN \#22 that integrated what was learnt after the Fukushima-Daïchi accident. SINAPS@ promoted and developed tools that made it possible to progress toward probabilistic seismic analysis, the outputs of which are associated with confidence levels that are representative of an explicit propagation of the uncertainties. The proposed methods are adequate for the physical processes that are involved for the seismic levels considered; i.e., the nonlinearities of all of the materials, soils, and buildings, the interactions between the seismic field, the geological complex and the often heterogeneous medium, the foundations of the structure, and the transfer within buildings up to equipment through their anchorage. These physical phenomena are obviously driven by the level of the seismic load. Since the Fukushima-Daïchi accident, the request to account for rare extreme events (i.e., beyond classical safe shutdown earthquake and paleo-event levels) quickens the need for accurate methods. The SINAPS@ research goes beyond the usual design context, with its associated simplified methods and fixed safety coefficients, and promotes the definition of the performance objectives and the formulation of the realistic failure criteria.

As shown in Fig. 7, SINAPS@ was built to investigate the data, models, and methods available to perform seismic analysis, aiming at the assessing of failure probability of a studied facility, structure or component, according to Eq. (1) defined below (where the risk is computed by the convolution of the failure probability with the consequences-the latter being out of the scope of SINAPS@).WP1 mainly worked to better constrain $H$ and the way to generate and select the time series $a(\alpha)$. By definition, in Eq. (1), $H(\alpha)$ is the hazard function obtained through PSHA. As the current French context still requires DSHA, some WP1 research concerned DSHA specifically. WP1 also worked on some site effects aspects, and shared the methodology and recommendations with WP2 and WP4, to promote a bedrock SHA definition and a control point definition consistent with the study case and configuration. WP2 contributed to the nonlinear SSI assessment and the full three-dimensional (3D) wavefield estimate 

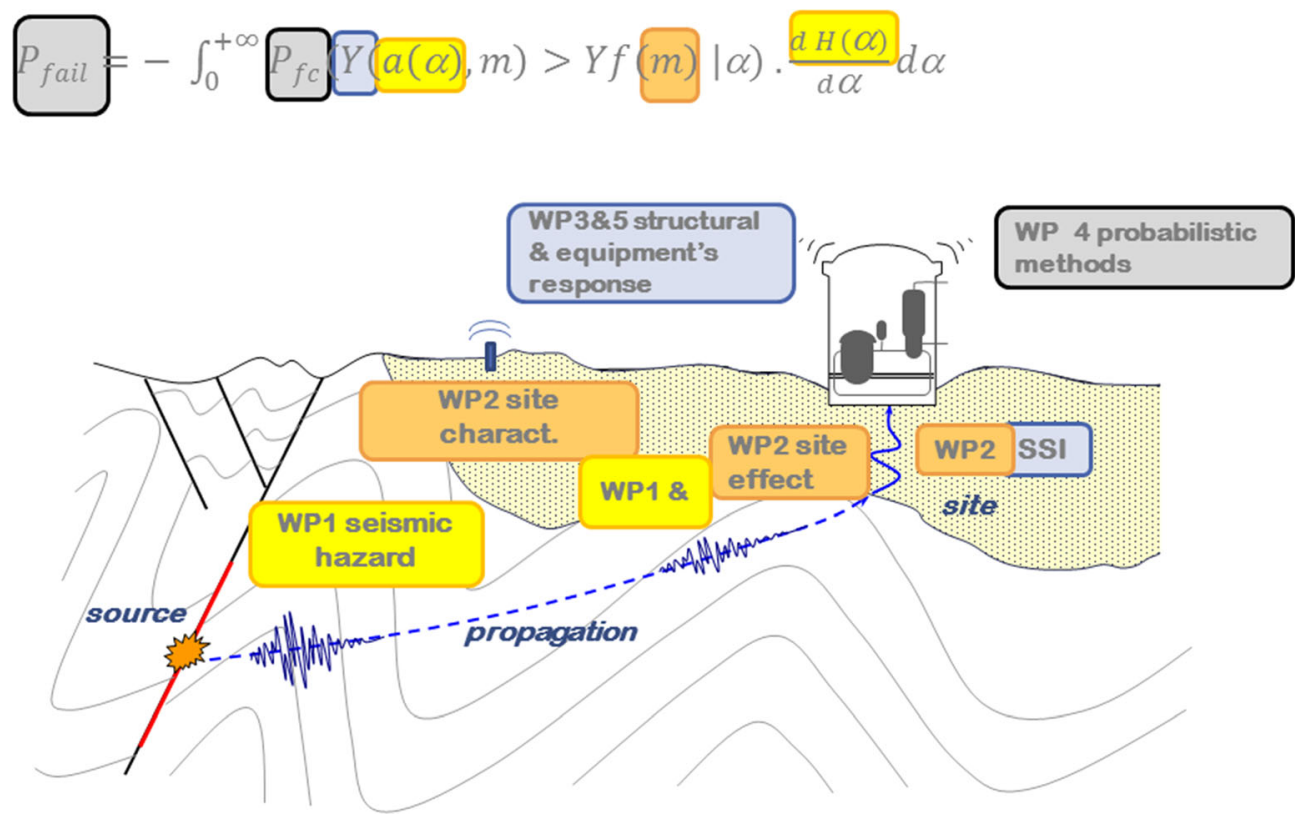

Figure 7

Illustration of the different contributions of SINAPS@, for WP1, 2, 3, 4 and 5, in the probabilistic seismic analysis scheme (Figure from SINAPS@ training 2018, Berge-Thierry et al. 2018). The risk analysis needs to assess the consequences, a topic not covered by SINAPS@

from fault to foundation, with integration of the uncertainties in the soil and structure materials. Site effects topics were treated both in WP1 and WP2, to improve the interface between the reference SHA and the SSI. WP3 focused on structure and equipment seismic response predictions, with the development of simplified and complex nonlinear structural mechanics models that are relevant to the treatment of various situations. WP4 was the integrative block of the WP1, WP2, and WP3 outputs, and challenged its developments against the data from the KARISMA benchmark exercise (IAEA 2014), based on the Kashiwazaki-Kariwa NPP site technical details provided by TEPCO. Finally, WP5 was fully focused on the building-building interactions topic and the damping identification, through the combination of a specific experimental approach and simulation.

By definition, SINAPS@ covered a very broad scientific domain and produced a large amount of data and a number of publications for each aspect. This article mainly presents the achievements or recommendations, with the invitation to the reader to further refer to the specific SINAPS@-related publications or to Berge-Thierry et al. (2018) for more detail.

\section{Main Scientific Advances in Seismic Hazard Assessment (WP1)}

\subsection{Preamble}

Before presenting the main achievements of SINAPS@WP1, it is important to remember that:

1. currently, and for several decades now, two SHA approaches have co-existed: deterministic and probabilistic, as previously discussed.

2. In France, the current 'reference' approach to assess seimic hazards is guided by RFS 2001-01, which prescribes a DSHA-type methodology in which the hazard is defined through reference earthquakes at the following three levels:

- The Seísme Maximal Historiquement Vraisemblable (SMHV; Maximal Historic Plausible Earthquake), chosen in the seismic catalog (as historic to instrumental) as being the worst known event in terms of intensity produced at the site of interest, when shifted as close as possible to the site according to geological and seismological relevance (e.g., with respect to the seismic zoning); 
- The Séisme Majoré de Sûreté (SMS; usually compared to the concept of 'Safe Shutdown Earthquake' in international nuclear documents), defined by an increment of 1 in Intensity (or 0.5 in magnitude units) with respect to the SMHV characteristics;

- The Paleo-earthquake, related to a significant event that produced surface ruptures and as suggested by field indices of active faults.

The definition of these three seismic levels dates back to discussions between the nuclear licensees and the ASN and IRSN, the most recent of which took place in the 2000s, along with the updating of the RFS. The way to obtain the reference events (i.e., SMHV, SMS, paleo-events) is guided by RFS 2001-01, in the perspective of accounting for uncertainties that are mainly related to historical seismic data.

Once the reference events are defined, the seismic movement is evaluated using a mandatory ground motion prediction equation (GMPE) (Berge-Thierry et al. 2003), and it is defined as the mean response spectrum associated to the considered levels (i.e., SMHV, SMS, paleo-event). The choice to consider the mean pseudo-spectral accelerations also resulted from consideration of the treatment of uncertainties when defining the reference events and their characteristics (i.e., in terms of magnitude, intensity on site, depth, and distance from the site) in a whole seismic safety analysis framework. The seismic design level is then defined on the basis of the two (or three) seismic levels listed above. A fourth seismic level was established in the post-Fukushima context: the HCSL.

RFS 2001-01 must be considered in its entirety. Indeed, treatment of uncertainties cannot be separated from the whole approach, which as mentioned above, is specifically intended to cover the uncertainties inherent in the definition of the reference earthquakes. The uncertainties taken into account within the RFS 2001-01 approach implicitly introduce safety margins into the seismic analysis. As a consequence, reconsideration of the treatment of the uncertainties in the RFS 2001-01 approach would necessary lead to reconsideration of the associated margins.
SINAPS@WP1 worked on the characterization of the data and methods uncertainties, and investigated alternative approaches to integrate and explore the uncertainties, using DSHA or PSHA.

It is also crucial to remember that:

3. any DSHA and PSHA performed for a target site shares:

- The overall knowledge in the seismic hazard field, and the references (e.g., the guidelines, practices, scientific publications);

- The basic data (e.g., geological, geophysical, seismological ones), the available software, and the empirical and numerical predictions models.

At the same time, DSHA and PSHA usually differ, as follows:

- First, in their intrinsic objective: DSHA aims to define one (or several) reference seismic event(s) where the seismic characteristics (e.g., magnitude, intensity, depth, distance) are directly translated into seismic motion (usually through a spectral response spectrum) using one (or several) prediction model(s). Whereas PSHA produces a seismic hazard through a probability of exceeding a certain seismic motion measure (e.g., acceleration, pseudo acceleration) during a defined period (or as an annual frequency of exceedance), and the output is usually a uniform hazard spectrum (UHS): in this case, there is no reference event(s) nor seismic scenario associated to the UHS as it is the result of the spatial and temporal seismicity distribution. This conceptual difference explains why only a PSHA provides, by definition, an annual frequency of exceedance, while a DSHA will never provide this probabilistic information. As an extension, this means that however it is performed, a DSHA will never produce an output that is relevant to conduct a full seismic risk analysis, as it requires, by definition, a probabilistic description of the hazard.

- Then in the treatment of uncertainties (of both data and models), be it epistemic or aleatory. On this point, the SINAPS@WP1 research proposes some alternatives to current French practice. 
As a consequence, several SINAPS@ WP1 actions finally benefited both DSHA and PSHA, as the improvement of all of the basic data, the earthquake occurrence, the ground motion prediction models, and the characterization of the uncertainties. In addition, the knowledge evolution achieved globally in the field of seismic hazard, and in specific topics within seismic hazard (e.g., ground motion prediction, site geological, geotechnical characterization) should be accounted for in both DSHA and PSHA approaches, and should motivate the updating of obsolete practices, and simplified assumptions and references.

Nevertheless, it is important to remember that SINAPS@ promotes continuous seismic risk analysis, which can be simply described as follows: Risk $=$ Probability of occurrence of Hazard $\times$ conditional probability of Failure $\times$ Consequences. In the framework of SINAPS@, the Consequences were not assessed. The SINAPS@ research relates to each component of the following Eq. (1):

$P_{\text {fail }}=-\int_{0}^{+\infty} P_{\mathrm{fc}}(Y(a(\alpha), m)>Y f(m) \mid \alpha) \cdot \frac{\partial H(\alpha)}{\partial \alpha} d \alpha$.

Equation (1) is in line with probabilistic risk analysis and performance-based earthquake engineering approaches [see EPRI, PEER and NRC references; Günay and Mosalam 2013]. In Eq. (1), $P_{\text {fail }}$ is the conditional probability distribution function of failure of the studied structure or equipment, $P_{f c}$ is the fragility curve that is defined as the probability that the seismic response of the structural element/equipment and the soil column (the properties of which are parameterized by the vectorial quantity $m$, possibly random too) quantified through the $Y$ engineering demand parameter (e.g.., drift, displacement, acceleration), $Y_{f}$ is the chosen threshold associated with the $Y$ parameter in terms of the failure criterion, $a(\alpha)$ is the time series, with $\alpha$ as the chosen seismic or intensity parameter (e.g., peak ground acceleration, pseudo acceleration, Arias intensity), and $H(\alpha)$ is the probabilistic seismic hazard curve at a specific return period and confidence level, to be explained. $H(\alpha)$ is necessarily obtained from PSHA. DSHA is not of interest in this framework.
Equation (1) needs to be associated to the hazard curve annual frequency occurrence and the confidence level information. As Guidelines ASN \#22 require the licensee to perform probabilistic safety assessment to evaluate the failure probabilities of structures and components important to safety, PSHA then becomes mandatory.

Fragility curves are a valuable tool, as they establish the link between seismic hazard and the effects on the built environment. Fragility curves express the probability distribution functions associated to a class of assets for the reaching or exceeding of predefined damage states for a range of ground motion intensities. A database of a great number of ground motions is required to provide enough information to estimate the parameters defining the fragility curves in any reliable way. However, earthquake-induced damage data in most earthquake-prone regions are too scarce to provide sufficient statistical information. Thus, two appropriate alternatives to correctly estimate the performance of structures under seismic load might be: (1) through certain sets of site-specific ground motion records and synthetic ground motion records; and (2) through a large set of non-site-specific unscaled ground motion records. This latter might provide information about the structural damage for extreme cases, and allow the evolution of the damage with increasing earthquake intensity to be shown.

The interest of performing seismic analysis following this approach is that uncertainties are explicitly integrated and well identified in each term of Eq. (1). This can be used whatever the context of the study, either for the design stage or the assessment of an existing facility.

\subsection{Synthesis of Main Contributions and Lessons from SINAPS@WP1}

\subsubsection{Quality Assurance: Recommendation Across All WP1 Topics}

Seismic hazard assessment studies use large amounts of input data from databases, models, and hypotheses proposed in different studies, and also from experts or extracted from the literature. Some documents that are 'regulation related' (e.g., RFS, Guidelines) 
explicitly indicate sources to be favored (e.g., SisFrance www.sisfrance.net, [EDF-BRGM-IRSN] database, specific GMPEs).

From the SINAPS@ study, we recommend that:

- Any database or model used in SHA studies must be published and fully accessible, and their procedures for data processing and modeling must be explained and justified, to ensure traceability and transparency.

- The selection of models (to describe seismicity in time and space, and/or to predict ground motion) should be driven by the level of their verification and validation against qualified data. The complexity of empirical models (and the number of proxies they consider) should be chosen with respect to the confidence level for the data and metadata; fixing some of the parameters with a priori values might induce additional uncertainties into the process.

- The most recent releases should generally be used, even if past observations, data and studies should not be disregarded (recommendation 3.4 of the OECD/NEA workshop, NEA/CSNIR(2015)15, 2015). For expert debate, the data (or database, model) as published is acceptable until superseded, with justification for new peer-reviewed publications.

\subsubsection{Basic Data in Metropolitan France}

SINAPS@ mainly continued the work initiated in the SIGMA project, see (Pecker et al. 2017). In particular, the SIHEX catalog was completed and made available for the community. This catalog contains information and metadata of instrumental events, and has been standardized to Mw through an explicit procedure, using the coda of signals. The SIHEX catalog has been merged with the historical events also characterized by Mw: the FCAT17 catalog was published as a SIGMA output (Manchuel et al. 2017; Traversa et al. 2017; Baumont et al. 2018).

SINAPS@WP1 considered FCAT17 was the most up-to-date seismic catalog for metropolitan France that covered historical and instrumental periods. Of note, it has the advantage of being published through the peer-review system, and was available to the whole community. Quantification of the uncertainties associated to the metadata was proposed. Some SINAPS@ research allow the uncertainty associated to specific metadata to be better appreciated (e.g., constraint on the depth depending on the event location and velocity model process; Turquet et al. 2019).

SINAPS@WP1 noted that the seismic catalog is a crucial input data for any SHA. It is common to DSHA and PSHA. Its completeness, the metadata, and the uncertainties it contains are the basic information that fully drive all assumptions and models used to perform SHA, be they deterministic or probabilistic (e.g., seismicity occurrence with Gutenberg-Richter or any other model, 'maximal magnitude').

\subsubsection{Seismic Source Characteristics}

SINAPS@WP1 contributed to improvements to the focal mechanisms of French earthquakes. These focal mechanisms are important, as they are, for example, used to propose seismotectonic zoning. They also characterize the deformation regime of faults. In addition to improving the French focal mechanism database, the work performed in SINAPS@ showed the strong dependency between the metadata, as shown in Fig. 8 (Do Paco et al. 2017). In some cases, the focal mechanism was correlated with the depth of the event, with the depth itself mainly controlled by the velocity model used to locate the event. This also means that the uncertainties of all of these metadata are correlated, and they cannot be considered as propagated independently when performing a SHA.

\subsubsection{Seismic Source Characterization in Metropolitan France}

SINAPS@WP1 had two main contributions to this field, the conclusions and impacts of which are of great importance for DSHA and PSHA. The first was the study of Craig et al. (2016) on the Fennoscandia region, which suffered a cluster of several severe earthquakes $(\mathrm{Mw}>7)$ that were triggered by postglaciation processes (i.e., elastic rebound of the crust delayed in time after ice melting). Craig et al. (2016) showed that this phenomenon still impacts today on 

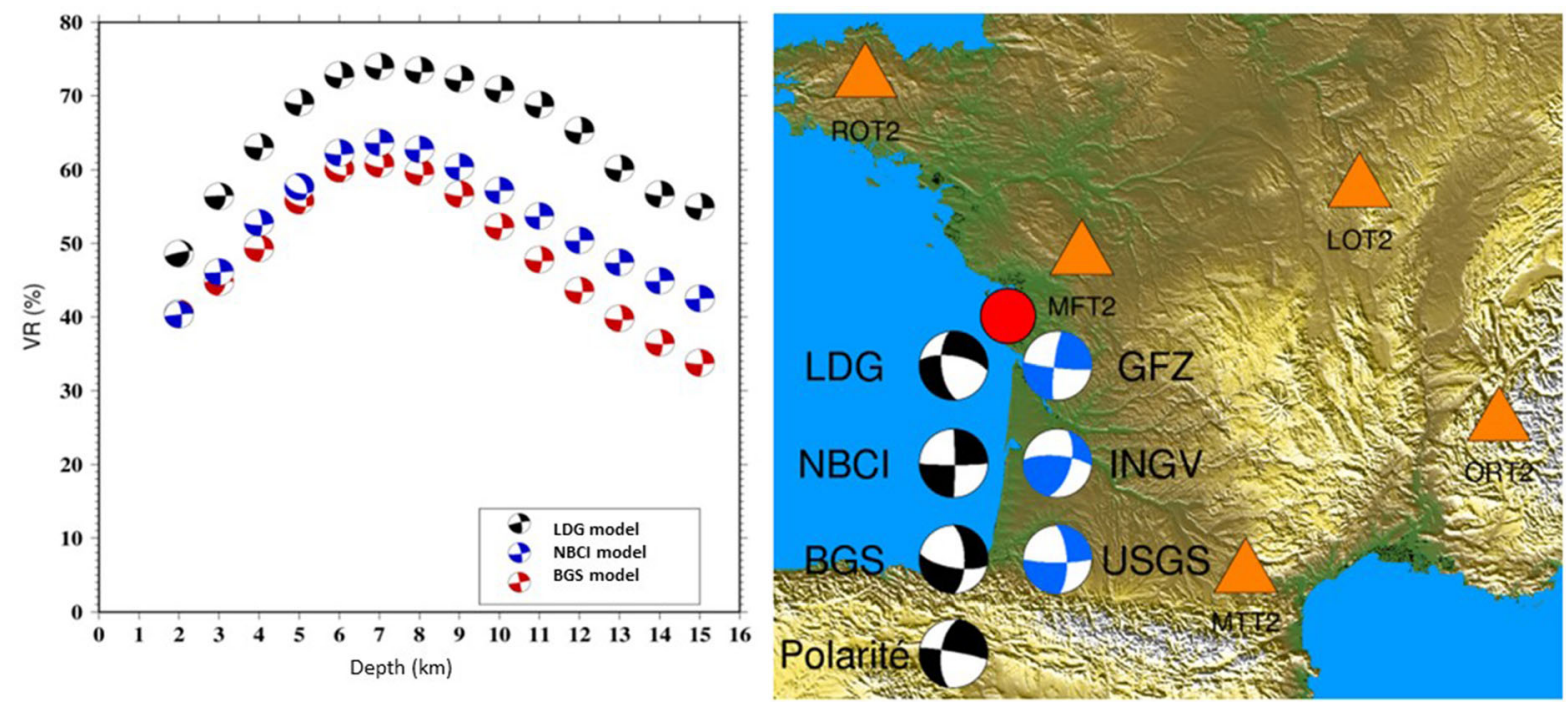

Figure 8

Variance reduction of focal solutions with respect to the velocity model and the event depth, for the Oléron Island event (28/04/2016) (Do Paco et al. 2017)

the stress field of the French territory. This study drew two important conclusions regarding the interpretation of singular severe events (e.g., paleoearthquake indices): (1) some of them occur on faults that are not promoted by the present day stress regime revealed by the seismicity considered in SHA models; and (2) there was non Poissonian behavior of the seismicity. Craig et al. (2016) showed that this phenomenon also impacted, and still impacts (although at lower amplitudes), upon the static stress changes applied to the faults in the French territory.

In line with a previous study, Bertran et al. (2017) investigated some periglacial deformation indices. They discussed these with respect to other brittle deformation indices of seismic origin. This study concluded that in metropolitan France, some quaternary indices of soft soil deformation are related to periglacial deformation, so they cannot be associated to paleo-seismic origins, and so they do not contribute to build or constrain assumptions of seismogenic fault behavior.

\subsubsection{Seismic Motion Prediction}

SINAPS@ WP1 partners used the strong motions available in open databases. The quality and usefulness of the NGA-West 2 (gathering worldwide, as shallow crustal earthquakes in active regimes) and the Resorce Euro Mediterranean databases are highlighted by SINAPS@WP1. These two databases:

- Fulfil the quality, traceability and signal treatment processes required for the use of the data and metadata, and the uncertainties they contain.

- Supersede previous published databases. In particular, the strong motion database used in 2000 to derive the GMPE prescribed by RFS2001-01 is not yet recommended (choice of metadata not appropriate, in terms of magnitude scale and event-tostation distance definition, or site characterization through classes based on large intervals of estimated shear-wave velocity).

SINAPS@WP1 underlines that in some cases, the metadata provided by the strong motion databases are not fully derived from empirical raw data. As an example, sometimes rupture parameters are provided, but they are related to a seismological model, and not directly deduced from the data. This is of great importance when these metadata (and their uncertainties) are used to produce ground motion prediction models. Some recent GMPEs proposed very complex functional forms, including rupture 
parameters; but are all of these seismic rupture models compatible? Is the model complexity in agreement with the level of knowledge provided by the raw seismological data? Among all of the metadata, the distance between the event and the recording station is of primary importance. The multiplicity of definitions with respect to the rupture area is representative of the seismic models behind these distance definitions.

For GMPEs, which are a key tool in any SHA (i.e., DSHA, PSHA), SINAPS@ WP1 recommends the use of recently published GMPEs (or the use of older GMPEs should be clearly justified). Indeed, peer review should guarantee the requirements (e.g., quality, relevance of the functional form with respect to the data) of any GMPEs in 2018. SINAPS@ WP1 recommends the use of GMPEs where the proxies are the most compatible with those chosen in the seismic catalog (e.g., magnitude scale, distance definition), to avoid as many conversions as possible. Indeed, these conversions add artificial uncertainties to the whole process.

\subsubsection{Toward Physical Based Strong Motion Prediction}

SINAPS@ WP1 worked on the ground motion predictions using physical rupture-based models. Kinematic rupture modeling was performed on extended seismic faults. The SINAPS@ study confirmed the relevance of a number of the available and published software packages. The focus was on the use of empirical Green's functions (EGFs; assumed to be a good representation of the seismic wavefield from the source to the site over a broad frequency range) to predict site-specific seismic responses. Several assumptions are nevertheless associated with the summation of EGFs to predict strong motion due to an extended seismic source, in terms of the relevance of EGFs in relation to focal mechanism with respect to the target event. The scarcity of strong motion data in metropolitan France meant that this technique was of very limited use in France, as there were few wellcharacterized events available (i.e., in terms of 3D location, magnitude, focal mechanism), and those that were available were clearly associated with a specific fault of interest. In the framework of SINAPS@, the work performed by Del Gaudio et al. (2017) that arose through an investigation of the source parameters, concluded on the capacity of such EGF kinematic models to predict strong motion in agreement with the GMPE predictions for the same scenario, including the variability of several intensity parameters. Dujardin et al. (2018a) conducted an extensive sensitivity study on a canonical case using the same EGF summation and kinematic source model. This work focused on the numerous precautions to respect when working in a region or with a fault case characterized by rare events that could be retained as EGFs. In such cases, many delicate corrections have to be implemented to allow for the distortion of the focal mechanism on the rupture plane. Without these adjustments, bias was introduced in the near-field strong motion. Despite current difficulties associated with these emergent techniques, the numerical ground motion prediction models should be developed in the future as a strategy to overcome the limits of GMPEs close to faults, given the lack of ground motion data. They are of interest for sensitivity analysis, and in particular to explore the hazard variability induced by complex seismic rupture processes and uncertainties.

In addition Dujardin et al. (2018b) present in this issue an application of the EGF summation method in a test case in southeastern France, at the nuclear Cadarache site. This Cadarache site-specific study supports several important SINAPS@ conclusions that apply to all sites:

- The necessity to correctly and fully carry out SHA for the bedrock condition, to define the reference motion;

- The inadequacy of generic GMPEs where the site characteristics are given through Vs-based classes roughly estimated or poorly constrained;

- The relevance of assessing the realistic seismic response by performing site-specific studies and taking advantage of in situ representative data;

- The interest in, and potential of, seismic networks.

\subsubsection{Bayesian Tool as an Objective Alternative to Expert Judgment}

SINAPS@WP1 successfully tested the potential of Bayesian model averaging approaches to rank and 
(a)

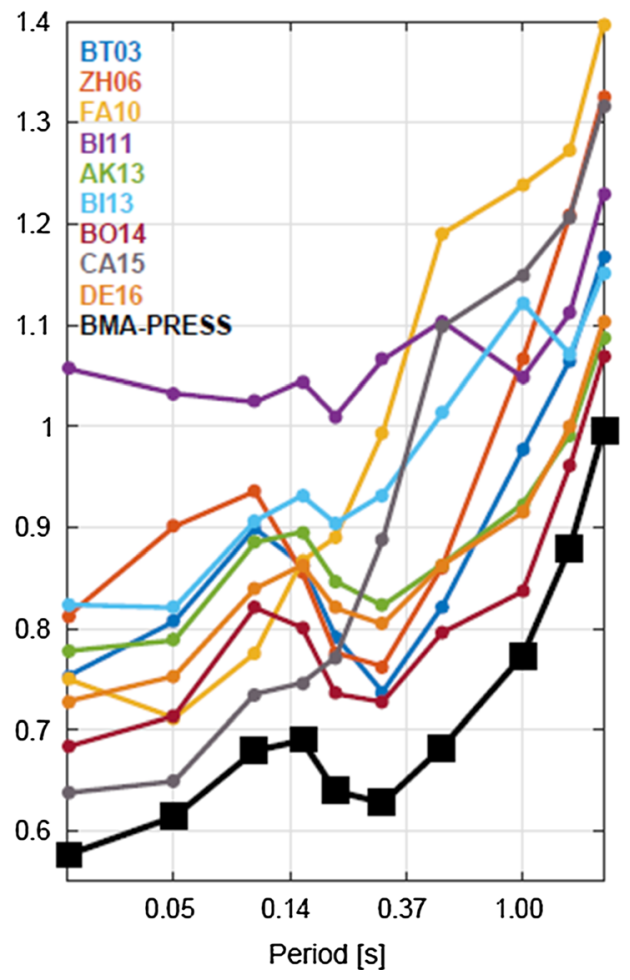

(b)

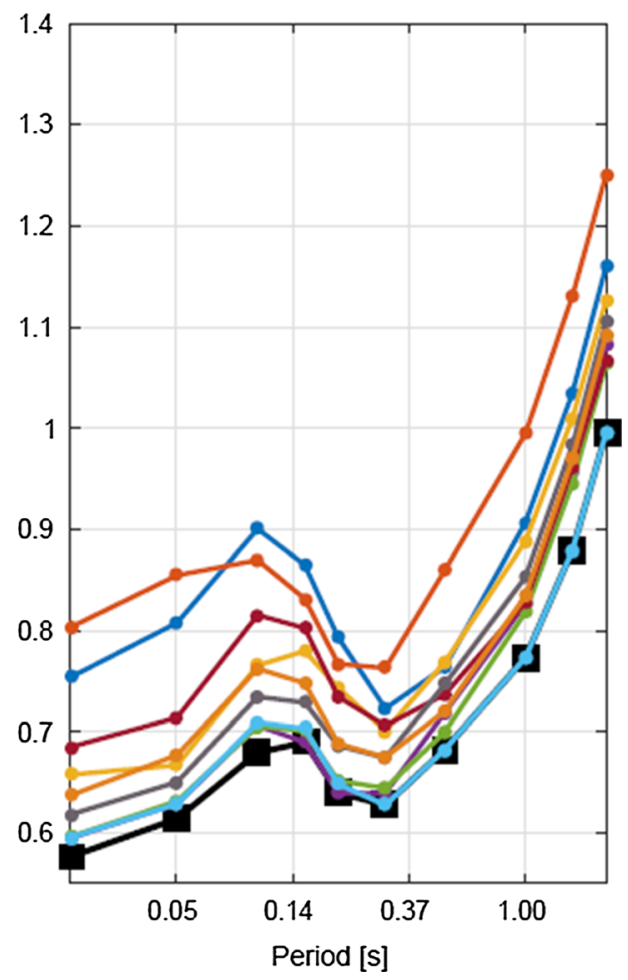

Figure 9

Quadratic means of prediction error using the Bayesian model averaging approach on a large GMPE set. a Prior predictions. b Posterior predictions. The black line corresponds to the predicted residual error sum of squares (PRESS) of the Bayesian model averaging combination of calibrated GMPEs (from Bertin et al. 2019)

weight a set of GMPE candidates to be included in DSHA or PSHA. This technique was applied using state-of-the-art GMPEs that were taken from a study in the French metropolitan territory. A strong motion dataset that was considered to be representative of the expected ground motion on site was extracted from the RESORCE database, to challenge the predictions of the different GMPEs against these observed data. The SINAPS@ study clearly showed that without any a priori information on the GMPEs, the Bayesian model averaging provided hierarchy and weighting of the GMPEs that was only based on their relevance with respect to real data (Bertin et al. 2019). This finally provided an objective ranking that avoided any expert advice that might be questionable (e.g., on the choice of the candidate GMPEs, on their weight in a logic-tree), as shown in Fig. 9. Using such an approach, any kind of GMPE (be it purely empirical, hybrid, or based on strong motion simulation as 'physical based' modeling) can be challenged against the data, and the final weight is justified objectively. The potential of Bayesian techniques is expected to be revealed in the future; e.g., for a posteriori testing of short return period outputs (i.e., hazard levels) of PSHA, to update a model (either considering existing data, or including new information).

\subsubsection{Site-Specific SHA}

Consistent with WP2 and WP4, SINAPS@WP1 contributed to better constrain SHA from a sitespecific point of view. SINAPS@ WP1 underlined the improvements that were made since the 2000s in the characterization of site properties. These have superseded the way in which sites were described; e.g., through rough categories such as 'rock' or 'soil'. Nowadays, any site SHA requires site measurements, especially if the facility is of a nuclear type (see Dujardin et al. 2018b; this issue). 
SINAPS@ and other national and worldwide research projects have converged to affirm that describing a seismic site response through a unique value (such as $\mathrm{Vs}_{30 \mathrm{~m}}$, which is sometimes not directly measured but assessed from geological maps) is clearly insufficient. There is the need to at least complete an estimate of the depth of the 'reference bedrock' and its velocity (Dujardin et al. 2018b). Other seismic parameters are of particular importance (e.g., Kappa, resonance frequency) and should complete the site description. State-of-the-art GMPEs require several site-specific parameters, used as 'proxys' in their functional forms.

Laurendeau et al. (2017) and Bora et al. $(2015,2017)$ took advantages of the availability of well-characterized strong motion databases (i.e., KikNet, Resorce, respectively) to propose alternative approaches to classical host-to-target corrections, mainly based on the $\mathrm{Vs}_{30 \mathrm{~m}}$ and Kappa parameters. These studies showed that the host-to-target adjustment is particularly 'approach-sensitive', and results might vary widely.

Site-specific studies require permanent and temporal geophysical and seismological instrumentations to better constrain the 'site term' (to allow adjustment to the GMPE predictions based on the ergodicity assumption, and derived in other territories). Instrumental investment is unavoidable to reduce the uncertainties for strong motion site-specific predictions. These instrumental geophysical data are also crucial to verify and validate site response simulations, whatever the site configuration (i.e., 1D, 2D, $3 \mathrm{D})$, as largely discussed and illustrated in WP2 and WP4.

SINAPS@WP1 also underlined that the Fourier spectrum is strongly preferable to the response spectrum for seismic analysis (Bora et al. 2017). Indeed, the Fourier spectrum is a direct measure of the strong motion, whereas the response spectrum is already an envelope of one degree-of-freedom maximal responses. In terms of uncertainties and margin assessment, the Fourier spectrum appears to be a better tool and should be used for future GMPE developments, and should be chosen as the intensity measure in SHA. The other advantages are its fully physical meaning (linked to the seismic scenario) and the direct generation of the corresponding time series.
Consistent with WP2 and WP4, SINAPS@WP1 strongly supported the evolution of the current French practice toward site-specific approaches, with clear definition of SHA at the relevant 'control point'. The control point is characterized by its depth and geotechnical/geophysical properties (see Fig. 10, where control points are considered for the Kashiwazaki Kariwa Nuclear Power Plant (KK NPP) demonstrative study case). The control point is chosen depending on the study case. A control point at the reference bedrock is strongly recommended to perform SHA (i.e., at least for outcropping bedrock, or at depth). The site effects are assessed in collaboration with geotechnicians and engineers through SSI computations. SINAPS@WP4 studies clearly showed the bias of a 'bad control point definition' when performing the whole computation from seismic hazard to SSI, and for fragility curve assessment (Wang and Feau 2019). In particular, the deconvolution step currently systematically applied by engineers is at least questionable or indeed inappropriate (especially when severe seismic levels are considered, and non-linear soil and/or structure behaviors are expected or suspected; in such cases, the relevance of the linear equivalent approach has not been supported).

\subsubsection{Selection of Time Series That are Compatible with Spectral Hazard Descriptions: Relevance to Engineering Application Needs and Variability Treatments}

The step of selecting the time series representative of the site-specific seismic hazard is crucial to the whole process of seismic analysis, as these are the seismic inputs of simulations performed to assess the site response, which include all interactions, as studied in WP2, WP3, and WP4.

SINAPS@WP1 and WP4 contributed to this topic through considering the outputs from DSHA and PSHA, to provide response spectra related to specific seismic scenarios and to uniform hazard spectra, respectively. These two kinds of outputs have significantly different physical meanings: the way to select time series (i.e., from real strong motion databases, or generated from simulations) that are representative of these spectra might drive their 


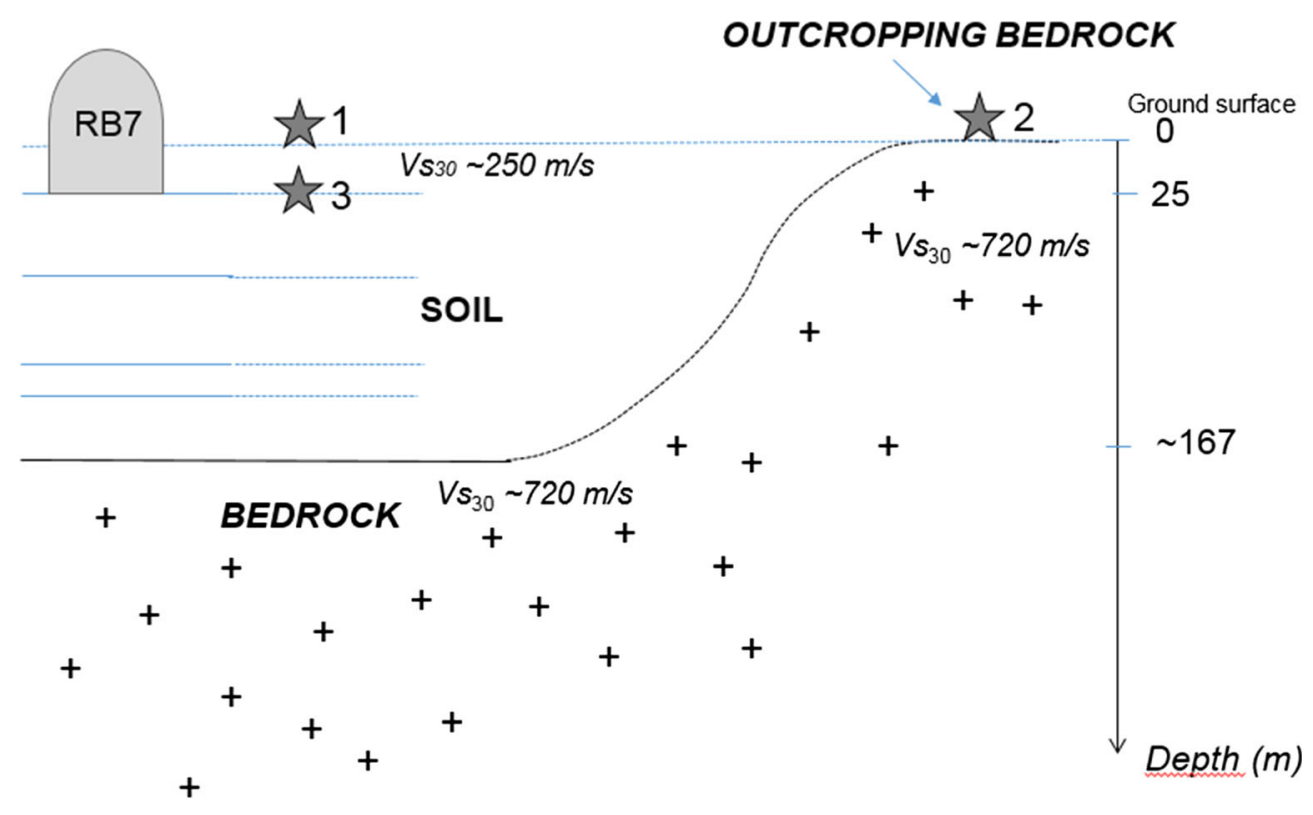

Figure 10

Simplified scheme of the KK SINAPS@ demonstrative case (see WP4). Reactor building RB7 is embedded by over $25 \mathrm{~m}$. Beneath the soil, the bedrock is found at $\sim 167 \mathrm{~m}$ in depth. Stars indicate locations of different 'control points': star 1 'free field at soil site condition'; star 2 'free field at the outcropping bedrock condition' and star 3 'at depth—foundation level—local soil condition' (modified from Berge-Thierry et al. 2017a)

seismic characteristics (e.g., in terms of frequency content, amplitude). Therefore, the seismic response of structures or components might vary from one set to another, especially in the case of nonlinear behavior.

Research on these topics was carried out from DSHA through a PhD (Isbiliroglu 2017), and a site specific case-study (Wang and Feau 2019), while Zentner et al. (2018) reported on the time series selection compatible with a UHS from PSHA, with the introduction of the state-of-the-art concept of conditional spectrum, as widely used in risk-based seismic analysis. The practical study of Wang and Feau (2019) was performed on the KK NPP site, and it outlined several important points that should be considered further, as follows:

- The choice of a synthetic ground motion generator and its relevance (i.e., consistency of the synthetic ground motion with respect to natural strong motion, in terms of several intensity measures beyond the unique spectral aspect).
- The scaling of the strong motion to cover a large motion intensity range, to perform vulnerability and failure analysis.

- The definition of the control point (e.g., free field including local site responses or outcropping bedrock, or at depth at a specific bedrock reference level). This assumption is crucial, as its drives the deconvolution process and finally strongly impacts upon the seismic loading properties imposed at the structure foundations.

- The relevance of using a linear equivalent method in this site specific study (nonlinear soil behavior needed under high seismic motion).

This study is particularly interesting for at least two reasons: (1) it illustrates how the strong motion variability can be fully integrated into the seismic analysis, and how it finally affects (or not) the response when the whole nonlinear soil structure equipment system is modeled; (2) it shows how the cumulation of simplified assumptions and methods can lead to poor representations of physical phenomena, which leads to bad failure probability predictions (Fig. 11). 

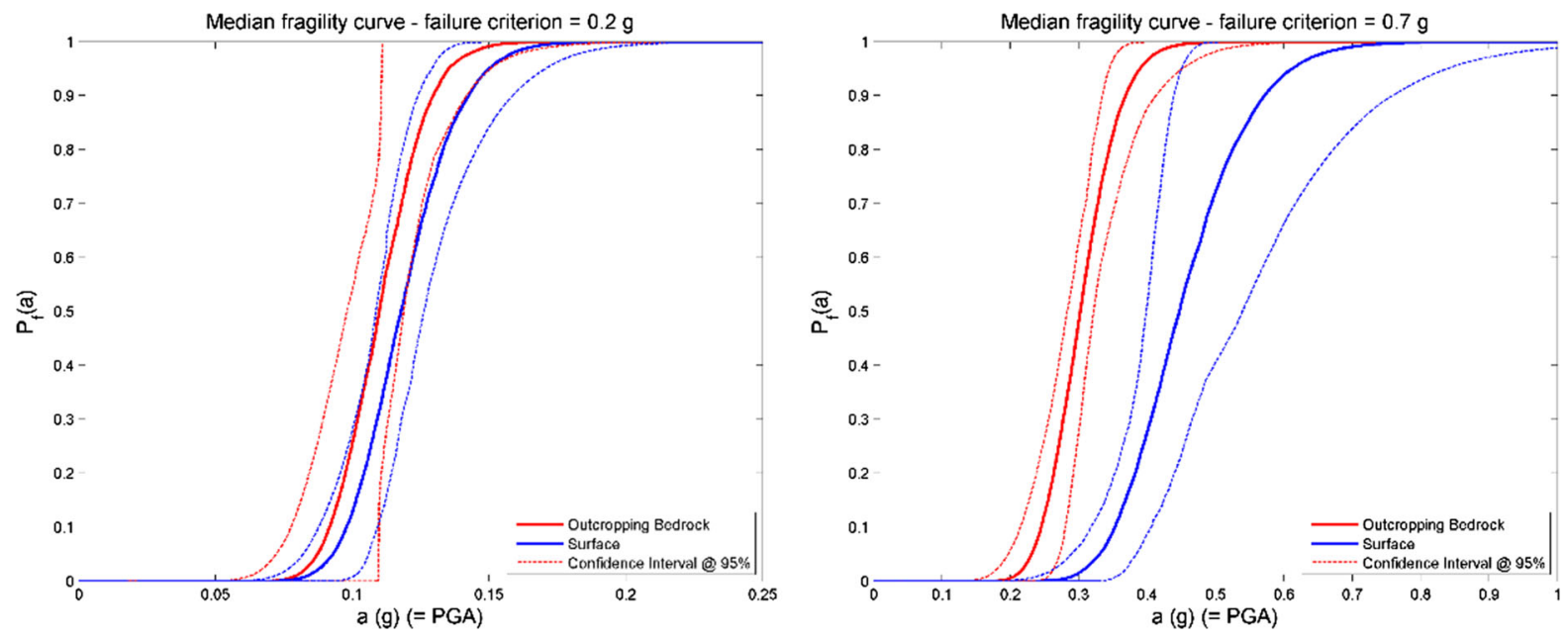

Figure 11

Two examples of median fragility curves and $95 \%$ confidence intervals for the $4 \mathrm{~Hz}$ resonant equipment, computed for a failure criterion of $0.2 \times g$ (left) and for a failure criterion of $0.7 \times g$. These data suggest that defining the control point of the input motion at the soil surface (blue curves) as prescribed for French nuclear practice is not appropriate, and can lead to biased results when performing nonlinear soilstructure fragility analysis. This study has shown that the approach for which the excitation is defined at the surface tends to quasisystematically underestimate the risk of failure (Wang and Feau 2019; Berge-Thierry et al. 2017c)

As already emphasized, the SINAPS@ research contributes to each step of an integrated seismic safety analysis, the aim of which was to compute the failure probability of key structures, systems and/or components, following Eq. (1). To follow such an approach, the need to assess the seismic hazard of a site using a probabilistic methodology is underlined: this requirement is because only PSHA can, by definition, be associated with the hazard probability (or the frequency exceedance) of the chosen seismic intensity measure over a specific time duration. The outputs of DSHA (i.e., response spectra associated to seismic scenarios) and PSHA (UHS, which result from the entire magnitude scenario range, with each weighted according to its occurrence rate) have significantly different physical meanings. Among these differences, and with respect to the probabilistic objectives and the mastered uncertainties propagation, it needs to be remembered that the UHS is a kind of spectral envelop, as there is no unique earthquake scenario that can generate the frequency content of a UHS. Then the process to select a set of ground motions (natural or synthetic) from a UHS might be different and optimized with respect to the methodologies classically used when spectra result from DSHA (as investigated by Isbiriloglu 2017 and Wang and Feau 2019). During SINAPS@, this step was studied and greatly improved by Zentner et al. (2018), as follows:

- First, the simulation of ground motion time histories in agreement with conditional spectra was developed through a stochastic ground motion simulation model. The methodology used was inspired by an innovative ground motion selection procedure that was previously proposed by Lin et al. (2013). The original method was based on simulation of sets of conditional spectra that represented the spectral shape as median and sigma, and selection (and possible scaling) of the recorded time history that best fit the conditional spectra, one by one. Ground motion simulation allows time histories to be obtained without having to resort to scaling and modification. Moreover, there is no limitation to the number of available appropriate time histories for the matching of various criteria, such as spectral shape, strong motion duration, and other ground motion proxies, which can be generated at low cost.

- Secondly, different ways to implement the conditional spectra approach for the computation of 


\section{- Integrated approach}
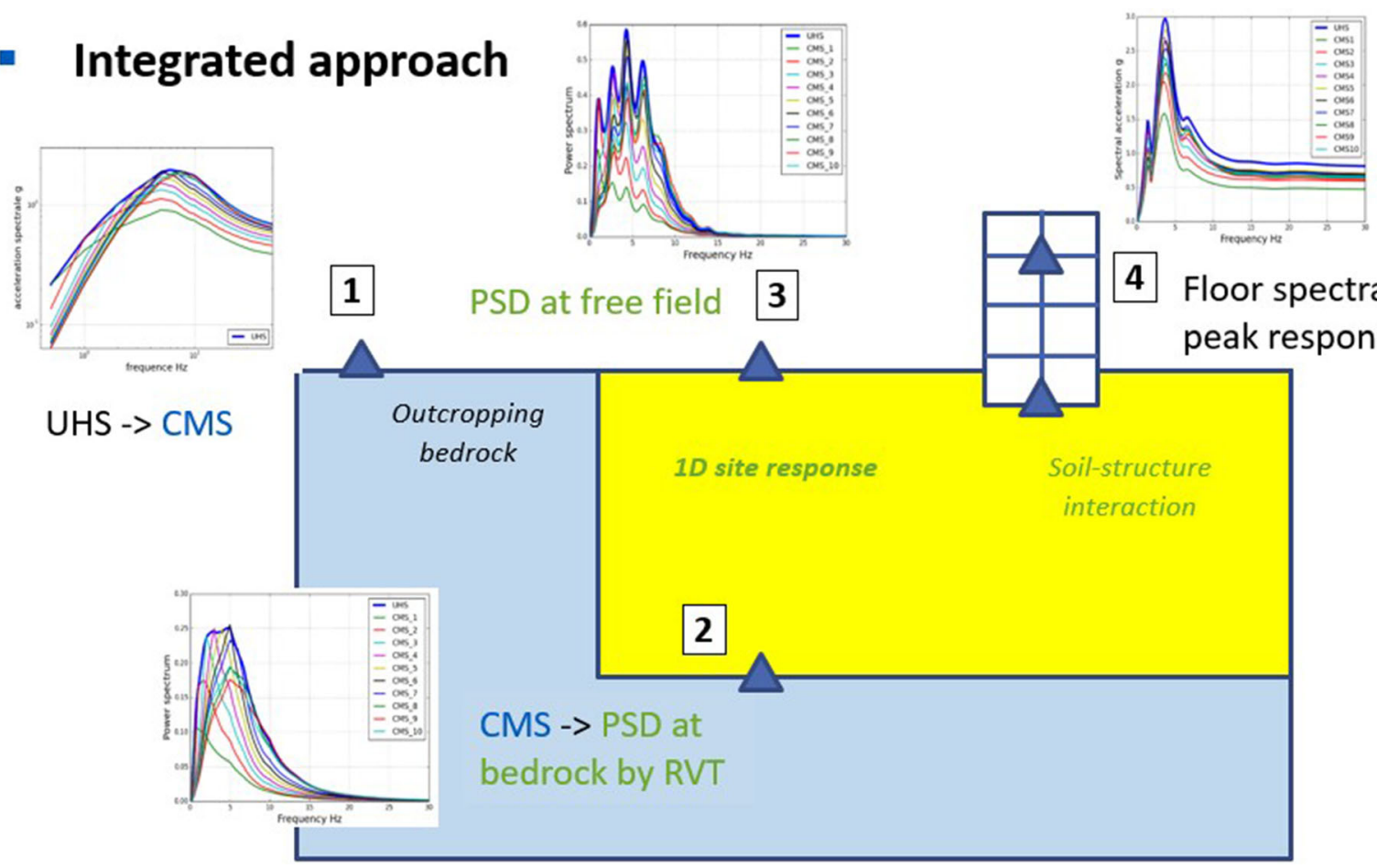

Figure 12

Illustration of the Zentner et al. (2018) integrated approach

fragility curves and probabilistic floor spectra were investigated.

- Finally, an integrated approach was investigated that was based on the transfer of ground motion defined on outcropping rock by conditional mean spectra to the NPP floor level, by means of a computational methodology with Code_Aster. The procedure is illustrated in Fig. 12, and this is in line with the international state-of-the-art procedures and with practice in a regulatory context in the USA, for example (Zentner 2014, 2017; Trevlopoulos and Zentner 2019).

\section{WP2 Non-linear Site Effects and Soil Structure Interactions}

\subsection{The Scientific Context}

In the framework of wave propagation from a source to equipment housed within a structure, the WP2 activities are positioned at the interface between soil and structure, seismology and structural dynamics, and hazard and structure vulnerability. Even if SSI effects are well known from the 1970s, they have often been tackled under simplified assumptions, including Winkler springs, uniform incident wave fields, shallow rigid footings, or linear equivalent soil behavior, among others. Some of these assumptions have been improved in recent years, to highlight the intrinsic safety margins. Moreover, these previous studies showed high sensitivity to the uncertainty for both the seismic loading and the properties of the soil domain surrounding the structure. Moreover, so as to take into account extreme events in the post-elastic behavior of structures, it is necessary to have a more detailed description of the seismic loading, both in time and space, that exceeds the given maximum acceleration or codified spectrum. Finally, instrumental and theoretical seismology has highlighted the complexity and variability of the incoming seismic waves, with near-field effects, site effects, non-linear filtering strong movement, and spatial variability. These advances have now been built into the bigger picture, which combines diverse methods with the associated 
difficulties, and is sometimes inconsistent with the regulations and common methods used around the world. WP2 was divided into three axes according to the tasks in the research, which define its main objectives.

\subsection{Objectives of $W P 2$}

WP2 has the following three objectives:

1. Improvement of traditional methods that define the input motion at the base of a structure,

(a) based on the results obtained in WP1;

(b) including spatial variability of the signals;

(c) with quantification of uncertainties of diverse soil materials.

2. Development of new methods,

(a) from the fault to the equipment, including nonlinearity and variability of soil properties;

(b) coupling structural and wave propagation codes.

3. New seismic data acquisition to validate:

(a) in the seismicity framework of France (i.e., low to moderate);

(b) for the validation site (Argostoli site, Kephalonia Island, Greece).

It is important to bear in mind that the deliverables of each task define the final product, which is to create a large-scale probabilistic model from the source to the structure, taking into account nonlinear site effects, SSI, and the propagation of uncertainties (e.g., material properties, type of sources) for the demonstrative case study which was performed in WP4.

\subsection{Soil-Structure Coupling}

One of the goals of this work was to simulate nonlinear SSI using the 'domain reduction method' approach. Usually a nonlinear SSI (NL-SSI) problem is solved using direct methods, which can be very expensive in terms of computation time, due to the treatment of infinite domains (i.e., fictive boundaries for a large-scale domain). To reduce the computation time, a possible strategy is to reduce the computational domain (i.e., the soil domain) and to get the soil boundaries close to the structure. In this case, two aspects are very important: (1) in the full finite element model (FEM) approach, the incident waves must be imposed according to the hypothesis of soil behavior at the fictive boundaries; and (2) moving the fictive boundaries close to the structure means that the influence of the outgoing waves induced from them are important. Then, absorbing boundaries are needed to satisfy the radiation condition for the incompatible outgoing waves. Thus, the efficiency of the absorbing layer is a key point to reduce the size of the problem. These points are the main highlights relating to domain reduction methods.

In this study, using the input data of the benchmark KARISMA exercise (IAEA 2014), the objective was to compare different strategies for fully nonlinear analysis for SSI problems using fictive boundaries to represent the infinite domain. Usually, to perform SSI simulations, periodic conditions are used to approximate the lateral boundaries. Moreover, the seismic loading is imposed as vertical incident waves at the bottom of the model. This approach is accurate under two conditions: the fictive boundaries are distant from the structure, and the problem respects the period conditions (e.g., symmetry of geometry and loading). Due to the presence of the structure, with the idea to reduce the size of the model, this is not the most accurate technique, and other kinds of boundary models are needed to eliminate toward infinity the outgoing waves from the structure. Hence, a parametric study was carried out using some strategies to absorb all of the outgoing waves for symmetrical and asymmetrical systems. In addition, a numerical procedure was defined to simulate the incoming waves. This was based on computation of the equivalent force field at the boundaries from a model without the structure. In this case, for the soil close to the structure, the computations were performed considering nonlinear behavior, which was described by a simple constitutive law developed in Cast3 $\mathrm{M}$ FEM Code. 


\subsection{Validation of Nonlinear Soil Models for Strong Ground Motion}

The aim of this study was to provide some clues concerning the evaluation and propagation of epistemic uncertainties in the simulation of seismic site responses. In this context, a benchmark allowed the performance of the different numerical models to be shown to represent the nonlinear soil behavior in a 1D nonlinear site response analysis. The results were compared to the observations at two sites of the Japanese accelerometric network (i.e., Sendai, Kushiro KSRH10) that were intensively characterized with in situ measurements and multiple laboratory measurements conducted on disturbed and undisturbed soil samples (Régnier et al. 2017).

The predictions obtained by the large amount of software were compared to observations on the selected sites of the Japanese accelerometric network. Then, the residuals and the software-to-software variability were calculated for the two sites, and compared to the part of the uncertainty in GMPEs that is associated to site amplification. According to these data, the misfit was generally higher than the software-to-software variability. In addition, it was also seen that contrary to what was expected, the software-to-software variability and the misfit were closely equivalent for the weakest input motions.

Another important aspect from this benchmark was that to simulate the seismic soil response numerically, a truly nonlinear approach was mainly considered (i.e., time domain analysis). Two types of nonlinear models were used: (1) those that rely on the description of the backbone and hysteretic curves; and (2) the advanced constitutive models based on the plasticity framework that can take into account the initial and critical state, volume deformations, and drainage conditions, among others. Here, the former numerical model approach allowed simulation of the dynamic soil behavior in a simple way, with an acceptable level of accuracy.

The levels of software-to-software variability obtained and the misfit might be due to the accuracy of the soil characterization. A large variety of tests were available, each of which has different advantages and limitations, which are mainly related to the level of strain tested. While efforts can be made to reduce errors in the interpretation, testing equipment, and sampling disturbance, uncertainties related to the inherent variability of soils resulting from natural geological formations and inherent or induced anisotropy should not be neglected.

\subsection{Validation Site and Data Acquisition at the Argostoli Test Site}

It is well known that the nonlinear behavior of soil can drastically change site responses in cases of strong ground motion. It is necessary to validate the nonlinear evaluation practices through comparison of simulation results with real data. Accelerometers were then installed along a vertical array (and in a rock reference site) within a small sedimentary basin near the town of Argostoli, on Kefalonia Island (Greece), one of the most seismic areas of Europe. This vertical array represented long-term investment toward the constitution of a new database for possible nonlinear practice validation in a $3 \mathrm{D}$ case. This site was chosen due to the feedback from previous studies, and especially the NERA European research program. The vertical array was installed in July 2015, and consisted of four downhole, three-component sensors, which were complemented by two surface sensors, one at the mouth of the borehole, and the other a few hundred meters away, on a rock outcrop. This array was operational, and has recorded hundreds of high-quality accelerograms, with peak ground acceleration sometimes up to $0.15 \times g$ (local Mw 3-4 events, and a distant Mw 6.5 event). The data recorded from July 2015 to December 2017 are available through various FTP sites, and were indicated by Theodoulidis et al. (2018) and Cushing et al. (2016).

This site was selected following a temporary seismological experiment that was accompanied by various geophysical measurements performed in 2011-2012. The available geotechnical and geophysical information was significantly improved within the SINAPS@ framework, with the first geological and geophysical survey conducted in September 2013, and with the borehole investigations (i.e., Vs, geotechnical measurements). The former led to a new geological map and a 2D cross-section, estimation of Vs profiles (obtained with surface-wave-based 
noninvasive methods), and a 3D overview of the basin through $\mathrm{H} / \mathrm{V}$ measurements. In addition, considering the occurrence of the January 26, 2014, Mw 6.2 earthquake less than $20 \mathrm{~km}$ from the test sites, it was decided to launch a post-seismic survey with two main objectives: (1) to install temporary accelerometers prior to installation of the permanent array, to record possible strong after-shocks; and (2) to install a dense array of sensors to set-up a database to study spatial short-scale variability. Different sensor types were used: accelerometers, broadband velocimeters, and rotational sensors, and these were deployed for different soil conditions. Even if this kind of database did not address the nonlinearity issue, it was also essential for the SSI studies within the WP2. The temporary accelerometric network has been operating since February 3, 2014 (a few hours after the second strong earthquake, with Mw 6.0) until July 2015, and it recorded several thousands of events. A first analysis of this database allowed the computation of standard spectral ratios between the rock site and several sites within the basin, which confirmed the location of the permanent vertical array. The dense array was composed of 21 broadband seismometers that were arranged on a five branches of a star, with a maximum radius $180 \mathrm{~m}$. It was in operation over a 5-week period. A database composed by more than 1800 well-recorded earthquakes is now available. These two outstanding databases have been extensively used within the whole SINAPS@ program (Svay 2017; Svay et al. 2017, Sbaa et al. 2017).

Finally, this study provided the opportunity to complement standard translational measurements by rotational measurements, to allow 'six degrees of freedom' recordings. The rotational measurements were performed on different sites, which allowed the study of soil conditions on rotation motion. The rotation measurements led to the recording of a total of 1373 events for three successive sites (Sbaa et al. 2017).

\subsection{Numerical Developments Performed in WP2: Use of the Argostoli Case Study for Verification and Validation}

The objective of this study was to develop highperformance numerical tools for earthquake scenarios. This relates to the possibility to perform a 3D regional scale nonlinear and probabilistic model. Simulation of realistic ground-shaking scenarios requires reliable estimation of several different parameters related to the source mechanism (e.g., extended fault or localized double-couple seismic moment), the geological configuration, and the mechanical properties of the soil layers and the crustal rocks. Due to the enormous extension of these regional scale scenarios, the degree of uncertainty associated with the whole earthquake process (from fault to site) is extremely large, and eventually increases at higher frequencies and when structural models are included. Another drawback lies in the computational effort required to routinely solve wave propagation on such huge domains and over such a large number of degrees of freedom. At this point, it appeared necessary to build up a multi-tool numerical platform to construct and calibrate the seismological model. To this end, three main issues had to be be tackled: (1) to mesh the domain of interest, its geological conformation (bedrock to sediment geological surfaces), the surface topography, and the bathymetry (if present); (2) to describe the natural heterogeneity of the Earth crust and the soil properties at different scales (i.e., regional geology, local basin-type structures, heterogeneity of granular materials); and (3) to couple the wave-propagation problem with the structural dynamic problem. In the present work, the definition of regional scale is not strictly equivalent to the one of IAEA (2010) which indicates a radius of $300 \mathrm{~km}$ to perform the regional scale SHA site investigation (data, construction of geological and seismological models ...). Here the regional scale is related to the numerical seismic scenario and site-specific SSI computation constraints: indeed the numerical model includes the extended fault for which the complex rupture process is assessed, and the geological-geophysical model from the seismic source up to the site were the seismic waves propagate. The regional scale in this case significates that the numerical model is not restricted to the site itself, and corresponds to several tenths of kilometers in the 3 directions (dimensions driven by the size of the seismic source to be modeled and its location with respect to the target site). 


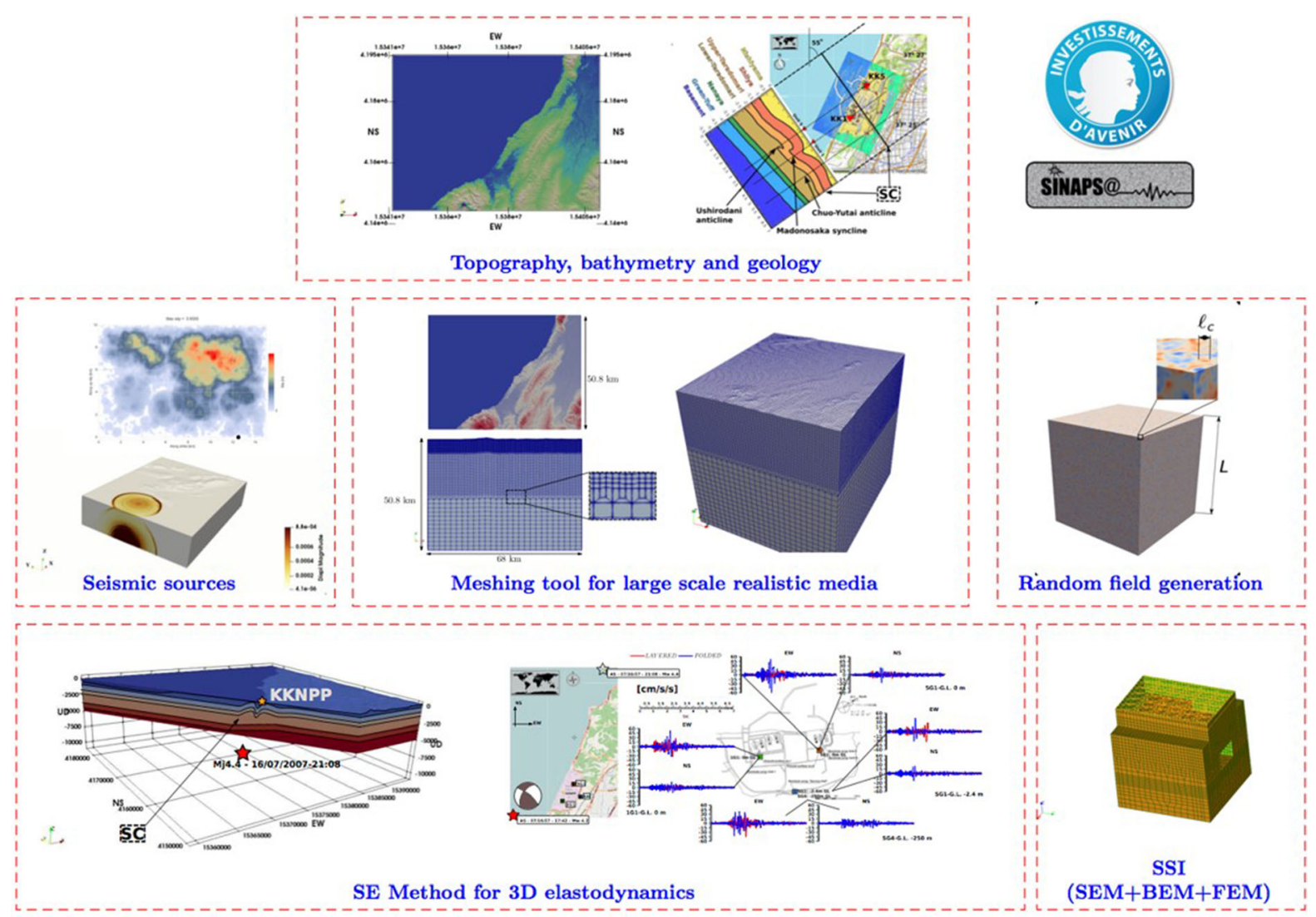

3D simulation of source-to-site earthquake scenario - SINAPS@ (ANR-11-RSNR-0022-04)

Figure 13

Schematic illustration of the multi-tool platform developed within the SINAPS@ project to reproduce realistic source-to-structure seismic scenarios (Figure from Gatti et al. 2018a, b)

Figure 13 (from Gatti et al. 2018b) outlines the features of the multi-tool platform that was developed to respond to those needs within the framework of the SINAPS@ project. Among the tools used, the main wave propagation solver is represented by the SEM3D software, which is tailored to efficiently solve wave propagation problems through the spectral element method (Komatitsch and Vilotte 1998; Komatitsch et al. 2005; Gatti et al. 2018b). The original core of the SEM3D software allowed the viscoelastic wave propagation problem to be solved in any velocity model, including with anisotropy, intrinsic attenuation, and Newtonian fluid-structure interactions. Moreover, the software makes use of a library called HexMesh (https://github.com/jcamata/ HexMesh.git), that implements an efficient linear 27-tree finite element mesh generation scheme, and that can generate large computational grids (i.e., $100 \mathrm{~km}$ ) by extruding the digital elevation model provided, and progressively coarsening it from topdown, so as to obtain a non-structured grid. HexMesh easily handles coastlines and bathymetries by cutting and locally refining the grid generated accordingly. The geological interfaces were introduced by a not honoring approach, which means the transition between geological domains is obtained by linearly interpolating the spatially distributed mechanical properties on the integration points used for the spectral approximation (Touhami et al. 2019).

On the other hand, the strategy adopted herein to model the heterogeneity of the Earth crust and the shallow soil layers consisted of the identification of the heterogeneous mechanical properties for a scalar stationary random field. This random field was linked 
to the fluctuation of the mechanical properties observed in situ.

Numerical applications using the implemented libraries (i.e., generation of the Gaussian randomfield and a non-linear constitutive relationship to represent the soil behavior) were carried out for the site of Argostoli and for the KK NPP. Special attention was given in SINAPS@ to the overall set-up of an efficient numerical workchain, to solve large wave-propagation problems. As an example, Fig. 14 (left) shows the evolution of the overall performance of the SEM3D software from the beginning of the project to date. This relates to the diminution of the CPU time for a same numerical model of wave propagation (size $600 \mathrm{~m} \times 600 \mathrm{~m} \times 600 \mathrm{~m}$ ) due to its efficient and cost-effective massively parallel implementation (using message passing interface) on large super-computers, and also the improvements in the capability of the software to generate a random-field for a large 3D model, which reduced the computational time (Fig. 14, right).

A recent study that involved several project partners provided insight into the advantages of a new, all-embracing, modeling approach of a strong ground motion scenario through a source-to-structure analysis at the regional scale, which accounted explicitly for the uncertainties related to the databases and models (Gatti et al. 2018a, b). To this end, a suitable case study is represented by the $2007 \mathrm{Mw} 6.6$ Niigata-Ken Chuetsu-Oki seismic sequence (west Japan) that damaged the Kashiwazaki Kariwa Nuclear Power Plant. This study described the effects of the wave propagation path within the Earth crust on the seismic response of the nuclear reactor buildings located near to seismogenic source. The multiscale problem was de-coupled into three steps: (1) a parallel simulation of seismic-wave propagation throughout the Earth crust at regional scale $(60 \mathrm{~km}$ wide, major 3D geological interfaces below the nuclear site), and reliable up to $5.0 \mathrm{~Hz}$; (2) a midhybridization step that consisted of enriching the synthetic wavefield at high frequency (up to $30 \mathrm{~Hz}$ ), using an artificial neural network to predict the shortperiod spectral ordinates; (3) a high-resolution structural dynamic analysis that introduced the hybrid broad-band synthetics as input wave motion. A simplified stress-test was performed by simulating two small point-wise aftershocks at different sourcesite positions. The impact of the underground 3D geology on the structural components was finally quantified by injecting the broad-band time-histories obtained into a SSI model of the nuclear reactor building. The good fit obtained in terms of the amplification factor at different recording stations assured the high-fidelity of the holistic philosophy endorsed.

At this point, a two-stage weak coupling framework was used to link the wave propagation software to the structural one. In the present case, the incident wave motion was directly simulated by the SEM3D numerical simulation introduced into the structural model. The wave propagation and transient structural dynamics models were interfaced by the introduction of compatible kinematic boundary conditions at the edge of a FE, the impedance matrix functions of which had been previously computed using a
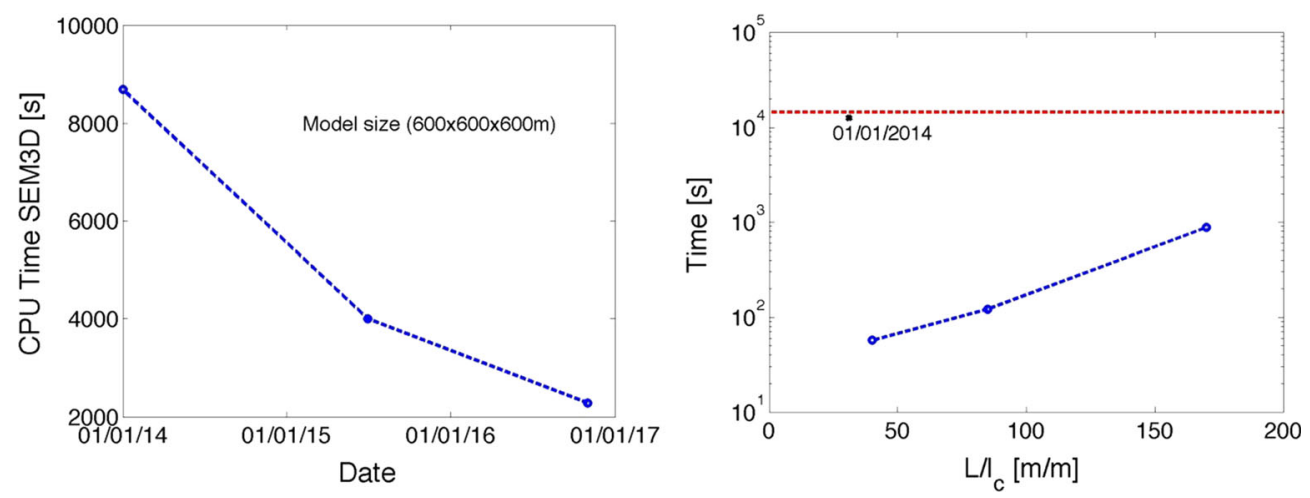

Figure 14

Examples of the evolution of the overall performance of the SEM3D code from the beginning of the project to date 
boundary element method (BEM) in the frequency domain software, over the assumption of a subhorizontally layered semi-infinite half space. The next step was to use the well-established engineering method known as domain reduction to take into account the local engineering models for geotechnical, site-effect, and structural analyses.

Finally, after verification from the experimental data, the study concerning both the simulation and measurement of the spatial variability of incident motion showed the relevance of the expression of coherence functions at the bedrock for predicting the spatial variability. In addition, a new coherence function defined by the soil properties of the site was proposed (Svay 2017; Svay et al. 2017). This function was developed after confrontation with the SEM3D numerical simulations on analytical cases.

\subsection{Some Examples of WP2 Research Transferred into the EDF Engineering Partner Studies}

This paragraph aims to illustrate how research performed as part of SINAPS@WP2 already serves, and has been endorsed by, an industrial partner, to demonstrate the usefulness of this project for applied nuclear studies.

- Estimation of the uncertainties in the modeling of nonlinear 1D site effects; consolidation of the computational methodology with Code_Aster (multi-purpose opensource FEM software, https:// code-aster.org); choice of adapted modeling; control of the variability associated with the computation.

- Implementation of a modeling tool in Code_Aster to deal with the 1D site effects under the equivalent linear elastic (ELQ) assumption for industrial applications, and applicable in SSI with the FEM-BEM linear sub-structuring approach and soil properties fitted to the amplitude of the seismic motion considered (doc R4.05.06, benchmark SDLS128, V2.03.128, see Code_Aster website).

- Modeling of spatial variability of incident motion (Svay 2017): verification from the experimental data of the relevance of the expression of coherence functions at the bedrock for predicting spatial variability, and proposition of a new coherence function defined by the soil properties of the site. Confrontation with SEM3D numerical simulations on analytical cases.

During the SINAPS @ project, EDF enriched the modeling choices in the NL-SSI analysis methodology by also proposing the full FEM approach, which has now proved to be more efficient for studies than at the beginning of the project; this was in addition to the analysis methodology using the Laplace-time approach by FEM-BEM sub-structuring methods (Nieto-Ferro et al. 2012). New documents for users and benchmarks were produced for Code_Aster; e.g. (sdls141, V2.03.141) for the case of the sites of Kushiro and Sendai, which resulted from the former Prenolin benchmark, to deal with nonlinear site effects.

\subsection{Synthesis and Recommendations}

SINAPS@ WP2 finally recommends several levels of complexity according to the stage of analysis of the project:

- For a pre-design stage, simplified methods using elastic or ELQ models to represent the soil behavior, and the assumption of rigid base conditions for the structure (i.e., no SSI), with modification of the input signal by propagation of the outcropping signal through a 1D soil column model (i.e., a two-step approach).

- For the design or verification stage, a weak SSI coupling approach using methods like BEM-FEM sub-structuring (in both the frequency and time domains) or the domain reduction method. For the input signal, outcropping must be used.

According to the available data and the project issues (e.g., economical, technical), a 3D regional scale model (source, site, SSI) can be performed.

\section{WP3 Seismic Behaviour of Structures and Equipment: Study Achievements}

\subsection{Scientific Challenges of WP3}

To transfer seismic signals (i.e., in terms of frequency content and amplification) from the soil 
and foundation to the structural elements and equipment, models for structural analysis can allow the different mechanisms prevailing in material and structural responses to be taken into account. However, such models should permit the evaluation of the robustness and fragility of the overall structure due to margins assessment regarding the design. It should be noted that model means the geometrical and kinematics description of the structural members, as well as the refined modeling of the materials responses involved.

Seismic ground motion is clearly nondeterministic, in terms of the acceleration level, and the frequency and time features of the signal waves that reach a building. The vulnerability assessment of a structure and its equipment is part of a general approach for criticality studies (e.g., nuclear facilities assessment, leakage prevision due to concrete cracking). Accounting for uncertainties has to be achieved at the structural level. Such studies imply refinement levels that should be in agreement with usual practice in engineering computing.

The interest of SINAPS@WP3 consists of developing or increasing the robustness of several types of modeling (from the simplest ones, to more complex ones), to address their identification regarding the available data, and finally to appreciate their usefulness in the framework of vulnerability analysis. Models that can handle the first feature are the elementary bricks that allow analyzing the structural impact of a SHA. From a conceptual point of view, the use of best-estimate approaches to assess the vulnerability of structures, systems and components is equivalent to accepting that they dissipate energy and they redistribute efforts within the structural system. Consequently, the corresponding performance criterion should no more require that they behave in their elastic range, which is now accepted for auxiliary buildings. On the contrary, the relevancy of this assessment in the case of equipment is highly dependent on their effect on global safety (e.g., core melt accident). It appears to be clear that the capability to categorize structures, systems and components according to their weight on safety is a key question, and it was addressed in the WP3, in terms of their nonlinear behavior, and in WP4 in terms of their uncertainty propagation and hierarchy.
In this sense, the work presented in WP3 of the SINAPS@ project presents a new paradigm regarding current engineering practice and safety standards in force in France.

The aforementioned key issue is at least partially answered regarding three aspects: evaluation of the ability of models to propagate uncertainties as a function of their refinement or simplicity level; the categorization of the critical equipment of NPP facilities regarding their role in global safety; and the study of structural seismic mitigation that is provided by building isolation.

\subsection{WP3 Study Achievements}

\subsubsection{Structure Modeling}

This first section defines the different tasks linked to the enhancement of the mechanical responses of structural elements subject to seismic loads. For this purpose, two different options were proposed:

- Kinematics enhancement of structural elements, to decrease the number of degrees of freedom.

- Keeping the 3D description of the structural behavior, but reducing CPU time by several techniques (e.g., model reduction, structural zooms on regions of interest).

\subsubsection{Enhanced Kinematics Models Different} sorts of models were developed or enhanced, which allowed the summing of their complex behavior to their 1D (beam) or 2D (plates) responses, due to adequately enriched kinematics.

$1 D$ modeling The study of the vulnerability of reinforced concrete (RC) structures requires powerful numerical tools. For nonlinear dynamic calculations, finite element analysis of the beam type represents a good compromise between calculation time and output data precision. Numerous finite element beam models based on Timoshenko kinematics have been developed in recent years, including elements that have adopted a force or a displacement formulation. The Timoshenko beam finite (displacement based) element model proposed by Caillerie et al. (2015), for example, makes it possible to obtain the exact solution at the nodes for complex computations using 
a single element (Bitar et al. 2017). Ecole Centrale de Nantes (ECN), Grenoble INP, and INSA de Lyon developed three enhanced finite element beam models for calculation of reinforced concrete beams. These three finite elements adopted a displacement formulation, have enriched kinematics at the fiber or section scale, and allow the following to be taken into account: concrete cracking, section warping under shear loading, and confinement effects of transverse reinforcement that occurs when concrete expands.

The SINAPS@ project allowed the three beam formulations presented in Bitar et al. (2017, 2018), Capdevielle et al. (2016) and Khoder et al. (2017) to be separately develop (by ECN, Grenoble INP, and INSA Lyon, respectively) within a Matlab framework. The common objectives and characteristics of the three models are described hereafter. The models allow the calculation of damage, plasticity, cracking and warping in a finite element framework using an implicit integration. Transient dynamic or cyclic calculations can be performed with the element that takes into account warping and reinforcement confinement, whereas the other model (considering cracking) has not yet been validated on dynamic and cyclic tests, and can therefore be used for the moment for quasi-static tests (pushover analysis in the context of seismic studies).

The beam element that takes into account cracking has been validated with numerical and experimental data on a beam under flexion and a reinforced concrete frame. Campaigns to validate the beams that consider warping and reinforced confinement have been carried out by torsion and by flexion and compression beam tests, respectively.

$2 D$ Modeling EGIS, ECN and EDF developed and implemented a stress resultant nonlinear constitutive model for cracked reinforced concrete panels in the finite element software Code_Aster. The GLRCHEGIS (Huguet et al. 2017, 2018) model takes into account concrete damage, cracking, steel-concrete bonding, and yielding of reinforcement bars. While the study was started prior to the SINAPS@ project, the SINAPS@ project made it possible to finalize and consolidate different aspects, including identification of the model parameters, and validation and robustness. The main features of the GLRC-HEGIS model are: constitutive law for the cyclic behavior of homogenized reinforced concrete panels, flexuralmembrane coupling, generalized standard formulation (associated flow rules), implicit time integration, stiffness degradation of concrete sections considering damage, tension-compression dissymmetry, explicit crack modeling, bridging and interlocking effects, yielding of reinforcement bars, tension stiffening, and bond slipping.

The model is suitable for quasi-static (e.g., pushover analysis, alternating cycles) and nonlinear transient dynamic problems, for vulnerability analyses, and for floor spectra calculations. It can be combined in a FEM that uses other types of structural elements: 3D beams, and multifiber non-linear beams. The model is suitable for moderate and strong earthquakes that cause degradation of reinforced concrete structures and steel yielding without reaching collapse (i.e., no softening phase at the global level). It does not take into account the dowel effect.

$\mathrm{EDF}$, for its part, confirmed its practice of 2D plate models and assessed the capabilities of the constitutive models previously developed in Code_Aster. These were homogenized models of reinforced concrete plates, as GLRC_DM (Markovic et al. 2007) and DHRC (Combescure et al. 2015), with damage and irreversible strains (associated to the steelconcrete bond). Although these models were developed prior to the start of the SINAPS@ project, this project consolidated many aspects: implementation of identification tools to help the engineer, validation, and robustness enhancement. The common characteristics of these two constitutive models are:

- Homogenized reinforced concrete plates for cyclic constitutive models that avoid the multi-layer approach;

- Dissipative phenomena in reinforced concrete, post-elastic phases to evaluate the safety design margins, for moderate seismic events far from building collapse;

- Stiffness degradation of sections by damaging the concrete, neglecting the softening phase, and tension-compression dissymmetry;

- No modeling of the plasticity of the steel bars (as soon as the first cracks are encountered regarding the considered seismic level); 
- Tools for identifying homogenized parameters from engineer data: geometry of the section (section and position of the steel rebar), material parameters (elasticity, tensile and compression thresholds), including according to design codes;

- Generalized standard formulation (normal flow laws) and direct implicit time integration;

- Field of application: quasi-statics and transient dynamics (e.g., progressive pushover, alternate cycles); targeted vulnerability analysis: calculation of floor response spectra for equipment safety analysis; robustness of buildings; compatibility with any type of modeling of other structural elements: 3D beams, nonlinear multi-fiber beams, extra offset reinforcement layers;

- Modeling of the damping by global viscous models: Rayleigh type, modal damping;

- Calculation of the engineering parameters: flexural-elastic up-dated stiffness due to concrete damage; maxima reached for the principal strains in concrete walls to verify the validity of the concrete tensile state;

- Limitation of use: moderate earthquakes producing 'moderate' degradation of the reinforced concrete structure, without going as far as collapse (i.e., steel remaining in the elastic range).

The specific objectives of the DHRC constitutive model are:

- Flexural-membrane coupling and representation of any reinforced concrete sections, starting from the distribution of the steels in the reference volume element;

- Modeling of damage and stiffness reduction, and the associated energy dissipation;

- Modeling of steel-concrete slipping and irreversible deformation, and tension-stiffening associated dissipation.

The differences between these two models are summarized in Table 1.

The model is maintained and distributed via Code_Aster. A validation campaign was carried out on the structural elements and then on the quasiindustrial reinforced concrete structures, with different representative reinforcement rates that are typical of industrial applications targeted at nuclear civil engineering (Fig. 15). Their use has thus been facilitated for engineering studies for the nuclear reactor fleet. The sensitivity of the responses is noticeable according to the choice of the threshold parameters of the concrete, as well as the post-peak behavior parameters. Considering model identification, the tests required are partly the classical ones performed in every civil engineering laboratory; however, it is noted that pathways of progress are expected on the characterization tests of the steelconcrete bond. Finally, there is the advantage of performing a flexural-membrane cyclic response analysis of a reinforced concrete representative volume element before launching the study of the reinforced concrete building to verify the suitability of the chosen parameters.

According to this comparison between experiment and FE simulations, as done also with others case studies, see Richard et al. (2016), Banci et al. (2018), it has been observed that these homogenized constitutive models present a certain degree of conservatism. This comes from the reduced number of phenomena retained in the proposed constitutive modeling (essentially diffused damage) and from the

Table 1

Differences between the constitutive GLRC_DM and DHRC models

\begin{tabular}{|c|c|}
\hline GLRC_DM model & DHRC model \\
\hline Maturity of use & Industrialization to finish \\
\hline $\begin{array}{l}\text { Heuristic homogenization, non- } \\
\text { extensible }\end{array}$ & $\begin{array}{l}\text { Numerical periodic } \\
\text { homogenization, extensible }\end{array}$ \\
\hline $\begin{array}{l}\text { Identical steel layers } x-y, \text { sup- } \\
\text { inf }\end{array}$ & Any kind of steel layers \\
\hline $\begin{array}{l}\text { Initial isotropy, induced } \\
\text { anisotropy }\end{array}$ & Native anisotropy \\
\hline No steel-concrete debonding & $\begin{array}{l}\text { Steel-concrete slip consecutive } \\
\text { to damage dissipation and } \\
\text { tension-stiffening effects }\end{array}$ \\
\hline No flexure-membrane coupling & $\begin{array}{l}\text { Flexure-membrane coupling } \\
\text { possible }\end{array}$ \\
\hline - & $\begin{array}{l}\text { CPU time: more expensive than } \\
\text { GLRC_DM: by } 30 \% \text { to } 100 \%\end{array}$ \\
\hline $\begin{array}{l}\text { Parameters to be provided in } \\
\text { Code_Aster from 'engineer' } \\
\text { data and assumptions on the } \\
\text { post-elastic strain range. }\end{array}$ & $\begin{array}{l}\text { Salomé_Méca automated } \\
\text { identification tool by FEM } \\
\text { numerical homogenization of } \\
\text { parameters from engineer }\end{array}$ \\
\hline $\begin{array}{l}\text { Number of parameters: steel, } 3 \text {; } \\
\text { concrete, } 8 \text {; geometry, } 5 \text {; } \\
\text { method, } 2\end{array}$ & $\begin{array}{l}\text { data. } \\
\text { Number of parameters: steel, } 3 \text {; } \\
\text { concrete, } 10 \text {; steel-concrete } \\
\text { sliding, 1; geometry, } 11\end{array}$ \\
\hline
\end{tabular}




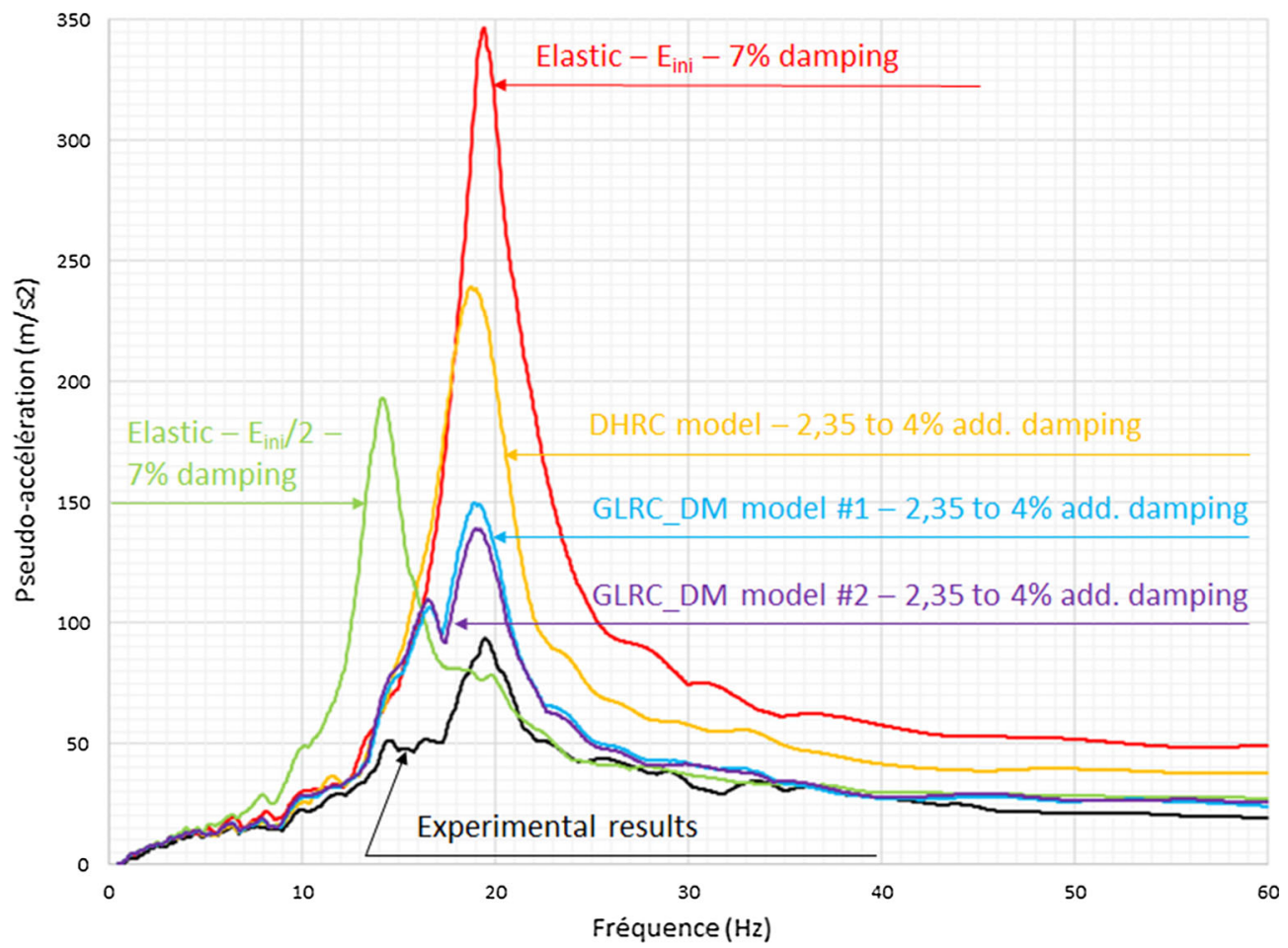

Figure 15

Response spectra computed using material parameters determined from the conventional civil engineering data (colored), compared to the experimental data (black spectrum, with 5\% damping, at the center of the floor, for run \#7 (ZPA $0.59 \times g$ ) of the experiment)

regulatory requirement of low values for the $\mathrm{RC}$ structural damping even after the nonlinear incursions into damaged states. Indeed, as revealed during these experimental campaigns, it is possible to identify an increasing damping level with the evolving damaged state of the RC sections, see for instance (Heitz et al. 2018). Nevertheless, it can be concluded on the relevance of structural nonlinear calculations in order to take profit of energy dissipation and internal forces redistribution, in terms of seismic safety margins best-estimate justification.

CEA and ENS Paris-Saclay developed the modeling strategy dedicated to the physical description of cracking in reinforced concrete structural elements. This approach is based on the following aspects:

- Enhanced kinematics that integrate explicitly the discontinuous nature of the displacement field in a medium crossed by a crack. This crack can propagate in mode I tension, mode II (shear), and mixed opening;
- Integration of an anisotropic cohesive law designed for cyclic responses. The law describes the link between stress vector versus displacement jump, allowing the specific effects of three type of cracking to be driven (i.e., tension, directional shear, anti-directional shear);

- A strategy for crack tracking to reduce the shear locking phenomena observed numerically.

The additional kinematic field used to describe crack opening was discretized through kinematic operators with zero average. This led to the possibility to condense the additional degrees of freedom and to avoid the modification of the global stiffness matrix. This approach was implemented in Cast $3 \mathrm{M}$, the finite element code developed by CEA. In particular, all of the source files are available online on the website of Cast3 M. The approach developed can be considered to determine the response of the reinforced concrete structures under quasi-static and dynamic loading (seismic loading). This has been implemented for the finite element of the 'constant 
strain triangle' type. For the sake of simplicity, this has been implemented for 2D problems under the plane stress hypothesis (Kishta et al. 2017a, b).

The main limitations of the proposed approach are due to two main reasons: (1) the simplifying assumptions; and (2) some numerical prerequisites. In particular, these include:

- No hysteretic dissipation and residual strain;

- The necessity to use a crack tracking method to reduce the locking phenomena;

- No coupling between membrane and flexural behavior.

These three items are still under investigation. Studies currently undergoing include developments relating to dissipation at the constitutive equations levels or at the element level regarding the multilayer framework for membrane-flexural coupling.

\subsubsection{3D Models Keeping a 3D approach for} kinematics in terms of structural analysis allows all of the dimensions and complexity of the seismic input to be accounted for. Nevertheless, the computation cost prevents the inclusion of such 3D approaches in a reliability analysis framework. Nowadays, recent and important breakthroughs concerning reduced order models make their use feasible.

Reinforced concrete is widely used in civil engineering. The PhD thesis of Vitse (2016) focused on the mechanical response of reinforced concrete structures subjected to cyclic loading conditions, which is critical when designing structural elements. For this purpose, preserving a 3D approach for the kinematics allows all of the complexity of the seismic load to be taken into account in the analysis of the structure. However, the very high computational cost prevents these approaches being integrated directly into a reliability framework. However, the recent and important progress in the field of model reductions provides a glimpse of their possible use for industrial simulations. This was thus the object of the studies carried out.

The thesis was dedicated to the development of an algorithm for resolution of nonlinear problems for which there is variability for some of the model parameters or the loading conditions, which are only described by their intervals of variation. The aim was to evaluate the uncertainties in civil engineering structures and to quantify their influence on the global mechanical response of a structure to a seismic hazard. The main numerical developments were achieved by allowing considering structural analysis. Unlike statistical or probabilistic approaches, we relied here on a deterministic approach. However, to reduce the computation cost of such problems, a proper generalized decomposition PGD-based reduced-order modeling approach was implemented, for which the uncertain parameters were considered as additional variables of the problem (Neron et al. 2015). These solutions led to what is called a 'virtual chart', which once post-processed at very low cost, makes it possible to draw conclusions about the influence of uncertainties on the response of the structure.

This method was implemented in the LATIN algorithm, which uses an iterative approach to solve the nonlinear aspect of the equations of the mechanical problem. This study presents the extension of the classical time-space LATIN-PGD algorithm to parametric problems for which the parameters are considered as additional variables in the definition of the quantities of interest. It also presents the application of such methods to a damage model with unilateral effects, highlighting the variability of both the material parameters and the amplitude of the loading (Vitse et al. 2019). The feasibility of such coupling is illustrated on numerical examples for reinforced concrete 3D structures subjected to different types of cyclic loading conditions (e.g., tensioncompression, bending). Its implementation in a framework of uncertain loads and signals will be the subject of a later studies (CEA-IRSN-ENS). These kinds of approaches are still under strong development. Their uses for direct civil engineering purposes require further efforts.

\subsubsection{Structural Applications}

\subsubsection{Simplified Models and Uncertainties Propa-} gation It is fundamental to provide engineers with quantitative elements that can be used to assess the influence of material parameter uncertainties on certain characteristic structural responses, for multiple modeling strategies and for different structural 
typologies. The work undertaken here also provided a critical view of all of the development studies carried out within WP3 through the analysis of the capacity of the modeling strategies to more or less propagate the material uncertainties. More specifically, two reinforced structures were considered: SMART 2013 (walls and slabs; Richard et al. 2016) and BANDIT (beams and columns; Garcia et al. 2014). These structures were modeled using different strategies (i.e., 1D, 2D, 3D). For each model, some material parameters were considered as random variables (e.g., concrete tensile strength, crack energy, steel yielding stress, damping ratio, concrete Young modulus). A probabilistic study was carried out to assess the variability of some of the engineering demand parameters (e.g., zero period acceleration, maximum spectral acceleration, dissipated energy) by Stocchi and Richard (2019). The data obtained allowed the classification of the sensitivity of the classically used engineering demand parameters according to two parameters: (1) the structural typology; and (2) the nature of the mechanical model used. Engineers who have to assess the vulnerability of a structure now have additional information, which can be taken into account when they analyze the values of related engineering demand parameters as they might influence their decision-making process.

4.2.2.2 Seismic Isolation Seismic base isolation is one of the most effective seismic mitigation methods. For nuclear facilities, an important expected benefit is the reduction of equipment demand through filtering of higher excitation frequencies. Nevertheless, in some cases, an amplification of the response of higher modes arises that might considerably reduce the efficacy of seismic isolation (Kelly 1999; Tsai and Kelly 1993; Wolf et al. 1983; Wolf and Obernhuber 1981). The objectives of this activity of the project are: (a) to study the sources of the amplification of the responses of the non-isolated modes (i.e., modes other than the first modes at low frequency); and (b) to investigate possible remedies to the above undesirable amplification.

For objective (a), it has been shown that in the case of relatively rigid superstructures, such as are found in nuclear facilities, the possible sources of the amplification of the nonisolated modes are:
- High base energy dissipation (e.g., linear or nonlinear viscous dampers, elastoplasticity of friction dissipative devices);

- Base rocking-induced excitation due to horizontally propagating waves, or to scattered motion in the case of embedded foundations;

- Coupling between vertical excitation and horizontal response with asymmetric superstructures.

These amplification mechanisms were investigated theoretically and numerically based on simple, yet representative, models. These studies provided qualitative and quantitative data that allowed us to draw clear and meaningful conclusions that are helpful to guide the design phase, and also to gain further insights into numerical simulation data of more complex models.

For objective (b), two alternatives to the commonly used isolation devices were examined:

Full 3D isolation devices (i.e., flexible in the vertical direction also), without anti-rocking devices These devices are relatively effective against rocking excitation, but they might have adverse effects even in the case of 'classical' translational excitation, due to unavoidable eccentricities that can induce coupling between vertical and horizontal directions. Hence, these are not recommended (unless further studies can provide more evidence of their beneficial effects).

Relaxation isolator that combines a device such as a classical low damping rubber bearing in parallel with a Maxwell element This kind of isolator is proposed for seismic isolation for the first time in this study. It has been shown that it is very efficient to reduce base displacement without amplifying the response of the no isolated modes. To make the use of this kind of isolator more appealing, technological issues related to their practical realization should be studied further.

4.2.2.3 Critical Equipment Ranking To reduce the seismic risk of a NPP, one solution is to progress in our understanding and modeling of the components that drive the overall fragility. In the framework of the SINAPS@ project, a first action of FRAMATOME was to identify these components. To do so, FRAMATOME developed a generic method to classify the components of the seismic equipment list, 
based on the results of seismic probabilistic risk assessment. The application of this method to the results of EPR@ (European Pressurized Reactor) that was completed by the feedback experienced on the seismic reassessment projects, led to the establishment of a generic seismic equipment list (GSEL) that contains major contributors to seismic risk. Clearly, the seismic vulnerability of some components of the GSEL is overestimated because of the use of too many conservative methods of analysis. Among those components, FRAMATOME selected two types of structure, for which FRAMATOME developed a less conservative methodology, namely:

- The elastic components with nonlinear supports;

- The electrical cabinets.

For the first point, FRAMATOME developed a new numerical method for introducing Rayleigh damping for structural responses including rigid body motion. For the second point, a new methodology was proposed in place of the conventional method that is based on qualification tests of electrical cabinets. Assuming that the chattering of relays is the most critical failure mode of cabinets, individual tests on relays were performed to identify the failure map of the relays. Based on these tests and knowledge of the dynamic behavior of the electrical cabinet, it was then possible to directly compare the seismic demand to the failure map of the internal components. The methodology is robust in the sense that it relies on bricks that are individually validated.

These two methodological improvements were aimed at reducing conservatism for a significant number of components of the GSEL. After SINAPS@, this study of methodological improvement for other components of the GSEL will be pursued. In the future, this will allow better assessment of the seismic risk for NPPs, and increased efficiency in detection of components that need to be redesigned (Robin-Boudaoud et al. 2018).

\subsection{Further Studies After SINAPS@}

A PhD project was activated between CEA, IRSN and ENS with the aim to continue the use of reduced order models to extend their applications to probabilistic seismic loading. A nonintrusive version will be implemented into Cast3 M Finite Element Code.

The study undertaken by Th. Heitz within WP5 concerned the identification of structural damping for reinforced concrete, and this will be continued ove the coming years. A doctoral study was activated by ENS-Paris-Saclay in collaboration with Pierre Léger (Ecole Polytechnique de Montréal, Canada). The enormous amount of data acquired during the SINAPS@ project (51Go of data coming from 643 experimental tests, 8 performed in quasi-static and 12 in dynamic conditions) will be further explored, with regard to the effects of nonlinearities on the evolution of damping. Classical models from the literature will be compared, and proposals will be made to help material and structural models to benefit from such an original experimental campaign.

A last PhD study was activated between EDF and ENS that was aimed at determining the contribution of wall-slab junctions to both the behavior and strength of nuclear buildings subjected to seismic loading. Another new experimental program was defined jointly with the CEA, to improve our knowledge of the behavior of these junctions. New experimental campaign was undertaken to include the effects of corrosion pathologies that induce changes in dynamic features of RC structural members (i.e., eigen-frequency shifts, damping increases).

The recommendation to improve current practice is to increase the validation tasks of constitutive models, methods, and simulation tools, in the sense of the regulation requirements, aimed at better acceptability, and to promote wide dissemination of simulation platforms among practitioners that include the necessary ingredients of the whole chain of seismic risk analysis. Well-documented validation output data should allow the ranking of conventional approaches, simplified methods, and best-estimated methods, with the view to reduce the epistemic uncertainty. The contribution of in-field data acquisition will also enhance the predictive capacity of numerical simulations, through better control of boundary conditions. It appears that the so-called '2D modeling' of reinforced concrete buildings is nowadays the more versatile and efficient solution for practical engineering studies, both for robustness 
analyses and for floor dynamics amplification analyses.

Specific topics need further research and development actions, such as damping modeling in reinforced concrete structural elements in the nonlinear range, or efficient reduced models devoted to uncertainty propagation in structural dynamics complex models.

\section{WP4 Seismic Risk Assessment}

The seismic safety assessment consists of aggregation of the various elements of the analysis chain within the convolution of seismic hazard, parameterized in terms of intensity measures, and the various conditional probabilistic estimates of the damage to structures and components (via fragility curves or distribution functions). Risk assessment can be based on a multiphysical expertise analysis for a given component, carried out during the design stage as in a periodic safety review, and including an analysis of the consequences of the failure. Estimates of failure probability are an efficient way to determine the contributions of the main structures, systems and components, and to assess the capacity of a nuclear installation in the context of an extended design assessment.

\subsection{Scientific Challenges of WP4}

WP4 partners were challenged:

1. to establish the overall methodological approach for the quantification of the seismic margins of a facility through coordinated implementation to global validation, by confronting the measures and data available for Unit 7 of the KashiwazakiKariwa NPP site, which suffered an earthquake on July 16, 2007 that was beyond its design level;

2. to consolidate the performance of probabilistic risk assessment methods, in terms of uncertainty propagation techniques and probabilistic metamodels, fragility curve calculations, and extreme statistics and Bayesian methods.

\subsection{Limitations at the Beginning of the SINAPS@ Project and Regulatory 'Constraints' Identified in the Topics of the Risk Assessment}

The general approach of the French safety regulations with respect to seismic safety was of a deterministic nature. Margins were introduced at the levels of analysis methodologies, criteria, and input data collection. The economic stakes for equipment seismic safety assessment are very strong for the French NPPs.

The uncertainties inherent in the input data, the knowledge of the physical processes and analytical methods used at each stage of the assessment of seismic hazard, and the vulnerability of the nuclear structures and components were not dealt with in practice in any coordinated manner. Current regulatory requirements define conservatism at each stage, independently. Uncertainties for the same parameter can be taken into account several times, for example, on quantification of site effects: in seismic hazard studies and also in dynamic SSI analysis. The main items of the current analytical methodologies used in engineering are discussed below. These are the topics under discussion that motivated the research and development actions during the SINAPS@ project.

The hard core seismic level (HCSL) soil target response spectrum is defined as a 'load case' by two components: (1) the median UHS probability spectra of the return period of 20,000 years; and (2) the deterministic SMS spectrum amplified by an overall coefficient of 1.5. The HCSL does not therefore necessarily represent a physically possible event, because it is composed of two spectra, and especially since the UHS spectrum itself cannot be considered to be physical (i.e., it is built frequency by frequency by aggregating near and distant earthquakes, on several seismic scenarios of the same probability; it is relatively flat-broadband-and its frequency content is therefore not physical). At low frequencies in particular, the HCSL spectrum is generally driven by the UHS spectrum (median or $84 \%$, according to the ASN demand for EDF studies). At higher frequencies, the HCSL spectrum is generally driven by the $1.5 \times$ HCSL level spectrum.

Therefore, there are many epistemic uncertainties in the determination of representative accelerograms 
and the associated variability. For example, we know that the strong motion phase duration can have an important impact (e.g., effects on the behavior of civil engineering and electrical equipment, and effects on the amplitude of the differential displacements).

The representation of vertical seismic motion (according to the RFS 2001-01) is another topic under discussion. This is determined by the assignment of a coefficient $2 / 3$ for all frequencies of the horizontal response spectrum. The vertical component of the signal is not processed in a manner consistent with the de-convolution of the horizontal motion. In addition, different soil characteristics (e.g., stiffness, damping) are adopted to cover uncertainties (by means of rule $2 / 3$ and $3 / 2$ ).

Structure-soil-structure interactions were almost never taken into account in traditional design practices; nevertheless, its use is more and more widespread for reassessment studies (e.g., Ostadan and Kennedy 2014). The ASN 02/01 guidelines (Guidelines ASN/2/01 2006) stipulate enlargement of the floor spectrum $\pm 15 \%$; however, extrapolation of this requirement to transient studies is not easy to justify. The elasticity modulus variability is then chosen in an arbitrary manner.

For equipment analysis, where the dynamic coupling with buildings is assumed to be negligible, the simplest approaches take into account a margin factor of 1.5 between the floor response spectrum established from building calculations and the demand used in the re-assessment of the equipment. This coefficient can be particularly penalizing, especially for pipe systems, although post-seismic observations are very favorable. A simplified rule is also used to evaluate the spectrum at another reduced damping value. It is known that the decoupled dynamic analysis of building and equipment via the floor response spectrum with enlargement and smoothing/envelope procedures introduces a nonuniform and sometimes excessive margin.

Spectral modal analysis is the most commonly used linear dynamic analysis method, especially in design-although some studies use transient analyzes (often linear, rarely nonlinear). However, its result is limited to providing conservative estimates of maxima (e.g. floor zero period acceleration, stresses in structural elements or equipment anchorages). The combination rules allow the correlations of modal and directional responses with other contributions (e.g., differential displacement) to be efficiently accounted for. The method of ellipses (taking into account statistical correlations between components as an effort for a more realistic manner) is not systematically implemented.

Less frequently, the linear random vibration analysis method is used, which includes the passage between the power spectral density and the response spectra (according to Vanmarcke 1975 and Rice 1945). In these cases, the SSI can be modeled by the traditional FEM_BEM approach. This allows some of the simplifying assumptions of spectral modal analysis to be overcome.

The overall seismic risk estimate is carried out within the framework of the probabilistic safety assessments, which is produced in a complementary way during the periodic reassessment surveys of French NPPs. One of the objectives is to identify the major contributor(s) to the risk. Although these probabilistic safety assessments are provided for in in the French regulation (RFS 2002-01, 2002) and even become mandatory since the publication of the Guidelines ASN \#22 (2017) for the NPPs, however there is no methodological guide for carrying them out so that the state of international available practice is used. Typically fragility curves are determined in a simplified way and then, they are applied within the probabilistic safety assessment procedure.

\subsection{Main Scientific Advances from WP4 Actions}

As already mentioned in Sect. 2.1, SINAPS@ did not address the full probabilistic risk assessment, which relies on (1) PSHA, (2) fragilities evaluation and on (3) the implementation of these two previous steps into a probabilistic safety assessment model that includes the safety systems of the plant, with due consideration of initiating events and success paths. This third step allows convolving the hazard and the fragility in order to calculate the risk in terms of core damage frequency or large early release frequency, and consequently, this step, related to the seismic PSA, has not been included into the research objectives of SINAPS@ project. However, the work performed by FRAMATOME on the critical 
equipment ranking presented in Sect. 4.2.2.3 could be considered as a contribution to this step of risk assessment. So, the WP4 of SINAPS@ mainly worked on fragilities evaluations focusing on physical processes on the whole chain of analysis, the identification of components that drive the overall fragility, and uncertainties representativeness, using given seismic scenarios.

The first area of action in WP4 dealt with the development and the consolidation of the computational chain in probabilistic and sensitivity analysis, through establishment of meta-models (to increase numerical performance, because we have to cope with the exploration of wide ranges of variability) and the calculation of fragility curves by bestestimate simulations. The use of neural network regression meta-models has been evaluated (Ostadan and Kennedy 2014). The efficiency of this approach for applications is sensitive to the modeling choices, and in particular the training algorithm might need large computational time to produce adequate precision. Another way to produce meta-models has been evaluated using a Gaussian process model. On a specific nonlinear structural case, it was concluded that satisfactory accuracy and CPU times can be achieved. The implementation of Bayesian analysis methods and extreme statistics for the calculation of fragility curves was studied in particular by Wang et al. (2017a, b).

The main conclusions of the demonstrative case study based on the data from the former benchmark KARISMA (2010) about unit 7 of the KashiwazakiKariwa NPP site of the SINAPS@ project are:

1. The capability to produce synthetic ground motion signals (Zentner 2014) has been shown on the basis of a scenario adapted to the case of the seismic event considered (here the NCOE July 2007 event) using a Campbell-Bozorgnia-type GMPE (Campbell and Bozorgnia 2008). The parameterization of this signal generation (e.g., with Code_Aster) makes it possible to take into account many characteristics that are representative of the real ground motion, including nonstationarity, correlation of the H/V components, and spatial variability of the characteristics (e.g., Svay et al. 2017), while ensuring the compatibility associated with a target spectrum, and the selected seismic intensity measure indicators.

2. To reduce the limitations arising from the definition of UHS, the possibility of disaggregating the UHS into scenario spectra (conditional mean spectra) was evaluated, based on a different seismic scenario and associated intensity measures (such as the strong phase duration). A more detailed analysis of the safety margins of the equipment can be derived.

3. Progress has been made in the methodology of SSI modeling, according to the following steps:

- First, EDF and FRAMATOME have challenged their methods of modeling the SSI, which led to the FRAMATOME choice of the Opensource Code_Aster + Miss3D solution. The ESSI solution (Davis Univ., LBNL and NRC, Ref. [10]) could not be accepted by FRAMATOME because it did not succeed in their own application. Nevertheless, the methods proposed in the ESSI solver had been explored in WP2 and appeared quite promising.

- Then CEA and EDF reinforced their 'FULLFEM' simulation methodologies with an equivalent linear elastic 3D model of the stratified soil domain (Alves-Fernandes et al. 2017), which was calibrated using a one-dimensional soil column model. This was based on the geotechnical profile data as well as on the maximum amplitude of the seismic motion prescribed on the substratum.

- Within its limit of validity in terms of maximal shear strain, this 1D soil column model based on the equivalent linear assumption was implemented at CEA and also at EDF, to perform the de-convolution/re-convolution processing of the seismic motion toward the level of the foundation from the substratum and previously from the free field (Berge-Thierry et al. 2017a); the corresponding tool DEFI_SOL_EQUI of Code_Aster was used for engineering purposes at EDF.

- The study carried out by CEA and EDF on the influence of the 'control point' (e.g., BergeThierry et al. 2017b; Wang and Feau 2019; 
Zentner 2018; the location of the transfer of the seismic motion that resulted from estimation of the seismic hazard to the SSI computation tool) led to significant evolution in terms of current practice in seismic nuclear engineering studies. It has been confirmed that the level of epistemic uncertainty is reduced by defining the seismic motion at depth rather than at the surface, even if it underlines the difficulty with the currently available data. Indeed, the motion defined at the 'outcropping rock' is not as affected by the nonlinearity of the superficial soil layers.

- The limit of validity of the equivalent linear elastic model (Guidelines ASN/2/01 2006) can be overcome by using a nonlinear soil behavior model. This offers the advantage of being able to represent in 3D the evolutions of all of the components of the fields during a transient, and to identify the amplification and the de-amplification at the free-field of the seismic ground motion, according to the frequency level. However, such models often require more data for the calibration procedure.

4. As explained above, the relevancy of accounting for the degradation of the soil behavior that produces a saturation of the amplitude of the transfer capacity of the seismic motion within the soil column from the substratum was assessed. The uncertainties in the resulting signal magnitude at the foundation due to the increase in the levels of seismic intensity measures via empirical attenuation relationships were thus reduced and their realism was increased;

5. The structure-soil-structure interaction (i.e., influence of neighboring buildings) was identified for a demonstrative study as having a significant role, which depended on site configuration, building characteristics, and signal frequency content (Alves-Fernandes et al. 2017; Touham et al. 2017), and it took into account the spatial variability of the incident field, in particular for the 'high frequency' content range.

Items (1)-(5) above are already the subject of operational applications in the engineering practices at EDF (Post-Fukushima studies).
6. The demonstrative case study made it possible to progress on the implementation of the SEM $3 D$ explicit dynamics spectral element software (Komatitsch et al. 2005, SEM3D) applied to seismic wave propagation in the vicinity of a NPP site, by evaluation of an extended source model, and by studying the necessary data, including the soil profile and ground motion recorded at different depths. This prepares future in-depth analyzes of the wave propagation properties of nuclear sites on a scale of about $50 \mathrm{~km} \times 50 \mathrm{~km} \times 15 \mathrm{~km}$ (Gatti et al. 2018a).

7. However, the demonstrative case study did not make it possible to implement and evaluate the progress made in the modeling of the nonlinear mechanical behavior of civil engineering structures. Indeed, the very robust building studied here remains in linear elastic range even under these severe seismic events.

8. An integrated approach has been proposed, which is based on the decomposition of UHS in conditional mean spectra and the transfer from the bedrock to the soil surface and finally the equipment.

All of these developments have been included in numerous publications and the associated methods and tools have been documented and disseminated via Opensource platforms (Salomé_Méca and Code_Aster for mechanical analyses, SEM $3 D$ for site effects analyses, increased ergonomics, and numerical performances needed for use in engineering. To end, under the results of the SINAPS@ project, in particular this demonstrative case study made it possible to define some recommendations for changes in engineering practices or regulatory approaches and also for future research and development guidance, that are reported in the conclusive Sect. 8.

\subsection{Proposals for Recommendations from WP4 Achievements}

SINAPS@ has led to the emphasis for possible evolution of engineering practices and regulatory approaches:

1. Identify the importance of seismic ground motion data control at the bedrock or outcropping rock 
instead of the free-field motion. This analysis of the site effects makes it possible to reduce the difficulty and the uncertainty associated with the de-convolution of the signal in a soil column defined by the geological profile of the site, taking into account the degradation of the properties of the soil according to the intensity of the seismic loading, the signal directivity. This approach might be associated with a 'host to target' adjustment of GMPEs. The epistemic uncertainties are also reduced by using a suitable geophysical, geotechnical site data analysis and an appropriate verification and validation procedure for tools and methods.

2. The development of the tools required for probabilistic safety analysis (convolution of vulnerability with hazard) and the associated study methodologies have reached a stage of maturity that makes them relevant for industrial use. Therefore, there is the need for more precise specification at different steps of fault probability computation; e.g., which confidence levels are required for hazard curves and for epistemic uncertainty treatment of fragility curves What acceptable level of failure probability is required according to the stakes?

3. Finally, a more refined estimate of contributors to failure and risk. Recommendations in terms of intensity measures of seismic ground motions can be formulated (e.g., for filtering). A new computing integrated tool, Fragility, is being developed to facilitate its dissemination. Finally, some promising ways to produce meta-models have to be pursued, to enhance the performance of fragility curve calculations.

\section{WP 5 Experimental Studies of Damping and Building-Building Interactions}

\subsection{Scientific Challenges of WP5}

Following the Fukushima Daiichi nuclear disaster, an analysis of the cliff effects for extreme events was carried out for nuclear installations in France, particularly with regard to seismic risk. In addition to the experienced feedback analysis, the experimental approach was also able to characterize and model the phenomena that appeared in these extreme situations.

Thus, WP5 of the SINAPS@ project provides experimental data from shaking table tests to:

- Refine the evaluation of seismic margins in nuclear reinforced concrete buildings by quantification of the various damping mechanisms (IDEFIX test campaign). Indeed, the models of damping used today suffer from lack of physics. In a closed interaction between WP3 and WP5 of the SINAPS@ project, the IDEFIX test campaign was carried out.

- Evaluate the number, magnitude and effects of impacts between buildings during an earthquake (the building-building interactions test campaign). This problem of the interaction between buildings under high seismic loads was clearly identified during the complementary safety studies in 2011 (Evaluations Complémentaires de Sûreté, rapport de l'Autorité de Sûreté Nucléaire, 2012). Indeed, with the increase in probable seismic levels in France, this interaction between nuclear buildings is sometimes possible due to the small distances between the structures. However, regulations suggest interaction avoidance. In addition to local damage, the impact between structures can amplify floor spectra in frequency ranges that penalize equipment fixed to these floors. There is very little experimental data available on this subject, which is too complex to be dealt with in only numerical studies. This test campaign must therefore create experimental data on building-building interactions to construct a numerical model to estimate the number and magnitude of impacts during an earthquake.

In conjunction with the other WPs of the SINAPS@ project, industrial and academic experts from these fields were integrated into the organization of these two original testing campaigns, which made it possible to obtain numerical analyses based on experimental data.

In the first phase of these two experimental campaigns, bibliographic studies and numerical analyses were used to design the models and define the measurements and test conditions. A second phase was dedicated to manufacturing and development of 
models and their set-up. A third phase allowed for the analysis of test data to identify some parameters and refine numerical models. Finally, the results obtained were disseminated through presentations and papers, as well as through a web-based database.

\subsection{Interactions Between Buildings: Experimental Campaign}

\subsubsection{Scientific Context}

Despite relatively extensive numerical research in this field, the potential damaging effects of pounding is a subject of controversy. Previous work has mainly focused on theoretical, numerical and small-scale experimental studies. Consequently, the effect of pounding on inter-story drift, forces and floor response spectra of actual buildings is difficult to estimate. Thus, it is important to experimentally investigate the effects of pounding on large-scale structures.

\subsubsection{Objectives}

The objectives of this activity within WP5 were: (a) to gain further insight into the response of pounding of buildings; (b) to experimentally investigate the effects of pounding on large-scale structures; (c) to evaluate the capability of numerical simulation tools to accurately predict the dynamic responses of interacting buildings; (d) to study the effectiveness of alternative solutions to prevent or control pounding; (e) this WP5 was also motivated by the limits of the complementary safety studies margin exercise of 2011 in France. Indeed, the ultimate values that were only based on expert advice were not often failure margins, but values related to shocks (justifying the non-loss of equipment that can lead directly to a nuclear accident).

\subsubsection{Work Performed}

To design the experimental specimens to be used for shake table tests, a sensitivity analysis was carried out on a simplified model of two one-degree-of-freedom interacting oscillators. This study was aimed at determination of the most important structural and excitation parameters regarding two criteria of interest. Thus, besides the amplification of the maximum displacement due to pounding, the maximum impact impulse was also of concern as an index of the effect of pounding on floor response spectra. This study highlighted the significant influence of the oscillator frequency ratio to the maximum displacement amplification, and the influence of both the oscillator masses and frequency ratios on the floor response spectra (Crozet et al. 2017a). Furthermore, since the sensitivity indices were computed using Monte Carlo simulations with a large number of input parameter sets, some configurations that amplified pounding effects were observed. These sets of parameters were chosen to determine the models to be tested and the excitation to be considered.

The models that were tested on the Azalée shaking table of CEA consisted of two adjacent, two storey, 5-m-high, steel frames with concrete slabs on each floor (Fig. 16). To ensure the representativeness of these tests, the two structures were designed to model the dynamic characteristics of actual buildings and the interacting areas were not localized, like in some previous studies (Papadrakakis and Mouzakis 1995; Filiatrault et al. 1995), to conserve realistic kinematics of slab pounding. As a consequence of the dynamic characteristics of the specimens, no scaling law was used and the models were subject to actual and artificial earthquake accelerograms. Thus, four different accelerograms were applied to different configurations: various initial gap values, a configuration with a rigid link between the structures, and tests with only one structure. Tests showing impacts were directly compared with those without impact. Finally, the two structures were subject to higher excitation levels so that yielding occurred at first storey columns of both structures.

To obtain accurate measures of the effects of pounding on structures, high frequency and low-tomedium frequency responses were recorded, using dedicated instrumentation. For instance, accelerations were measured using both high frequency $(10-4000 \mathrm{~Hz})$ and low-to-medium frequency $(0-150 \mathrm{~Hz})$ acceleration sensors. Strain gauges were also mounted on the steel frame columns. As for displacements, LVDT, wire sensors, laser sensors, 

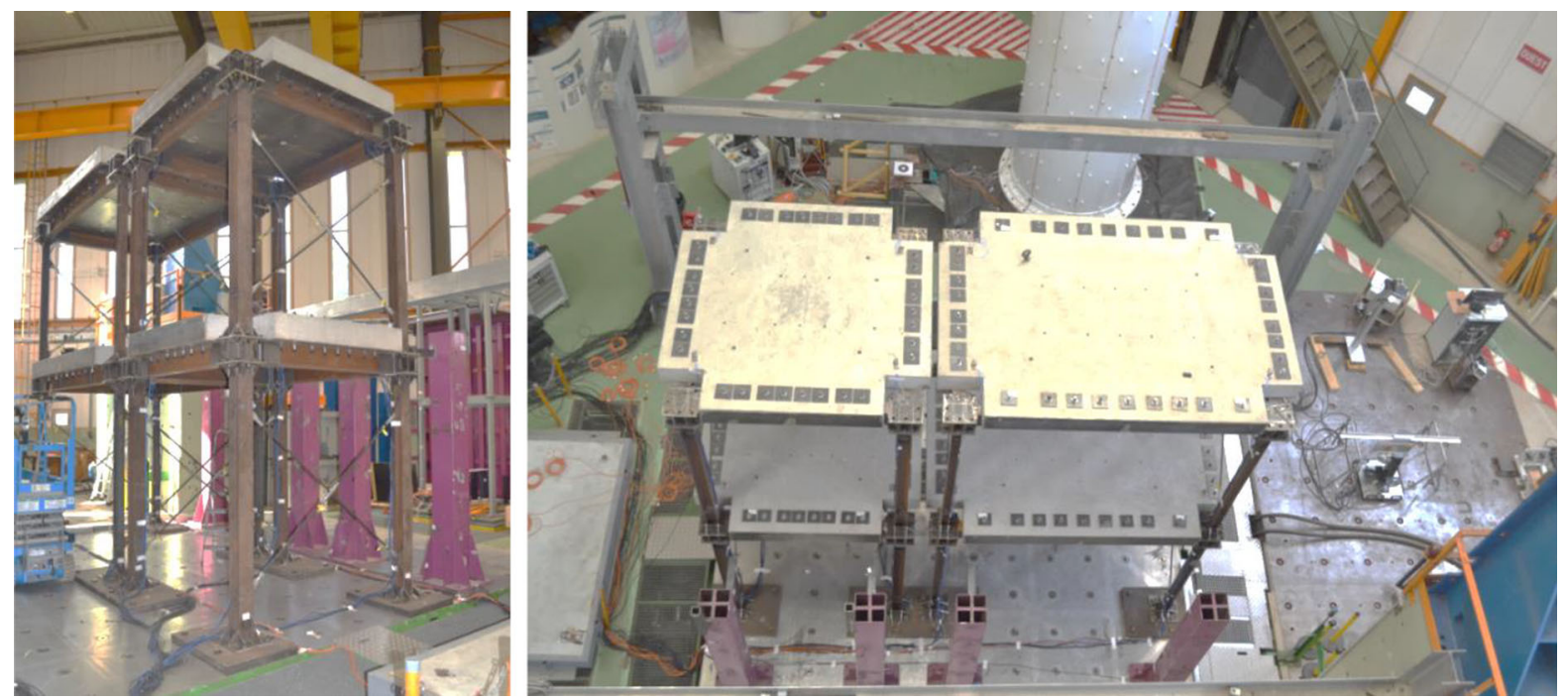

Figure 16

Experimental specimens on the Azalee shake table

and video-metric methods were used. In addition the motion of the shake table itself was accurately monitored using additional acceleration sensors.

As an overall observation, the experimental data highlighted the important effects of pounding on acceleration time history (Fig. 17). The acceleration peaks measured during the impacts also strongly modified the corresponding spectrum in the high frequency range. Acceleration in that high frequency content might then be an issue for some equipment with high natural frequencies (such as electrical components). During the tests with impacts, a torsional motion and an important excitation of the higher modes of the structures were observed. Moreover, for some excitation signals, a significant amplification of the first storey drift of both structures was measured with respect to the tests without pounding. For pounding mitigation, a significant improvement in the floor response spectra was obtained using a rigid link between the two structures, compared with the tests with pounding. Nevertheless, such a technique might considerably increase in most cases the displacements and forces in the more rigid structure. The tests have been interpreted by numerical simulation also. The agreement in the analytical and experimental data was satisfactory (see Crozet et al. 2017b).

\subsection{Behavior and Numerical Modeling of Damping in Dynamic Civil Engineering Structures}

\subsubsection{Scientific Context}

The ability of a structure to withstand a seismic event is driven by its capability to store and/or dissipate the input energy without compromising its integrity. Even though the available material constitutive laws are now able to provide realistic and accurate predictive data about nonlinear behavior of reinforced concrete, the computational cost is a strong counterpart that designers and engineers are rarely willing to pay for when dealing with full-scale structures. Overshadowing the uncertainties coming from external sources that are considered in the other WPs, and apart from the dimensional constraints that lead to this need for computational resources, important uncertainties arise from the material properties and might sometimes require extensive numerical sensitivity studies. That is why simplified modeling strategies are still popular among the engineering and research communities.

In practice, an additional viscous damping is often used to represent the dissipations not taken into account by the structural model (Ragueneau 1999; Crambuer et al. 2013), particularly in its linear range (Correia et al. 2013). The amount of viscous damping depends on the phenomena included. Indeed, the 
(a)

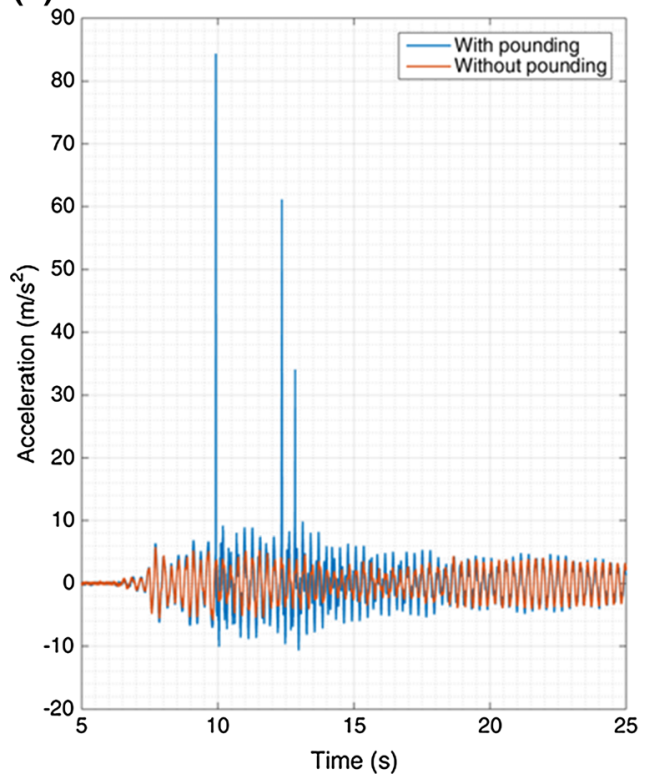

(b)

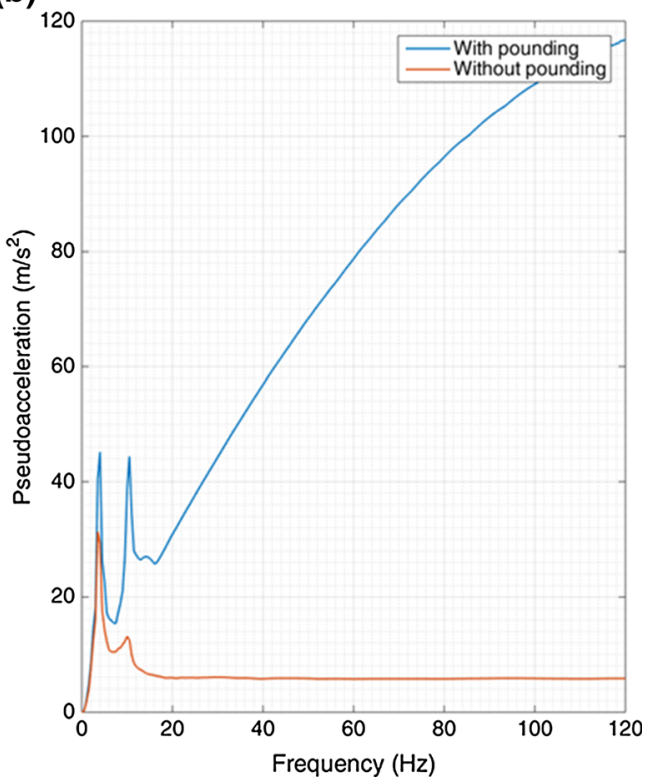

Figure 17

Comparisons of the dynamic responses of the top floor of the more rigid structure for the Kobe excitation scaled at $0.2 \times g$ peak ground acceleration. a Acceleration time history. b Floor response spectra (damping 5\%)

structural model might represent only a part of the energy dissipation, given that the additional viscous damping accounts for the remaining dissipated energy. For example, displacement-based methods have become popular in recent decades, mainly because they only require the knowledge of (1) a monotonous nonlinear force-displacement curve; and (2) a value of viscous damping. While this damping ratio has a key influence when assessing maximum structural responses, some studies have shown that it is the second source of uncertainty after ground motion (Celik and Ellingwood 2010; Lee et al. 2004). Furthermore, as shown by Charney (2008) and Hall (2006), combining both types of dissipation (i.e., hysteretic and viscous damping) should not be considered as a trade-off as it might compromise the validity of a study and might require a reduction in the viscous damping in the nonlinear range (Correia et al. 2013). To weight this effect, several evolving Rayleigh-type viscous damping models were compared by Jehel et al. (2014).

The concept of the equivalent viscous damping ratio is more accurate. The equivalent viscous damping coefficient is calibrated to dissipate the right amount of energy using a viscous force field that acts in opposition and proportionally to the velocity field. If some evidence shows that slight viscous effects exist in the linear range, most researchers consider that it is artificial modeling of the dissipations in reinforced concrete structures. Friction phenomena between different components and crack surfaces, or in the steel-concrete bond, are closer to solid damping (such as the Coulomb friction model) than to viscous damping. The traditional strategy is to assign damping ratio values to each eigenmode of the structure. For the classical Rayleigh model, the damping is calibrated on one or two eigenmodes, depending whether the damping matrix is massproportional, stiffness-proportional, or both. A more general approach is possible through the Caughey series (Caughey 1960; O'Kelly and Caughey 1965), with which modal damping ratios can be set for an arbitrary number of modes, although this strategy can induce large variations to damping ratios other than those set by the user (Clough and Penzien 2003). In addition, the mass-proportional term creates spurious damping when rigid body motions are involved, as stated by Hall (2006) for partially constrained structures and base-isolated buildings. 
Again, the question of the assessment of the equivalent viscous damping ratio arises. Different tests can be found in the literature, and there is no reason for which they would all provide the same damping ratios values. Mostly, they do not necessarily involve the same phenomena. Some of them rely on quasi-static loading, whereas others use dynamic signals that can in turn be either harmonic or broadband. Which velocity and frequency should be considered to evaluate the dissipated energy? Moreover, natural seismic signals have broadband frequency content: how does this influence the equivalent viscous damping ratio? Do the main eigenmodes interact with each other in terms of damping? Beyond the nature of the signal, the phenomena involved might also depend on the amplitude of the displacements shown by the structure. Hence, the choice of the experimental method to evaluate the equivalent viscous damping ratio is of primary importance, bearing in mind that the ideal test does not exist.

\subsubsection{Objectives}

To address the aforementioned questions, a testing procedure was designed to provide the key information regarding the dependency of the dissipated energy on structural and signal characteristics (i.e., material properties, structural design, signal content, response amplitude). The resulting IDFEFIX experimental campaign will be explained (French acronym for Identification of damping/dissipations in reinforced concrete structural elements). It was carried out with the support of the Azalée shaking table and the strong-floor of the TAMARIS experimental facility operated by the French Alternative Energies and Atomic Energy Commission (CEA) (see Figs. 18, 19). The main issue is to define the testing procedure to address the questions point-by-point, in terms of the relationships between the dissipation and the quantities of interest. Some remarkable data and the associated post-processing methods are presented. This mainly concerns qualitative analyses, regarding for example the influence of material properties over capacity curves. More in-depth analyses are performed after some necessary numerical tools are described. An identification method based upon

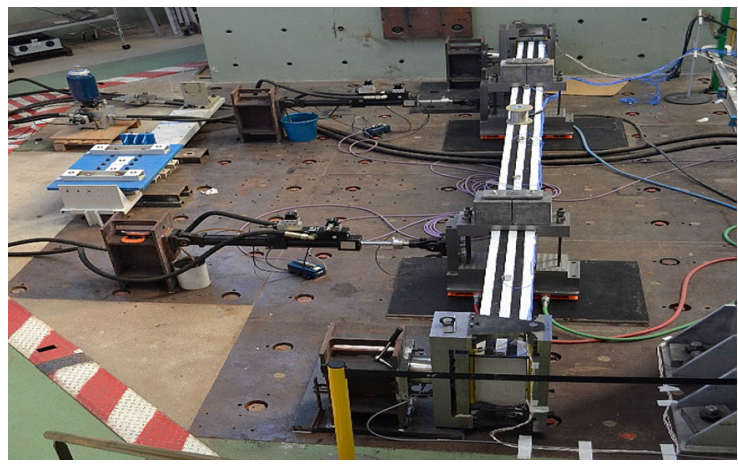

Figure 18

Quasi-static experimental setup on strong-floor

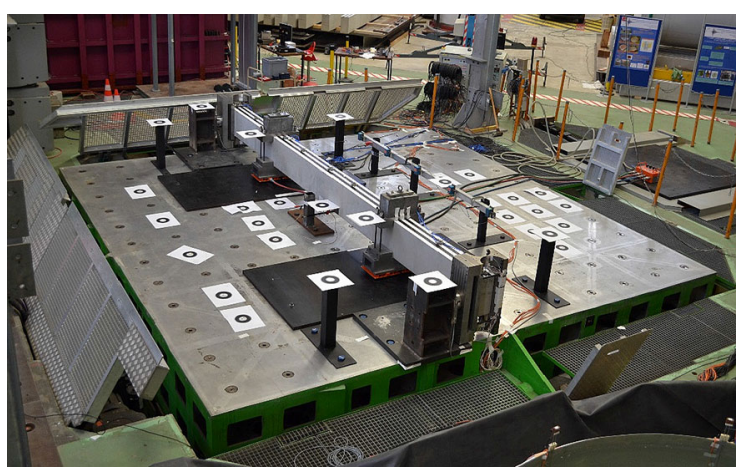

Figure 19

Dynamic experimental set-up on the Azalée shaking table

digital image correlation allows for the identification of the equivalent viscous damping ratio evolution. A spring-like model is formulated to describe the evolution of the stiffness of the single degree-offreedom associated to the beam during the nonlinear time-history analysis. Finally, two numerical simulation approaches are compared with the experimental data. The first one is based on the aforementioned identified model, while the second one is based on a finite element model. Their performances and the relevance of an additional viscous damping model are assessed.

\subsubsection{Main Achievements}

The Ph.D. study of T. Heitz (2017) allowed the performing of a huge experimental seismic campaign, and part of the data were studied and interpreted 
(Heitz et al. 2018). Nevertheless, the problematics of the damping in reinforced concrete structures during seismic events represent a vast field of challenges that has still to be tackled. The amount of tests and experimental results consecutive to the IDEFIX experimental campaign certainly contained many other interesting features to investigate further. The main results currently obtained during the IDEFIX test campaign were as follows:

- Evaluation of seismic margins in nuclear reinforced concrete buildings is highly dependent on building depreciation. In the linear range, "the dissipative capacity of materials is modeled conventionally by viscous damping (...) according to Rayleigh's formulation” (ASN guidelines 2/01). The IDEFIX experimental campaign showed that this formulation does not allow dynamic responses of a reinforced concrete structures to be satisfactorily modeled if their behavior changes during an earthquake. Work is underway to test an evolutionary Raleigh formulation.

- These static and dynamic tests also allowed for testing and comparison of several methods of damping evaluation. These methods give equivalent results for comparable levels of solicitation.

- A study was carried out on a method ('Jacobsen's areas method') of measuring the area of forcedisplacement cycles that have the advantage of having physical meaning. This study highlights quite clearly the strong influence on damping of the measured historical maximum relative displacement (i.e., the ductility level of the structure).

- A nonlinear numerical hysteretic model with seven parameters was identified and verified in several tests. This model has in particular the ability to represent 'pinch' at a low range of force. Identification of this model was from dynamic tests using an optical measurement system with images correlation; a procedure for identifying non-linear parameters by modal decomposition was used to evaluate the evolution of the damping for each mode during the test. This analysis also made it possible to visualize higher damping when crack openings are small.
- The data from the tests carried out at different deformation speeds showed that the value of the damping coefficient changed with deformation speed of the structure, whereas this value was a constant in the regulations.

As part of SINAPS@ project, an important work of storage, formatting, classification and communication was necessary to make these data available and exploitable by the scientific community.

\subsubsection{Outlook}

- This experimental campaign generated more than 600 tests that can verify several approaches. Indeed, even if the analyses of these tests carried out as part of the SINAPS@ project are numerous, the exploitation potential of the test data is high, as it would be possible, for example, to use these data to evaluate and improve finite element models.

- The test data were obtained on a very simple and 'classical' structure, and they can easily be used for other analyses than the evaluation of damping.

- The test method developed for IDEFIX can be extended to other structural elements such as floors, to evaluate the behavior (damping) of plate elements.

\subsection{Further Studies After SINAPS@ as an Extension of WP5 Research and Development}

At the end of the project, presentations related to damping identification and the study of buildingbuilding interactions received very positive responses and great interest from the international community, because these topics have been little discussed (in the literature) and are studied as both experimental and modeling through SINAPS@.

The database that will be opened to the scientific community is currently under study and must be set up to disseminate the experimental data more widely, which can be used beyond SINAPS@. In this sense, actions have already been launched to reuse the experimental data from WP5: (1) initiation of a PhD (EDF and INSA) on the interactions between buildings; (2) EDF FRAMATOME ENS for the use of 
IDEFIX data and the possibility to carry out new IDEFIX tests.

Other perspectives have been drawn: (1) The effect of 'blue' type (Fig. 17) floor response spectra on structure, system and component behavior should be examined (on a piping system and on an electrical cabinet: note that this research on an electrical cabinet is planed for after SINAPS@ with EDF). (2) During SINAPS@ scientific discussions, the relevance of using the conventional linear response spectrum as a tool to analyze the damaging potential of the time histories in presence of pounding and shocks should be examined. Indeed the response spectrum is by nature constructed on a criterion expressed as an internal force inside a mechanical system (probabilistic safety analysis) that is assumed to be a relevant engineering demand parameter. However, other engineering demand parameters that account for ductility might be more relevant in case of high frequency content in the time histories. (3) The work carried out during the IDEFIX experimental campaign has contributed to the identification of the evolution of dissipation in operating regimes (e.g.., elasticity, nonlinear) of reinforced concrete structural elements. The experimental damping was studied for the first two vibration modes and the Rayleigh damping coefficients (used as usual practice) were determined to guide future structural modeling. (4) Tests regarding interactions between buildings have been interpreted with a 3D numerical model using nonlinear modal superposition. As a guide for future structural modeling, the numerical model used reproduces the essential characteristics of the response of the impacting structures observed during the tests with low computational cost.

\section{WP 6 Dissemination of Knowledge}

The SINAPS@ project funded nine PhD projects and 21 1-year full-time post-doctoral positions entirely. In addition, studies performed by partners in the framework of 12 complementary (but independently funded) $\mathrm{PhD}$ projects and five post-doctoral research positions benefited from SINAPS@. The SINAPS@ project has greatly contributed to the scientific training of $\mathrm{PhD}$ students and post-doctoral researchers (and also several internships). The multidisciplinary environment and the sharing of objectives related to seismic risk mitigation (through accurate identification and mastered propagation of uncertainties) were very constructive for the young researchers and engineers: indeed, some of them even worked on very specialized and precise topics and their research was systematically integrated into the whole seismic analysis as a key step.

With its main contributions to the International BESTPSHANI workshop (which focused on the use of physics-based models for nuclear safety) co-organized by CEA, the US-NRC, the Japanese NRA, and the AIEA, SINAPS@ also gave the young scientists the opportunity to defend and discuss their studies with international experts, among which some were familiar with practical issues, which challenged the 'pure fundamental research approach'.

Finally, the two main objectives of this WP6 were to build, organize and realize two trainings sessions during the project (information on https://www. institut-seism.fr/formation). This goal has been reached (and indeed exceeded, due to the success encountered and the feedback from trainers and participants).

Two training sessions were organized:

- In May, 2016, at "Les Houches Physics- School” (https://www.institut-seism.fr/formation/ sinaps2016/.

- And in April 2018, on Porquerolles Island (https:// i2.wp.com/www.institut-seism.fr/wp-content/ uploads/2018/06/PhotoGroupe1_soustitree. jpg?ssl=1).

The first session was primarily designed for $\mathrm{PhD}$ students and post-doctoral researchers. Indeed, of the 60 participants, 55 had this profile (mainly from the SINAPS@ partnership). The second session was aimed at young scientist and researchers, and was opened to an international audience, with more than 60 people finally participating. It is important to note that around 20 researchers and young scientists from SINAPS@ were involved in the design and gave the courses and practical exercises (to cover the large scope). 
These two sessions were designed to address the whole seismic risk analysis for sensitive buildings, through a multidisciplinary, academically and more applied teaching approach. Courses were delivered that combined plenary lectures and practical sessions, during which the participants work on actual data, used and tested different software, and faced practical issues. The two sessions lasted over one full week, and were structured differently. During the second session, a full day was dedicated to a 'specialized module', where the participants experimented with the scientific topic they choose (e.g., seismic hazard assessment, experimental and numerical site effect characterization and prediction, SSI, structural and component seismic vulnerability, probabilistic seismic analysis) (working with state-of-the-art databases and tools, with some directly linked with the SINAPS@ products). To summarize, the participants then improved their knowledge and practical experience for:

- data, processing, metadata, databases;

- Methods;

- Uncertainties identification, quantification and propagation;

- Continuous seismic risk analysis, with the full physical seismic wave path modeling (from fault, SSI, structure and components);

- Contribution of experimental seismic testing (i.e., on site characterization, structural dynamics properties identification, damage characterization, dynamic seismic responses, SSI) to verify and validate or improve models;

- Benchmarking, test-cases.

To end, we note that the SINAPS@ second session was particularly satisfying and exciting for trainers and participants, as we were able to perform full seismic analysis (from hazard, site effects and vulnerability assessment, fragility curves estimates) at the Porquerolles site. The content and form of the two sessions clearly did not exist before SINAPS@ and was highly appreciated. These training sessions also contributed to the transfer from the academically research field to the engineering practice, and should continue after SINAPS@.

\section{Conclusions and Perspectives}

\subsection{Context of SINAPS@Project}

The second BESTPSHANI workshop was a great opportunity to present the progress made through the SINAPS@ project to the international community involved in seismic risk research and its management, in the framework of nuclear safety. Over the 5 years, SINAPS@ produced numerous research actions in the entire field of seismic safety analysis for nuclear facilities. SINAPS@ research was initially oriented, and accounted for:

- The French regulatory practices anchored in a deterministic safety approach since the 1970s, and written for the design purpose;

- The long experience of French nuclear facilities safety reviews that faced the lack of any approved dedicated documentation that described acceptable practices for existing facilities;

- The scientific challenges raised by recent mega earthquakes in Japan that struck nuclear power plants, and the unavoidable questions of the engineering practices, especially to assess the seismic margins of nuclear facilities. In this framework, the review of nuclear facilities during the French complementary safety studies following the Fukushima-Daïchi accident pointed out recommendations that were considered to define the SINAPS@ research studies.

The need to improve the practice of probabilistic seismic safety analysis in France clearly appeared and was motivated by the organization and scientific tasks of SINAPS@. Indeed the request of the French Nuclear Safety Authority to better assess and quantify the seismic margins of nuclear facilities (to be designed or those already existing) (see Guidelines ASN \#22, 2017) indicated the need to conduct probabilistic safety seismic analysis.

\subsection{Main Achievements and Recommendations of SINAPS@}

Among the issues, improving the way to model the physical phenomena that can occur during an earthquake is crucial, from the initial location where 
the seismic waves are generated (i.e., at depth on a fault plane), during their travel in complex geological media from the seismic source to the foundations of a nuclear facility, up to the transfer of the vibrations to the sensitive components. SINAPS@ then promoted, improved and developed an innovative approach (with respect to current French regulatory practice), based on continuous description of the seismic field with explicit quantification and mastered propagation of the uncertainties. So SINAPS@ has led to the emphasis for possible evolution of engineering practices and regulatory approaches and recommendations for research development, synthetically presented hereafter through the different topics:

1. SINAPS@ contributed to better identify key contributors to the uncertainties in the seismic motion transmitted to buildings, by refining methods of propagation of uncertainties, and by improving their performance. Progress has been made on the probabilistic establishment of seismic hazard and the selection of seismic ground motion. These advancements allow better allocation of engineering resources in new site studies and in re-assessments of existing nuclear plants, thus focusing on improving the knowledge of these main contributors.

2. SINAPS@ proposed a new definition of the 'control point', where assessing of seismic hazard at the reference bedrock (outcropping or in-depth bedrock). This is of great importance to accurately model and evaluate (in a second step) the potential specific site effects, through a full SSI study, using the adapted physics, as either linear or nonlinear, depending on the seismic level under consideration (from weak to very strong motions, including 'extreme' events as mandatory in the framework of 'post-Fukushima' HCSLs), and the associated SSI and structural behavior. By means of this new methodology defining the SHA at the bedrock or at the outcrop for controlling the seismic loading data, an easier confrontation with seismological observations can be considered, making it possible to reduce uncertainties by treating the site effects separately from the analysis of the seismic hazard. This recommendation is likely to significantly change engineering practices: specific methodologies will need to be evaluated.

3. SINAPS@ allowed the improvement of structural models from very simple to complex ones. The authors recall that the complexity of the models and methods used depends fully on the framework of the study, the associated safety issues, the level of knowledge of the site, the facility, and the considered physical phenomena. Through two demonstrative study-cases (the Argostoli basin modeling, and the Kashiwazaki-Kariwa NPP site that suffered the Niigata-Chuetsu Oki 2007 earthquake),SINAPS@ has showed the limits, if not the bias (especially when rare extreme seismic events are considered), induced using conventional, over-simplified assumptions or methods, and decoupling entirely the SHA from the soil-structure-equipment seismic response analyses. It has been shown that when the physics of the phenomena is not properly modeled, as for example using equivalent linear methods in the case of moderate or strong nonlinear soil behavior, the assessing of the failure probabilities through the fragility curve computation might be totally inaccurate.

4. SINAPS@ research pointed out the relevance of structural nonlinear calculations in order to take advantage of energy dissipation and internal forces redistribution, in terms of safety margins best estimate justification and mastering of the degree of conservatism: a variety of structural elements modelling is available, according to the related objectives of the engineering studies.

5. SINAPS@ investigated also the sensitive and critical step of selecting time series compatible with site-specific seismic hazard. In a seismic probabilistic approach as followed in SINAPS@, the seismic hazard output is given through a uniform hazard spectrum. Generating or selecting time series from a UHS might be very different and optimized with respect to the methodologies classically used when the spectra are from a DSHA. The work performed in SINAPS@is in line with the international state-of-the-art and engineering practice, and the validated tools are now available for French applications.

6. Finally, whatever the topic in seismic risk analysis,SINAPS@ has shown and underlined the 
necessity to invest in temporary and permanent instrumental networks, be it to record earthquakes (from very weak to very strong motion) or noise, or to characterize static, dynamic, linear and nonlinear soil and structure behavior. The site and structure specific data are unavoidable and are the key: (1) to investigate accurate and reliable geological and structural models, as performed in SINAPS@ on the Greek Argostoli test-site; (2) to catch in the models the specific physical properties and phenomena of the studied case; (3) to reduce, or at least to better quantify, the uncertainties and their epistemic and random components; and finally (4) to compare and test various competitive models and to use Bayesian methods to rank and weight them. Moreover, SINAPS@ conducted specific experimental campaigns using seismic shaking tables that showed how experimental data and modeling approaches are complementary and mutually serving. The qualification and validation of all of the databases and their openness to the international community are also a strong recommendation from SINAPS@.

7. Last but not least, the SINAPS@data, lessons and recommendations should be now considered by the French nuclear stakeholders to propose stateof-the-art references that can be considered as acceptable for designing new installations or for assessing an existing nuclear facility. Such a perspective would necessarily imply the definition for each case (as design, periodic assessment, dismantling phase) of specific safety objectives and associated acceptable methods to reach specific criteria, with these last obviously depending on the type of facility under consideration and on its intrinsic risks and issues (in terms of environmental, human and economic impact in case of failure).

\subsection{Synthesis: How SINAPS@ Reached the Stated Objectives?}

With regard to the four main objectives stated at the beginning of SINAPS@ that were (details in Sect. 1.2) to
1. Rank various parameters and evaluate the impact of uncertainties (through data and methods) at each step;

2. Propose an innovative method for the modeling of seismic wave propagation in the most integrated and continuous way, from the fault to the seismic response of the structures and equipment;

3. Improve seismic margin assessment methodologies;

4. Formulate recommendations on research and development actions (...) and the evolution of the regulation.

This conclusive section clearly shows that the SINAPS@ partnership has been able to propose an innovative method (with respect to the current French practice in force) through the probabilistic seismic analysis (objective \#2). This method is mainly based on the development of state-of art PSHA performed at the bedrock (or outcropping rock) condition, whereas a set of physical-based software's has been tested and validated against data in order to perform full site-specific seismic wave propagation computations considering the non linear interactions between the soil, the structures and the components and potentially including the extended seismic source. SINAPS@ research has shown the need to clearly track the uncertainties at each step of the seismic analysis, but also underlined the need to avoid any double counting of some them: to reach this goal, the strong recommendation of the project is then to definitively evaluate the seismic hazard at the reference bedrock and to perform in a second step the sitespecific seismic response assessment using relevant assumptions and approaches compatible and enabling to accurately model the physical phenomena. Among important improvements achieved by the project, SINAPS@ pointed out the need to explicit which uncertainties and how they are investigated, quantified and propagated in the whole seismic analysis (meaning that the uncertainties identification, sensitivity study on results have to be conducted at each step from hazard, to SSI, structural and equipment response and fragility curves computations as expected through the objective \#1). With respect to the objective \#1, SINAPS@ research does clearly not result in a generic ranking of the parameters and their 
uncertainties: such a ranking is obviously site and level of knowledge dependent. Through the introduction and reminder of the French context and practice in the nuclear field, SINAPS@ showed the incompatibility of the deterministic current approach to allow any seismic margin quantification (simplified methods not able to respect and predict the physical phenomena, assumptions not necessary coherent from the SHA definition to the SSI study and more important the introduction of conservatisms or fixed coefficients to account for some uncertainties). Then through the research performed in the different topical areas (WP 1 to 5), the tools developed and the promoted methodology, SINAPS@ really enhanced the capacities offered to practitioners aiming at seismic margin assessment (objective \#3). Finally and as illustrated in this article, SINAPS@ partnership has been able to formulate recommendations especially to improve the current seismic analysis in the nuclear field in France at least, and perspectives for further research needs are identified as expected (objective \#4).

\section{Acknowledgements}

The work carried out under the SINAPS@ project received French funding managed from the National Research Agency under the program "Future Investments" (SINAPS@ reference No. ANR-11-RSNR0022).SINAPS@ is a SEISM Institute project http:// www.institut-seism.fr/en/. The authors thank all of the SINAPS@ contributors, reseachers, engineers, $\mathrm{PhD}$ students, post-doctoral researchers, internships and technicians: the content of this article is based on their work.

Open Access This article is distributed under the terms of the Creative Commons Attribution 4.0 International License (http:// creativecommons.org/licenses/by/4.0/), which permits unrestricted use, distribution, and reproduction in any medium, provided you give appropriate credit to the original author(s) and the source, provide a link to the Creative Commons license, and indicate if changes were made.

Publisher's Note Springer Nature remains neutral with regard to jurisdictional claims in published maps and institutional affiliations.

\section{REFERENCES}

Alves-Fernandes, V., Banci, F., Devesa, G., Greffet, N., Jacquet, M., Kham, M., Nieto-Ferro, A., Voldoire, F., Zentner, I. (2017). Dynamic soil-structure interaction modeling strategies applied to kashiwazaki-kariwa nuclear power plant case-study, In $\mathrm{M}$. Papadrakakis, M. Fragiadakis (Eds.), COMPDYN 2017, 6th ECCOMAS thematic conference on computational methods in structural dynamics and earthquake engineering. Rhodes Island, Greece, 15-17 June 2017. https://doi.org/10.7712/120117.5571. 17197

Banci, F., Herve-Secourgeon, E., Richard, B., Voldoire, F., \& Zentner, I. (2018). New advances in the seismic analysis of nuclear structures and equipment from the SINAPS@ project. 2nd BESTPSHANI workshop proceedings, Cadarache.

Baumont, D., Manchuel, K., Traversa, P., Durouchoux, C., Nayman, E., \& Ameri, G. (2018). Intensity predictive attenuation models calibrated in $\mathrm{Mw}$ for metropolitan France. Bull Earthquake Eng, 16, 2285. https://doi.org/10.1007/s10518-018-03446.

Berge-Thierry, C., Griot-Pommera, D., Cotton, F., \& Fukushima, Y. (2003). New empirical response spectral attenuation laws for moderate European earthquakes. Journal of Earthquake Engineering, 7(2), 193-222.

Berge-Thierry, C., Hollender, F., Guyonnet-Benaize, C., Baumont, D., Ameri, G., \& Bollinger, L. (2017a). Challenges ahead for nuclear facilities site-specific seismic hazard assessment in France: the alternative energies and atomic energy commission (CEA) vision. Pure and Applied Geophysics, 174, 9.

Berge-Thierry, C., Lopez-Caballero, F., Ragueneau, F., Voldoire, F., \& Le Maoult, A. (2018). Synthesis of lessons, recommendations and further research needs resulting from SINAPS@ project. Commissariat à l'Energie Atomique et aux Energies Alternatives, Report CEA-R-6510 (2018). (Reference ISSN 0429-3460).

Berge-Thierry, C., Svay, A., Laurendeau, A., Chartier, T., Perron, V., Guyonnet-Benaize, C., et al. (2017b). Toward an integrated seismic risk assessment for nuclear safety improving current French methodologies through the SINAPS research project. Nuclear Engineering and Design, 323, 185-201.

Berge-Thierry, C., Wang, F., Feau, C., Zentner, I., Voldoire, F., Lopez-Caballero, F., Le Maoult, A., Nicolas, M., \& Ragueneau, F. (2017c). The SINAPS@ French Research Project: first lessons of an integrated seismic risk assessment for nuclear plants safety. In 16th World Conference on Earthquake, 16WCEE 2017, Santiago Chile, January 9th to 13th 2017, Paper No. 3553.

Bertin, M., Marin, S., Millet, C., \& Berge-Thierry, C. (2019). Using Bayesian Model Averaging to improve ground motion predictions, accepted for publication. Geophysical Journal International (accepted).

Bertran, P., Andrieux, E., Antoine, P., Deschodt, L., Font, M., \& Sicilia, D. (2017). Pleistocene involutions and patterned ground in France: Examples and analysis using a GIS database. Permafrost and periglacial processes. https://doi.org/10.1002/ppp. 1957. (Published online in Wiley Online Library (wileyonlinelibrary.com)).

Bitar, I., Benkemouny, N., Kotronis, P., \& Grange, S. (2017). A novel multi-fiber Timoshenko beam finite element formulation with embedded discontinuities to describe reinforced concrete failure under static loading. In J. Bolander, \& E. Landis (Eds) 9th 
International Conference on Fracture Mechanics of Concrete and Concrete Structures, FraMCoS-9 V. Saouma. https://doi.org/ 10.21012/fc9.102.

Bitar, I., Kotronis, P., Benkemoun, N., \& Grange, G. (2018). A generalized Timoshenko beam with embedded rotation discontinuity. Finite Element Analysis and Design, 150, 43-50.

Bora, S.S., Cotton, F., Scherbaum, F., Edwards, B., \& Traversa, P. (2017). Stochastic source, path and site attenuation parameters and associated variabilities for shallow crustal European earthquakes. Bulletin of Earthquake Engineering 15(11):4531-456. Code_Aster, general public licensed structural mechanics finite element software. http://www.code-aster.org.

Bora, S., Scherbaum, F., Kuehn, N., Stafford, P., \& Edwards, B. (2015). Development of a response spectral ground-motion prediction equation (GMPE) for seismic hazard analysis from empirical Fourier spectral and duration models. Bulletin of the Seismological Society of America, 105, 2192-2218.

Caillerie, D., Kotronis, P., \& Cybulski, R. (2015). A Timoshenko finite element straight beam with internal degrees of freedom. International Journal for Numerical and Analytical Methods in Geomechanics, 2015(39), 1753-1773. https://doi.org/10.1002/ nag.2367.

Campbell, K. W., \& Bozorgnia, Y. (2008). NGA Ground Motion Model for the Geometric Mean Horizontal Component of PGA, PGV, PGD and 5\% Damped Linear Elastic Response Spectra for Periods Ranging from 0.01 to $10 \mathrm{~s}$. Earthquake Spectra, 24, 1.

Capdevielle, S., Grange, S., Dufour, F., \& Desprez, C. (2016). A multifiber beam model coupling torsional warping and damage for reinforced concrete structures. European Journal of Environmental and Civil Engineering, 20(8), 914-935.

Caughey, T. K. (1960). Classical normal modes in damped linear dynamic systems. Journal of Applied Mechanics, 27(2), 269-271.

Celik, O., \& Ellingwood, B. R. (2010). Seismic fragilities for nonductile reinforced concrete frames-Role of aleatoric and epistemic uncertainties. Structural Safety, 32(1), 1-12. (ISSN: 01674730).

Charney, F. A. (2008). Unintended consequences of modeling damping in structures. Journal of Structural Engineering, 134(4), 581-592. (ISSN: 0733-9445).

Clough, R.-W., \& Penzien, J. (2003). Dynamics of structures. Berkeley: CSI Computers and Structures Inc.

Code_Aster. (2019). General public licensed structural mechanics finite element software. http://www.code-aster.org.

Combescure, C. H., Dumontet, H., \& Voldoire, F. (2015). Dissipative homogenised reinforced concrete (DHRC) constitutive model dedicated to reinforced concrete plates under seismic loading. International Journal of Solids and Structures, 73-74, 78-98. https://doi.org/10.1016/j.ijsolstr.2015.07.007.

Correia, A. A., Almeida, J. P., \& Pinho, R. (2013). Seismic energy dissipation in inelastic frames: Understanding state-of-the-practice damping models. Structural Engineering International: Journal of the International Association for Bridge and Structural Engineering, 23(2), 148-158. (ISSN: 10168664).

Craig, T. J., Calais, E., Fleitout, L., Bollinger, L., \& Scotti, O. (2016). Evidence for the release of long-term tectonic strain stored in continental interiors through intraplate earthquakes. Geophysical Research Letters, 43(13), 6826-6836.

Crambuer, R., Richard, B., Ile, N., \& Ragueneau, F. (2013). Experimental characterization and modeling of energy dissipation in reinforced concrete beams subjected to cyclic loading. Engineering Structures, 56, 919-934. (ISSN: 01410296).

Crozet, V., Politopoulos, I., Yang, M., Martinez, J. M., \& Erlicher, S. (2017a). Sensitivity analysis of pounding between adjacent structures. Earthquake Engineering and Structural Dynamics. https://doi.org/10.1002/eqe.2949.

Crozet, V., Politopoulos, I., Yang, M., Martinez, J. M., \& Erlicher, S. (2017b). Influential structural parameters of pounding between buildings during earthquakes. Procedia Engineering, 199, 1092-1097.

Cushing, M. E., Hollender, F., Guyonnet-Benaize, C., \& Perron, V. (2016). In J. P. McCalpin \& C. Gruetzner (Eds.), Close to the lair of Odysseus Cyclops: the SINAPS@ postseismic campaign and accelerometric network installation on Kefalonia island-Site effect characterization experiment (Vol. 7). ISBN 978-09974355-2-8.

Décision ASN. (2015). DC-0523 de l'Autorité de sûreté nucléaire du 29 septembre 2015 établissant une classification des installations nucléaires de base au regard des risques et inconvénients qu'elles présentent pour les intérêts mentionnés à l'article L. 593-1 du code de l'environnement. https://www.asn.fr/ Reglementer/Bulletin-officiel-de-1-ASN/Installations-nucleaires/ Decisions-reglementaires/Decision-n-2015-DC-0523-de-1-ASNdu-29-septembre-2015.

Décision ASN. (2017). DC-0579 de l'Autorité de sûreté nucléaire du 17 janvier 2017 établissant la liste des installations nucléaires de base au 31 décembre 2016. https://www.asn.fr/Reglementer/ Bulletin-officiel-de-1-ASN/Installations-nucleaires/Decisionsreglementaires/Decision-n-2017-DC-0579-de-1-ASN-du-17janvier-2017.

Del Gaudio, S., Hok, S., Festa, G., Causse, M., \& Lancieri, M. (2017). Near-fault broadband ground motion simulations using empirical Green's functions: Application to the Upper-Rhine Graben (France-Germany case-study). Pure and Applied Geophysics. https://doi.org/10.1007/s00024-017-1075-1.

Do Paco, D., Bollinger, L., \& Trilla, A. (2017). Elaboration d'une base de mécanismes ay foyer pour la France métropolitaine, compilation des mécanismes existants et complément sur l'Ouest de la France, CEA/DIF/DASE/LDG/171/2017/DO.

Dujardin, A., Causse, M., Berge-Thierry C., \& Hollender, F. (2018a). Radiation patterns controls the near-source ground motion saturation effect. Bulletin of Seismological Society of America. https://doi.org/10.1785/0120180076

Dujardin, A., Hollender, F., Causse, M., Berge-Thierry, C., Delouis, B., \& Foundotos, L. (2018b). Optimization of extended source simulation code (K2) using empirical Green's functions. Application to the Middle Durance Fault case, Pure and Applied Geophysics (submitted, this issue).

Evaluations Complémentaires de Sûreté, rapport de l'Autorité de Sûreté Nucléaire. (2012). Avis n 2012-AV-0139 de l'Autorité de sûreté nucléaire du 3 janvier 2012 sur les évaluations complémentaires de la sûreté des installations nucléaires prioritaires au regard de l'accident survenu à la centrale nucléaire de Fukushima Daiichi. https://www.asn.fr/Reglementer/Bulletinofficiel-de-1-ASN/Installations-nucleaires/Avis/Avis-n-2012AV-0139-de-1-ASN-du-3-janvier-2012.

Filiatrault, A., Wagner, P., \& Cherry, S. (1995). Analytical prediction of experimental building pounding. Earthquake Engineering and Structural Dynamics, 24, 1131-1154. 
Garcia, R., Jemaa, Y., Helal, Y., \& Guadagnini, M. (2014). Seismic strengthening of severely damaged beam-column RC joints using CFRP. Journal of Composites for Construction. https://doi.org/ 10.1061/(ASCE)CC.1943-5614.0000448.

Gatti, F., Lopez-Caballero, F., Clouteau, D., \& Paolucci, R. (2018a). On the effect of the 3-D regional geology on the seismic design of critical structures: The case of the Kashiwazaki-Kariwa Nuclear Power Plant. Geophysical Journal International, 213(2), 1073-1092.

Gatti, F., Touhami, S., Lopez-Caballero, F., Paolucci, R., Clouteau, D., Fernandes, A. V., et al. (2018b). Broad-band 3D earthquake simulation at a nuclear site by an all-embracing source to structure approach. Soil Dynamics and Earthquake Engineering, 115(1), 263-280.

Guidelines 2/01 ASN. (2006). Prise en compte du risque sismique à la conception des ouvrages de génie civil des installations nucléaires de base, à l'exception des stockages à long terme des déchets radioactifs". The French Nuclear and Safety Authority (ASN). https://www.asn.fr/Informer/Actualites/Guide-relatif-ala-prise-en-compte-du-risque-sismique.

Guidelines ASN \#22. (2017). Conception des réacteurs à eau sous pression, published by the French Nuclear and Safety Authority (ASN) and the Nuclear and Radioprotection Institut (IRSN), July 18th, 2017 https://www.asn.fr/Professionnels/Installationsnucleaires/Guides-de-1-ASN/Guide-de-1-ASN-n-22-Conceptiondes-reacteurs-a-eau-sous-pression.

Günay, S., \& Mosalam, M. K. (2013). PEER performance-based earthquake engineering methodology. Revisited. Journal of Earthquake Engineering., 17, 829-858. https://doi.org/10.1080/ 13632469.2013.787377.

Hall, J. F. (2006). Problems encountered from the use (or misuse) of Rayleigh damp-ing. Earthquake Engineering and Structural Dynamics, 35(5), 525-545. (ISSN: 00988847).

Heitz, T. (2017). Nonlinear local behaviours and numerical modeling of damping in civil engineering structures in dynamic. Comportements non linéaires locaux et modélisation numérique de l'amortissement dans les structures de Génie Civil en Dynamique, $\mathrm{Ph}$. D. Thesis, CEA and ENS-Paris Saclay, HAL Id: tel01684727 https://tel.archives-ouvertes.fr/tel-01684727.

Heitz, T., Le Maoult, A., Richard, B., Giry, C., \& Ragueneau, F. (2018). Dissipations in reinforced concrete components: Static and dynamic experimental identification strategy. Engineering Structures, 163, 436-451.

Huguet, M., Bourahla, M., Erlicher, S., \& Kotronis, P. (2018). GLRC_HEGIS global constitutive law for RC walls and slabs for seismic nonlinear structural analyses. In Proceedings of the 16th European conference on earthquake engineering (ECEE) (pp. 18-21), Thessaloniki.

Huguet, M., Erlicher, S., Kotronis, P., \& Voldoire, F. (2017). Stress resultant nonlinear constitutive model for cracked reinforced concrete panels. Engineering Fracture Mechanics, 176, 375-405.

IAEA. (2010). Specific safety guidelines SSG-9. Seismic hazards in site evaluation for nuclear installations. The International Atomic Energy Agency. https://www-pub.iaea.org/MTCD/Publications/ PDF/Pub1448_web.pdf.

IAEA. (2014). Review of seismic evaluation methodologies for nuclear power plants based on a benchmark exercise, IAEATECDOC-1722 (p. 2014). Vienna: International Atomic Energy Agency.
IAEA. (2015). Report on The Fukushima Daiichi accident-Vienna: International Atomic Energy Agency, 2015. STI/PUB/1710 ISBN 978-92-0-107015-9.

Isbiliroglu, L. (2017). Strategy for selecting input ground motion for structural seismic demand analysis, Ph D. thesis, IRSN \& Isterre, Université Grenoble Alpes, 2018 (HAL id: tel01809010).

Jehel, P., Léger, P., \& Ibrahimbegovic, A. (2014). Initial versus tangent stiffness-based Rayleigh damping in inelastic time history seismic analyses. Earthquake Engineering and Structural Dynamics, 43, 467-484.

Kelly, J. M. (1999). The role of damping in seismic isolation. Earthquake Engineering and Structural Dynamics, 28, 3-20.

Khoder, N., Grange, S., \& Sieffert, Y. (2017). Enhancement of multifiber beam elements in the case of reinforced concrete structures for taking into account the lateral confinement of concrete due to stirrup. In 6th International Conference on Computational Methods in Structural Dynamics and Earthquake Engineering Methods in Structural Dynamics and Earthquake Engineering, pp, 2323-2329. https://doi.org/10.7712/120117. 5570.17138.

Kishta, E., Giry, C., Richard, B., Ragueneau, F., \& Balmaseda, M. (2017a). A discrete anisotropic damage constitutive law with an enhanced mixed-mode kinematics: Application to RC shear walls. Engineering Fracture Mechanics, 184, 121-140.

Kishta, E., Richard, B., Giry, C., \& Ragueneau, F. (2017b). Strong discontinuity analysis of a class of anisotropic continuum damage constitutive models-Part II: Concrete material application. Mechanics Research Communications, 86(2017), 27-31.

Komatitsch, D., \& Vilotte, J. P. (1998). The spectral element method: an efficient tool to simulate the seismic response of $2 \mathrm{D}$ and 3D geological structures. Bulletin of the Seismological Society of America, 88(2), 368-392.

Komatitsch, D., Tsuboi, S., \& Tromp, J. (2005). The spectral-element method in seismology. In Geophysical monograph series (pp. 205-227). https://doi.org/10.1029/157GM13.

Laurendeau, A., Bard, P. Y., Hollender, F., Perron, V., Foundotos, L., Ktenidou, O. J., et al. (2017). Derivation of consistent hard rock $(1000<\mathrm{VS}<3000 \mathrm{~m} / \mathrm{s})$ GMPEs from surface and downhole recordings: analysis of KiK-net data. Bulletin of Earthquake Engineering. https://doi.org/10.1007/s10518-017-0142-6.

Lee, S. H., Kyung, W. M., Jae, Seung H., \& Jinkoo, K. (2004). Evaluation of equivalent damping ratio of a structure with added dampers. Engineering Structures, 26(3), 335-346. (ISSN: 01410296).

Lin, T., Haselton, C. B., \& Baker, J. W. (2013). ConditionalSpectrum-based ground motion selection. Part I: Hazard consistency for risk-based assessments. Earthquake Engineering \& Structural Dynamics, 42(12), 1847-1865.

Manchuel, K., Traversa, P., Baumont, D., Cara, M., Nayman, E., \& Durouchoux, C. (2017). The French seismic CATalogue (FCAT17). Bulletin of Earthquake Engineering. https://doi.org/10.1007/ s10518-017-0236-1.

Markovic, D., Koechlin, P., Voldoire, F. (2007). Reinforced concrete structures under extreme loading: Stress resultant Global Reinforced Concrete Models (GLRC). In ECCOMAS thematic conference on computational methods in structural dynamics and earth-quake engineering (COMPDYN 2007), Rethymno, Crete, 13-16 June 2007.

Martin, C., Ameri, G., Baumont, D., et al. (2018). Probabilistic seismic hazard assessment for South-Eastern France. Bull 
Earthquake Eng, 16, 2477-2511. https://doi.org/10.1007/s10518017-0249-9.

NEA/CSNI/R(2015)15. (2015). Workshop on testing probabilistic seismic hazard analysis results and benefits of Bayesian techniques. OECD/NEA. https://www.oecd-nea.org/nsd/docs/2015/ csni-r2015-15.pdf.

Neron, D., Boucard, P. A., \& Relun, N. (2015). Time-space PGD for the rapid solution of $3 \mathrm{D}$ nonlinear parametrized problems in the many-query context. International Journal for Numerical Methods in Engineering, 103(4), 275-292. https://doi.org/10. 1002/nme.4893.

Nieto, Ferro A., Clouteau, D., Greffet, N., \& Devésa, G. (2012). On a hybrid Laplace-time domain approach to dynamic interaction problems. European Journal of Computational Mechanics, 21(3-6), 290-299.

NRC ESSI simulator. University of California, Davis, and LBNL http://nrc-essi-simulator.info/.

NRC RG.1.208. (2007). Regulatory Guidelines by the Nuclear Energy Commission. A performance-based approach to define the site-specific earthquake ground motion. https://www.nrc.gov/ docs/ML0703/ML070310619.pdf.

O'Kelly, M. E. J., \& Caughey, T. K. (1965). Classical normal modes in damped linear dynamic systems. Journal of Applied Mechanics, 32(3), 583-588.

Ostadan, F., \& Kennedy, R. (2014). Consistent site-response/soilstructure interaction analysis and evaluation. Nuclear Engineering and Design, 269, 72-77.

Papadrakakis, M. H., \& Mouzakis, P. (1995). Earthquake simulator testing of pounding between adjacent buildings. Earthquake Engineering and Structural Dynamics, 25, 811-834.

Pecker, A., Faccioli, E., Gurpinar, A., Martin, C., \& Renault, P. (2017). An overview of the SIGMA research project. A European approach to seismic hazard analysis. http://www.springer.com/fr/ book/9783319581538.

Ragueneau, F. (1999). Fonctionnement dynamique des structures en béton-Influence des comportements hystérétiques locaux. $\mathrm{PhD}$ thesis. École Normale Supérieure de Cachan.

Régnier, J., et al. (2017). Prenolin: International benchmark on 1D nonlinear site response analysis-Validation phase exercise. Bulletin of Earthquake Engineering. https://doi.org/10.1785/ 0120170210.

RFS2001-01. (2001). Règle fondamentale de sûreté no. 2001-01 relative aux installations nucléaires de base. Détermination $d u$ risque sismique pour la sûreté des installations nucléaires de base. Nuclear Authority Safety website https://www.asn.fr/ content/download/53897/367951/version/1/.../RFS-2001-01.pdf.

RFS2002-01. (2002). Règle fondamentale de sûreté no. 2002-01 relative au développement et utilisation des études probabilistes de sûreté. Nuclear Authority Safety website https://www.asn.fr/ Reglementer/Regles-fondamentales-de-surete/RFS-relativesaux-REP/RFS-2002-1-du-26-12-2002.

Rice, S. O. (1945). Mathematical analysis of random noise. Bell System Technical Journal, 24, 146-156.

Richard, B., Cherubini, S., Voldoire, F., Charbonnel, P. E., Chaudat, T., Abouri, S., et al. (2016). SMART 2013: Experimental and numerical assessment of the dynamic behavior by shaking table tests of an asymmetrical reinforced concrete structure subjected to high intensity ground motions. Engineering Structures, 109, 99-116.

Robin-Boudaoud, M. C., Boudy, B., Graf, C., Liebig, K., \& Moussallam, N. (2018). Progress in the understanding and modelling of components that could drive the overall fragility of a nuclear power plant. In Proceedings of the BEST PHSANI workshop, May 2018, Cadarache. https://hal.archives-ouvertes.fr/ hal-02100930.

Sbaa, S., Hollender, F., Perron, V., Imtiaz, A., Bard, P. Y., Mariscal, A., et al. (2017). Analysis of rotation sensor data from the SINAPS@Kefalonia (Greece) post-seismic experiment—link to surface geology and wavefield characteristics. Earth, Planets and Space, 69, 124. https://doi.org/10.1186/s40623-017-0711-6.

Stocchi, A., \& Richard, B. (2019). Sensitivity of engineering demand parameters as a function of structural typology and assessment method. Nuclear Engineering and Design, 343, $151-165$.

Svay, A. (2017). Modelisation de la Variabilité Spatiale du Champ Sismique pour les Études d'Interaction Sol-Structure. CENTRALESUPELEC/EDF. PhD thesis.

Svay, A., Perron, V., Imtiaz, A., \& Lopez-Caballero, F. (2017). Spatial coherency analysis of seismic ground motions from a rock site dense array implemented during the Kefalonia 2014 aftershock sequence. Earthquake Engineering \& Structural Dynamics, 46(12), 1895-1917.

Theodoulidis, N., Hollender, F., Mariscal, A., Moiriat, D., Bard, P. Y., Konidaris, A., et al. (2018). The ARGONET (Greece) seismic observatory: an accelerometric vertical array and its data. Seismological Research Letters, 89(4), 1555-1565. https://doi.org/ 10.1785/0220180042.

Touhami, S., Alves-Fernandes, V., Lopez Caballero, F. (2017). Structure-soil-structure interaction analysis of NUPEC test cases. In M. Papadrakakis, M. Fragiadakis (Eds.), COMPDYN 2017, 6th ECCOMAS thematic conference on computational methods in structural dynamics and earthquake engineering, Rhodes Island, 15-17 June 2017. https://2017.compdyn.org/proceedings/pdf/ 18174.pdf.

Touhami, S., Lopez-Caballero, F., \& Clouteau, D. (2019). A holistic approach of numerical analysis of the geology effects on ground motion prediction: Argostoli site test. Pure and Applied Geophysics (in review).

Traversa, P., Baumont, D., Manchuel, K., \& Nayman, E. (2017). Exploration tree approach to estimate historical earthquakes $\mathrm{Mw}$ and depth, test cases from the French past seismicity. Bulletin of Earthquake Engineering, 1, 1. https://doi.org/10.1007/ s10518-017-0178-7.

Trevlopoulos, K., \& Zentner, I. (2019). Seismic fragility curve assessment based on synthetic ground motions with conditional spectra. Pure and Applied Geophysics (accepted).

Tsai, H. S., \& Kelly, J. (1993). Seismic response of heavily damped base isolation systems. Earthquake Engineering and Structural Dynamics, 22, 633-645.

Turquet, A., Bodin, T., Arroucau, P., Sylvander, M., \& Manchuel, K. (2019). Quantifying location uncertainties in seismicity catalogs: Application to the Pyrennees. Journal of Seismology (accepted).

Vanmarcke, E. H. (1975). On the distribution of the first passage time for normal stationary random processes. Journal of Thermal Science and Engineering Applications, 42, 215-220.

Vitse, M. (2016). Réduction de modèle pour l'analyse paramétrique de l'endommagement dans les structures en béton armé. $\mathrm{Ph} \mathrm{D}$ thesis, Paris-Saclay University.

Vitse, M., Néron, D., \& Boucard, P. A. (2019). Dealing with a nonlinear material behavior and its variability through PGD 
models: application to reinforced concrete structures. Finite Elements in Analysis and Design, 153, 22-37.

Wang, F., \& Feau, C. (2019). Equipment seismic fragility curve estimation using signals generated with GMPEs-Case study on the Kashiwazaki-Kariwa power plant. Pure and Applied Geophysics (in review).

Wang, Z., Zentner, I., Pedroni, N., \& Zio, E. (2017a). Adaptive artificial neural networks for seismic fragility analysis. 2nd International Conference on System Reliability and Safety (ICSRS). https://doi.org/10.1109/icsrs.2017.8272857.

Wang, Z., Zentner, I., Pedroni, N., \& Zio, E. (2017b). Computation of seismic fragility curves using artificial neural network metamodels. Volume: safety, reliability, risk, resilience and sustainability of structures and infrastructure, pp. 1525-1534. ICOSSAR Wien.

Wolf, J. P., \& Obernhuber, P. (1981). Effects of horizontally propagating waves on the response of structures with a soft first storey. Earthquake Engineering and Structural Dynamics, 9, $1-21$.

Wolf, J. P., Obernhuber, P., \& Weber, B. (1983). Response of a nuclear plant on aseismic bearings to horizontally propagating waves. Earthquake Engineering and Structural Dynamics, 11, 483-499.

Zentner, I. (2014). A procedure for simulating synthetic accelerograms compatible with correlated and conditional probabilistic response spectra. Soil Dyn Earth Eng., 63(1), 226-233.

Zentner, I. (2017). Simulation of hazard consistent accelerograms compatible with target UHS and application to the computation of in-structure floor spectra. Chile: WCEE.

Zentner, I. (2018). Use of RVT for computation of in-structure response spectra and peak responses and comparison to time history and response spectrum analysis. Earthquake Spectra, 34(4), 1913-1930.

(Received October 24, 2018, revised January 16, 2019, accepted April 9, 2019, Published online May 3, 2019) 